\title{
Cinnamonitrile Adjuvants Restore Susceptibility to $\beta$-Lactams Against Methicillin-Resistant Staphylococcus aureus
}

\author{
Enrico Speri, Choon Kim, Stefania De Benedetti, Yuanyuan Qian, Elena \\ Lastochkin, Jennifer Fishovitz, Jed F. Fisher, and Shahriar Mobashery*
}

Department Chemistry and Biochemistry, University of Notre Dame, Notre Dame, Indiana 46556, United States

KEYWORDS: MRSA, bacterial resistance, antibiotic adjuvants.

Table of content

General synthetic procedures (A) and (B) and synthesis of compounds 17, 26, 27, 28, and $29 \quad$ S2

Minimum-inhibitory concentration (MIC) determination and checkerboard testing S5

Cloning of the gene for the full-length and the kinase domain of the stk1 S5

Construction of chimeric cap5A1ct/cap5B2 (A1ct/B2) S6

$\begin{array}{ll}\text { Cloning of } r s b W \text { and } r s b V & \text { S6 }\end{array}$

$\begin{array}{ll}\text { Expression and purification of proteins } & \text { S6 }\end{array}$

$\begin{array}{ll}\text { In vitro phosphorylation assay } & \text { S7 }\end{array}$

$\begin{array}{ll}\text { Table S1: } 19 \text { supplementary final compounds } & \text { S8 }\end{array}$

Table S2: Reduced MICoxa against four MSSA strains in the presence of adjuvants at $20 \mu \mathrm{M} . \quad$ S9

$\begin{array}{lr}\text { Table S3: Primers used in this study } & \text { S10 }\end{array}$

Figure S1: Synergy of adjuvants on the resistance of MRSA to oxacillin S11

$\begin{array}{ll}\text { Figure S2: SDS-PAGE of the purified kinases } & \text { S12 }\end{array}$

$\begin{array}{ll}\text { Figure S3: Influence of } \mathbf{2 6} \text { on the activity of kinases } & \text { S12 }\end{array}$

$\begin{array}{ll}\text { Synthetic experimental procedures and characterization data } & \text { S13 }\end{array}$

${ }^{1} \mathrm{H}$ NMR, ${ }^{13} \mathrm{C}$ NMR, and MS for compounds 17, 26, 27, 28 and $29 \quad$ S32

$\begin{array}{ll}\text { References } & \text { S42 }\end{array}$ 


\section{General synthetic procedures (A) and (B) and synthesis of compounds 17, 26, 27, 28, and 29.}

All chemicals were used as supplied. The following general synthetic procedure (A and B) pertain to compounds 17, 26, 27, 28, 29; and for all diarylmethane and biphenyl derivatives. The remaining syntheses and their characterization data (NMR and MS) are given in the Supporting Information (SI). The purity of all final compounds was $\geq 95 \%$ by Waters Acquity UPLC. Purification of products was accomplished by silica chromatography using a Teledyne ISCO CombiFlash Rf 200i.

\section{General procedure (A) for diarylmethane-aldehyde and diphenyl-aldehyde derivatives.} Tetrahydrofuran (THF, $25 \mathrm{~mL})$, water $(10 \mathrm{~mL})$ and $\mathrm{K}_{2} \mathrm{CO}_{3}(2.76 \mathrm{~g}, 20.0 \mathrm{mmol})$ were added to a flask under an argon atmosphere. The boronic acid $(6.7 \mathrm{mmol})$ and the benzyl bromide or bromobenzene derivative $(6.1 \mathrm{mmol})$ were added after $5 \mathrm{~min}$. Argon was bubbled through a needle into the solution for 20 min. Tetrakis(triphenylphosphine)palladium(0) $\left(\mathrm{Pd}\left(\mathrm{PPh}_{3}\right)_{4}, 210 \mathrm{mg}, 0.2 \mathrm{mmol}\right)$ was added. The reaction mixture was heated to $80{ }^{\circ} \mathrm{C}$ and aged overnight at that temperature. The reaction was quenched by adjusting the solution to $\mathrm{pH} 4$ with $1 \mathrm{M}$ aqueous $\mathrm{HCl}$. The resulting solution was washed with EtOAc $(2 \times 20 \mathrm{~mL})$. The organic layers were combined, dried $\left(\mathrm{Na}_{2} \mathrm{SO}_{4}\right)$, and evaporated to dryness in vacuo. The crude product was purified by silica chromatography using gradient elution from 9:1 Hexane/EtOAc to EtOAc, affording the desired diarylmethane-aldehyde or diphenyl-aldehyde derivatives. Isolated yields were typically $19-73 \%$.

General procedure (B) for the Knoevenagel condensation with acetonitrile derivatives. The aldehyde $(0.6 \mathrm{mmol})$ and dry ethanol $(5 \mathrm{~mL})$ were added to an oven-dried $25 \mathrm{~mL}$ flask under an atmosphere of nitrogen. The acetonitrile derivative $(0.6 \mathrm{mmol})$ and L-proline $(35 \mathrm{mg}, 0.3 \mathrm{mmol})$ were added after $5 \mathrm{~min}$. The reaction was stirred for $3 \mathrm{~h}$ at r.t. The desired Knoevenagel condensation product was isolated after washing the solid precipitate with hexane. Purification of this precipitate was performed by silica chromatography using gradient elution from 9:1 Hexane/EtOAc to EtOAc. Isolated yields were typically $11-90 \%$. The alkene stereochemistry of the $\alpha$-cyanovinylsulfone and the $\alpha$-cyanovinyl carbonyl structures is $E$. The chemical shift of the vinyl hydrogen is diagnostic of alkene stereochemistry: the resonance for this hydrogen of the $E$-alkene is substantially more deshielded $(\delta>8)$ than the hydrogen of the $Z$-alkene $(\delta<8) .{ }^{1}$ The $E$-alkene is customarily the major (if not the exclusive) diastereomer. ${ }^{2-4}$

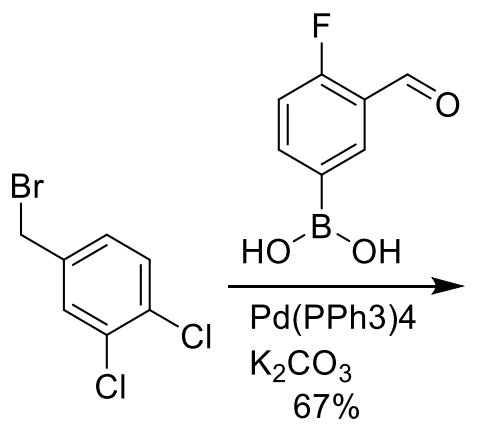

$67 \%$

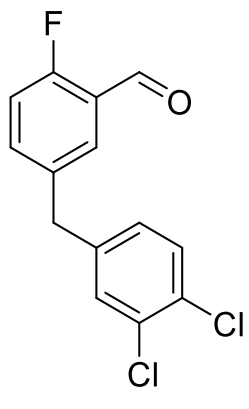

80

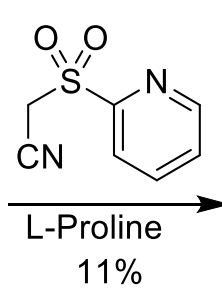
5-(3,4-Dichlorobenzyl)-2-fluorobenzaldehyde (80) This compound was prepared by the general procedure A, affording 80 as a white solid in $67 \%$ yield $(2.25 \mathrm{~g}) .{ }^{1} \mathrm{H}$ NMR $\left(400 \mathrm{MHz}, \mathrm{DMSO}-d_{6}\right) \delta \mathrm{ppm}$ $10.18(\mathrm{~s}, 1 \mathrm{H}), 7.72(\mathrm{dd}, J=2.6,6.9 \mathrm{~Hz}, 1 \mathrm{H}), 7.64(\mathrm{ddd}, J=2.8,5.2,8.6 \mathrm{~Hz}, 1 \mathrm{H}), 7.55-7.59(\mathrm{~m}, 1 \mathrm{H}), 7.53$ $(\mathrm{d}, J=8.3 \mathrm{~Hz}, 1 \mathrm{H}), 7.33(\mathrm{dd}, J=10.6,8.7 \mathrm{~Hz}, 1 \mathrm{H}), 7.20-7.28(\mathrm{~m}, 1 \mathrm{H}), 4.02(\mathrm{~s}, 2 \mathrm{H}) .{ }^{13} \mathrm{C} \mathrm{NMR}(101 \mathrm{MHz}$, DMSO-d $d_{6} \delta$ ppm 187.70, 187.64, 163.50, 160.95, 141.89, 137.37, 137.07, 136.97, 131.02, 130.66, $130.65,129.11,128.95,128.86,123.66,123.58,117.03,116.89,38.46$. HRMS $(m / z):[\mathrm{M}+\mathrm{H}]^{+}$, calcd for $\mathrm{C}_{14} \mathrm{H}_{10} \mathrm{Cl}_{2} \mathrm{FO}$, 283.0087; found, 283.0102 .

(E)-3-(5-(3,4-Dichlorobenzyl)-2-fluorophenyl)-2-(pyridin-2-ylsulfonyl)acrylonitrile (17). This compound was prepared by the general procedure B, affording 17 as a white solid in $11 \%$ yield (45 $\mathrm{mg})$. 
${ }^{1} \mathrm{H}$ NMR (400 MHz, DMSO-d6) $\delta$ ppm 8.85 (dt, $\left.J=4.5,1.4 \mathrm{~Hz}, 1 \mathrm{H}\right), 8.49(\mathrm{~s}, 1 \mathrm{H}), 8.21-8.31(\mathrm{~m}, 2 \mathrm{H})$, $7.99(\mathrm{dd}, J=6.9,2.0 \mathrm{~Hz}, 1 \mathrm{H}), 7.86(\mathrm{ddd}, J=6.2,4.7,2.6 \mathrm{~Hz}, 1 \mathrm{H}), 7.62-7.71(\mathrm{~m}, 1 \mathrm{H}), 7.56(\mathrm{~d}, J=2.0$ $\mathrm{Hz}, 1 \mathrm{H}), 7.52(\mathrm{~d}, J=8.3 \mathrm{~Hz}, 1 \mathrm{H}), 7.43(\mathrm{dd}, J=10.4,8.7 \mathrm{~Hz}, 1 \mathrm{H}), 7.24(\mathrm{dd}, J=8.3,2.0 \mathrm{~Hz}, 1 \mathrm{H}), 4.02$ (s, 2H). ${ }^{13} \mathrm{C}$ NMR $\left(101 \mathrm{MHz}\right.$, DMSO- $\left.d_{6}\right) \delta$ ppm 160.85, 158.31, 154.81, 151.07, 147.11, 147.05, 141.39, 139.69, 137.74, 137.71, 137.12, 137.03, 131.04, 130.64, 130.61, 129.12, 129.05, 128.97, 123.17, 118.17, 118.06, 116.88, 116.67, 113.67, 112.34, 38.48. HRMS $(\mathrm{m} / z)$ : $[\mathrm{M}-\mathrm{H}]^{-}$, calcd for $\mathrm{C}_{21} \mathrm{H}_{12} \mathrm{FN}_{2} \mathrm{O}_{2} \mathrm{~S}$, 444.9986; found, 445.0000 .

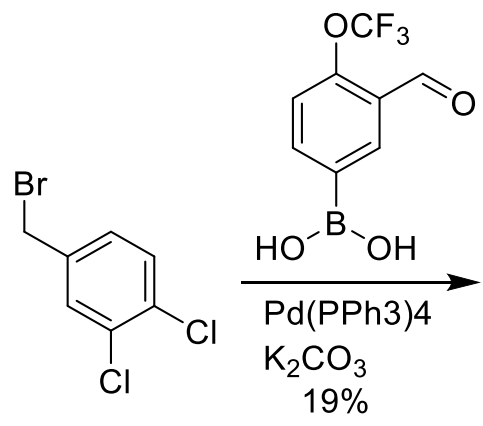<smiles>O=Cc1cc(Cc2ccc(OC(F)(F)F)c(C(F)(F)F)c2)ccc1Cl</smiles>

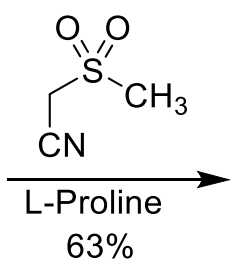

81

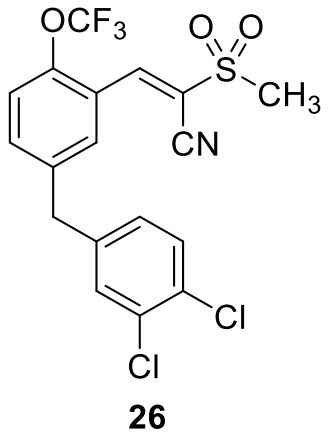

26

5-(3,4-Dichlorobenzyl)-2-(trifluoromethoxy)benzaldehyde (81). This compound was prepared by the general procedure A, affording 81 as a white solid in 19\% yield (260 mg). ${ }^{1} \mathrm{H}$ NMR (400 MHz, DMSO$\left.d_{6}\right) \delta \mathrm{ppm} 10.23(\mathrm{~s}, 1 \mathrm{H}), 7.86(\mathrm{~d}, J=2.5 \mathrm{~Hz}, 1 \mathrm{H}), 7.75(\mathrm{dd}, J=2.5,8.6 \mathrm{~Hz}, 1 \mathrm{H}), 7.64(\mathrm{~d}, J=2.2 \mathrm{~Hz}, 1 \mathrm{H})$, $7.58(\mathrm{~d}, J=8.31 \mathrm{~Hz}, 1 \mathrm{H}), 7.53(\mathrm{dd}, J=1.6,8.4 \mathrm{~Hz}, 1 \mathrm{H}), 7.31(\mathrm{dd}, J=2.0,8.3 \mathrm{~Hz}, 1 \mathrm{H}), 4.10(\mathrm{~s}, 2 \mathrm{H}) .{ }^{13} \mathrm{C}$ NMR (101 MHz, DMSO-d6) $\delta$ ppm 188.22, 147.66, 147.64, 141.50, 140.82, 136.65, 136.38, 131.10, $130.79,130.76,130.67,129.63,129.24,129.11,128.24,122.39,121.20,118.64 .{ }^{19} \mathrm{~F}$ NMR $(376 \mathrm{MHz}$, DMSO-d $\left.d_{6}\right) \delta \mathrm{ppm}-56.92$. HRMS $(\mathrm{m} / \mathrm{z}):[\mathrm{M}+\mathrm{H}]^{+}$, calcd for $\mathrm{C}_{15} \mathrm{H}_{10} \mathrm{Cl}_{2} \mathrm{~F}_{3} \mathrm{O}_{2}, 349.0004$; found, 349.0031.

(E)-3-(5-(3,4-Dichlorobenzyl)-2-(trifluoromethoxy)phenyl)-2-(methylsulfonyl)acrylonitrile (26). This compound was prepared by the general procedure B, affording $\mathbf{2 6}$ as a white solid in 63\% yield (102 $\mathrm{mg}) .{ }^{1} \mathrm{H}$ NMR $\left(400 \mathrm{MHz}, \mathrm{DMSO}-d_{6}\right) \delta \mathrm{ppm} 8.31(\mathrm{~s}, 1 \mathrm{H}, \mathrm{C}=\mathrm{CH}), 8.06(\mathrm{~d}, J=2.2 \mathrm{~Hz}, 1 \mathrm{H}, \mathrm{CH}), 7.74(\mathrm{dd}$, $J=2.2,8.5 \mathrm{~Hz}, 1 \mathrm{H}, \mathrm{CH}), 7.62(\mathrm{~d}, J=2.2 \mathrm{~Hz}, 1 \mathrm{H}, \mathrm{CH}), 7.60(\mathrm{dd}, J=1.7,8.3 \mathrm{~Hz}, 1 \mathrm{H}, \mathrm{CH}), 7.58(\mathrm{~d}, J=$ $8.3 \mathrm{~Hz}, 1 \mathrm{H}, \mathrm{CH}), 7.30(\mathrm{dd}, J=2.2,8.3 \mathrm{~Hz}, 1 \mathrm{H}, \mathrm{CH}), 4.11\left(\mathrm{~s}, 2 \mathrm{H}, \mathrm{CH}_{2}\right), 3.44\left(\mathrm{~s}, 3 \mathrm{H}, \mathrm{CH}_{3}\right) .{ }^{13} \mathrm{C}$ NMR $(101$ MHz, DMSO-d6) $\delta$ ppm $146.36(\mathrm{~s}, 1 \mathrm{C}, \mathrm{C}=C \mathrm{H}), 145.54(\mathrm{ddd}, J=1.5 \mathrm{~Hz}, 1 \mathrm{C}, C O C F 3), 145.53,141.14$, 140.80, 135.70 (s, 1C, CH), 131.22, 130.83 (s, 1C, CH), 130.80 (s, 1C, CH), 129.46 (s, 1C, CH), 129.24 $(\mathrm{s}, 1 \mathrm{C}, C \mathrm{H}), 123.50,121.98$ (s, 1C, $C \mathrm{H}), 119.88$ (ddd, $J=261.9 \mathrm{~Hz}, 1 \mathrm{C}, \mathrm{OCF} 3), 117.37,112.51,41.81$ $\left(\mathrm{s}, 1 \mathrm{C}, \mathrm{CH}_{3}\right), 38.72\left(\mathrm{~s}, 1 \mathrm{C}, \mathrm{CH}_{2}\right) .{ }^{19} \mathrm{~F}$ NMR $\left(376 \mathrm{MHz}, \mathrm{DMSO}-d_{6}\right) \delta \mathrm{ppm}-56.72\left(\mathrm{~s}, 3 \mathrm{~F}, \mathrm{OC} F_{3}\right)$. HRMS $(\mathrm{m} / z):[\mathrm{M}-\mathrm{H}]^{-}$, calcd for $\mathrm{C}_{18} \mathrm{H}_{11} \mathrm{Cl}_{2} \mathrm{~F}_{3} \mathrm{NO}_{3} \mathrm{~S}$, 447.9794; found, 447.9791.
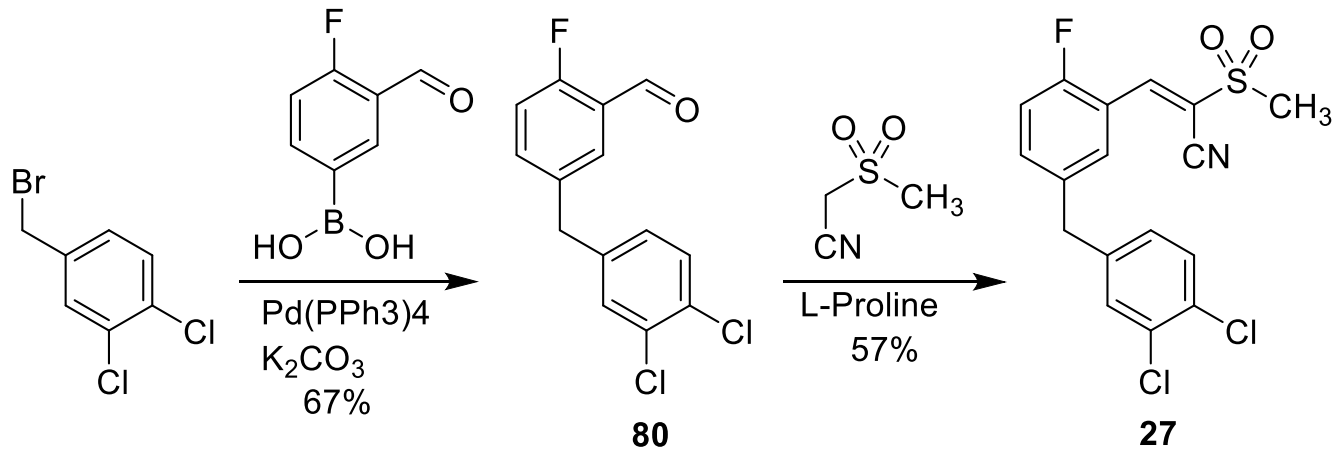

(E)-3-(5-(3,4-Dichlorobenzyl)-2-fluorophenyl)-2-(methylsulfonyl)acrylonitrile (27). This compound was prepared by the general procedure B, affording 27 as a white solid in 57\% yield (127 mg). ${ }^{1} \mathrm{H}$ NMR $\left(400 \mathrm{MHz}, \mathrm{DMSO}-d_{6}\right) \delta \mathrm{ppm} 8.26(\mathrm{~s}, 1 \mathrm{H}), 7.97(\mathrm{dd}, J=6.7,2.0 \mathrm{~Hz}, 1 \mathrm{H}), 7.66(\mathrm{ddd}, J=8.1,5.3,2.0 \mathrm{~Hz}$, 
1H), 7.50-7.61 (m, 2H), $7.43(\mathrm{dd}, J=10.2,8.7 \mathrm{~Hz}, 1 \mathrm{H}), 7.26(\mathrm{dd}, J=8.3,2.0 \mathrm{~Hz}, 1 \mathrm{H}), 4.04(\mathrm{~s}, 2 \mathrm{H}), 3.42$ $(\mathrm{s}, 3 \mathrm{H}) .{ }^{13} \mathrm{C}$ NMR $\left(101 \mathrm{MHz}, \mathrm{DMSO}-d_{6}\right) \delta \mathrm{ppm} 160.82,158.28,145.39,145.33,141.50,137.70,137.67$, 136.67, 136.57, 131.16, 130.73, 129.14, 129.01, 118.37, 118.25, 116.88, 116.67, 115.82, 112.80, 41.81, 38.63. HRMS $(m / z):[\mathrm{M}-\mathrm{H}]^{-}$, calcd for $\mathrm{C}_{17} \mathrm{H}_{11} \mathrm{Cl}_{2} \mathrm{FNO}_{2} \mathrm{~S}, 381.9877$; found, 381.9866 .

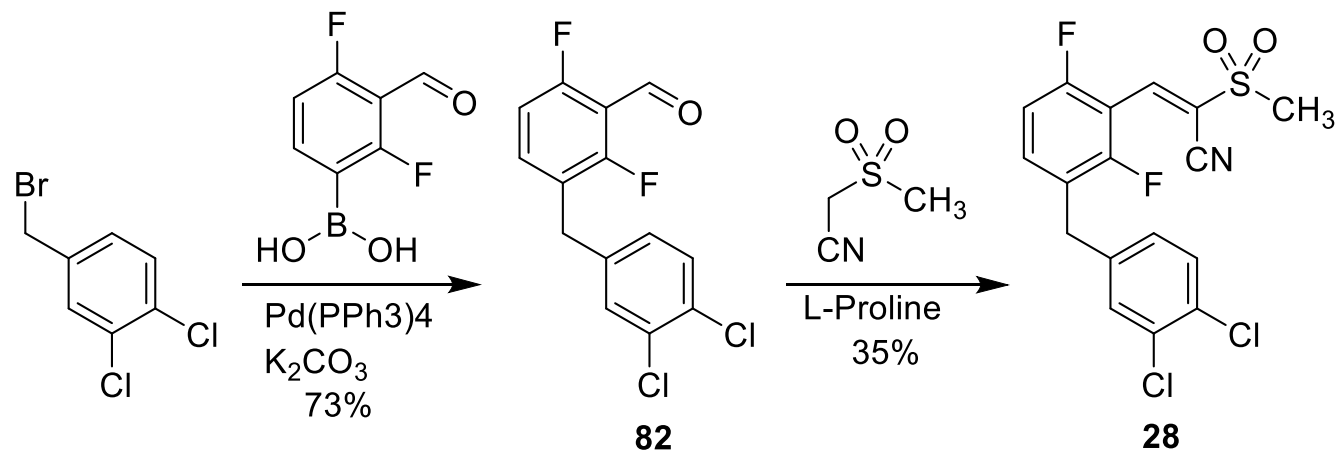

3-(3,4-Dichlorobenzyl)-2,6-difluorobenzaldehyde (82). This compound was prepared by the general procedure A, affording 82 as an off-white solid in 73\% yield (5.40 g). ${ }^{1} \mathrm{H} \mathrm{NMR}\left(400 \mathrm{MHz}, \mathrm{DMSO}-d_{6}\right) \delta$ ppm 10.19 (s, 1H), 7.73 (dt, $J=6.4,8.6 \mathrm{~Hz}, 1 \mathrm{H}), 7.54$ (d, $J=8.3 \mathrm{~Hz}, 1 \mathrm{H}), 7.51$ (d, $J=2.2 \mathrm{~Hz}, 1 \mathrm{H}), 7.18-$ $7.25(\mathrm{~m}, 2 \mathrm{H}), 4.01(\mathrm{~s}, 2 \mathrm{H}){ }^{13} \mathrm{C}$ NMR $\left(101 \mathrm{MHz}, \mathrm{DMSO}-d_{6}\right) \delta \mathrm{ppm} 185.09,185.04,185.00,162.28,162.22$, $161.30,161.24,159.70,159.64,158.70,158.64,140.33,137.75,137.68,137.56,131.09,130.69,130.51$, $129.18,128.94,124.37,124.33,124.21,124.18,113.72,113.60,113.49,112.74,112.53,112.49,32.34$, 32.31. HRMS $(\mathrm{m} / \mathrm{z}):[\mathrm{M}-\mathrm{H}]^{-}$, calcd for $\mathrm{C}_{14} \mathrm{H}_{10} \mathrm{Cl}_{2} \mathrm{~F}_{2} \mathrm{O}, 300.9993$; found, 301.0020 .

(E)-3-(3-(3,4-Dichlorobenzyl)-2,6-difluorophenyl)-2-(methylsulfonyl)acrylonitrile (28). This compound was prepared by the general procedure B, affording 28 as a white solid in 35\% yield (62 $\mathrm{mg}$ ). ${ }^{1} \mathrm{H}$ NMR $\left(400 \mathrm{MHz}, \mathrm{DMSO}-d_{6}\right) \delta \mathrm{ppm} 8.21(\mathrm{~s}, 1 \mathrm{H}), 7.75(\mathrm{td}, J=8.7,6.6 \mathrm{~Hz}, 1 \mathrm{H}), 7.58(\mathrm{~d}, J=8.3 \mathrm{~Hz}$, $1 \mathrm{H}), 7.55(\mathrm{~d}, J=2.0 \mathrm{~Hz}, 1 \mathrm{H}), 7.36(\mathrm{t}, J=9.2 \mathrm{~Hz}, 1 \mathrm{H}), 7.25(\mathrm{dd}, J=8.2,2.1 \mathrm{~Hz}, 1 \mathrm{H}), 4.06(\mathrm{~s}, 2 \mathrm{H}), 3.47$ (s, 3H). ${ }^{13} \mathrm{C}$ NMR $\left(101 \mathrm{MHz}, \mathrm{DMSO}-d_{6}\right) \delta \mathrm{ppm} 160.26,160.20,159.37,159.31,157.72,157.67,156.82$, $156.77,142.45,140.73,137.03,136.96,136.92$, 136.85, 131.57, 131.21, 131.01, 129.66, 129.46, 124.84, $124.80,124.68,124.64,121.26,113.16,113.12,112.95,112.91,112.35,109.48,109.31,109.13,42.10$, 32.96, 32.94. HRMS (m/z): [M - H] $]^{-}$, calcd for $\mathrm{C}_{17} \mathrm{H}_{10} \mathrm{Cl}_{2} \mathrm{~F}_{2} \mathrm{NO}_{2} \mathrm{~S}, 399.9783$; found, 399.9789 .

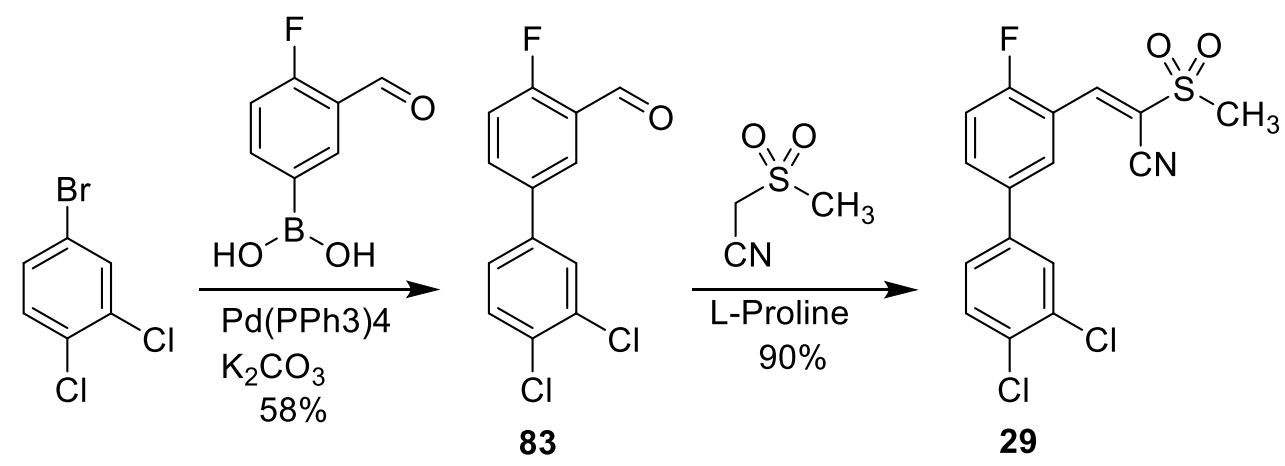

3',4'-Dichloro-4-fluoro-[1,1'-biphenyl]-3-carbaldehyde (83). This compound was prepared by the general procedure A, affording 83 as a white solid in $58 \%$ yield $(850 \mathrm{mg}) .{ }^{1} \mathrm{H}$ NMR (400 MHz, DMSO$\left.d_{6}\right) \delta \mathrm{ppm} 10.23(\mathrm{~s}, 1 \mathrm{H}), 8.09-8.13(\mathrm{~m}, 1 \mathrm{H}), 8.03-8.09(\mathrm{~m}, 1 \mathrm{H}), 7.96(\mathrm{dd}, J=0.6,1.8 \mathrm{~Hz}, 1 \mathrm{H}), 7.67-7.70$ $(\mathrm{m}, 2 \mathrm{H}), 7.49(\mathrm{dd}, J=8.6,10.5 \mathrm{~Hz}, 1 \mathrm{H}) .{ }^{13} \mathrm{C}$ NMR $\left(101 \mathrm{MHz}, \mathrm{DMSO}-d_{6}\right) \delta \mathrm{ppm} 187.87,187.83,164.23$, $161.65,138.50,134.94,134.84,134.41,134.38,131.85,131.05,130.80,128.57,128.16,128.14,126.93$, 124.10, 124.02, 117.65, 117.45. HRMS $(\mathrm{m} / z)$ : $[\mathrm{M}+\mathrm{H}]^{+}$, calcd for $\mathrm{C}_{13} \mathrm{H}_{8} \mathrm{Cl}_{2} \mathrm{FO}, 268.9931$; found, 268.9936. 
(E)-3-(3',4'-Dichloro-4-fluoro-[1,1'-biphenyl]-3-yl)-2-(methylsulfonyl)acrylonitrile (29). This compound was prepared by the general procedure B, affording 29 as a white solid in $90 \%$ yield (167 mg). ${ }^{1} \mathrm{H}$ NMR (400 MHz, DMSO-d $\left.d_{6}\right) \delta \mathrm{ppm} 8.43(\mathrm{dd}, J=2.5,6.6 \mathrm{~Hz}, 1 \mathrm{H}), 8.38(\mathrm{~s}, 1 \mathrm{H}), 8.06-8.13(\mathrm{~m}, 1 \mathrm{H})$, $7.98(\mathrm{~d}, J=2.5 \mathrm{~Hz}, 1 \mathrm{H}), 7.79(\mathrm{~d}, J=8.3 \mathrm{~Hz}, 1 \mathrm{H}), 7.69(\mathrm{dd}, J=2.2,8.3 \mathrm{~Hz}, 1 \mathrm{H}), 7.55-7.63(\mathrm{~m}, 1 \mathrm{H}), 3.47$ $(\mathrm{s}, 3 \mathrm{H}) .{ }^{13} \mathrm{C}$ NMR $\left(101 \mathrm{MHz}, \mathrm{DMSO}-d_{6}\right) \delta \mathrm{ppm} .161 .85,159.29,145.77,145.71,138.45,134.57,134.54$, 134.41, 134.32, 131.91, 131.26, 131.02, 128.53, 128.07, 126.78, 119.00, 118.88, 117.40, 117.18, 117.00, 112.89, 41.95. HRMS (m/z): [M - H] $]^{-}$, calcd for $\mathrm{C}_{16} \mathrm{H}_{9} \mathrm{Cl}_{2} \mathrm{FNO}_{2} \mathrm{~S}, 367.9721$; found, 367.9736.

Minimum-inhibitory concentration (MIC) determination and checkerboard assay. MICs were determined with the microdilution broth method following Clinical \& Laboratory Standards Institute (CLSI) guidelines. ${ }^{5}$ Briefly, determination of MICs was performed by two-fold serial dilutions of each compound in cation-adjusted Mueller-Hinton II broth (without or with $2 \% \mathrm{NaCl}$ for Staphylococcus aureus when tested with OXA). Experiments were performed in triplicate in 96-well plates with $5 \times 10^{5}$ $\mathrm{CFU} / \mathrm{mL}$ of bacteria. The plates were incubated at $36^{\circ} \mathrm{C}$ for $16^{-20} \mathrm{~h}$, and the MIC was recorded as the concentration where bacterial growth was not observed.

Eight MRSA strains were used for MIC determination. NRS1 (strain Mu50), which was isolated in Japan in 1991, ,.7 $^{-7}$ has SCCmec type II and is resistant to aminoglycosides and tetracycline and less susceptible to vancomycin. NRS70 (strain N315; USA100) has SCCmec type II and is resistant to clindamycin, erythromycin and spectinomycin. NRS119 (strain SA LinR \#12) has SCCmec type IV and was isolated in 2001 as the first reported linezolid-resistant strain (LRSA). ${ }^{10}$ NRS123 (strain MW2; USA400) was isolated in 1998, has SCCmec type IV and is a community-associated MRSA (CAMRSA)." NRS382 (strain 626; USA100, New York/Japan clone) has SCCmec type II and is resistant to ciprofloxacin, clindamycin, and erythromycin. It is the second most common healthcare-associated MRSA (HA-MRSA) in the USA. ${ }^{912}$ NRS383 (strain 96758; USA200) has SCCmec type II and is resistant to ciprofloxacin, clindamycin, erythromycin, and gentamicin. ${ }^{9.12}$ NRS384 (strain USA300-0114) has SCCmec type IV and is resistant to erythromycin and tetracycline. ${ }^{9}$ MRSA252 is a strain isolated from the epidemic hospital-acquired MRSA-16 (EMRSA-16). ${ }^{13.14}$ Checkerboard assay was performed to determine the synergy of adjuvants 17, 26, 27, 28 and 29 on the resistance of MRSA to oxacillin, as described in the literatures. ${ }^{15-17}$

Cloning of the gene for the full-length and the kinase domain of the stk1. An expression plasmid pASK-IBA17plus was purchased from IBA Lifesciences (Göttingen, Germany), followed by replacing an ampicillin-resistance gene in the plasmid to a kanamycin-resistance gene. The resulting plasmid was named pIBA $17 \mathrm{~K}$. In order to compare the effect of compounds, the full-length (stkl) and the kinase domain (1-348 residues; stklkd) were subcloned into pIBA17K plasmid with a fast-cloning method. ${ }^{18-19}$ Briefly, the stkl gene in the genomic DNA of $S$. aureus NCTC8325 was amplified by PCR with pairs of primers stk1F/stk1R and stk1F/stk1kdR for the full-length stk1 and the stk1kd, respectively (Table S3). The plasmid pIBA17K was amplified by PCR with primers IBA17F and IBA17R. After PCR, the vector and each of the inserts were mixed with 1:1 ratio, and $1 \mu \mathrm{L}$ of DpnI (New England Biolabs, MA) was added and incubated for $1 \mathrm{~h}$ at $37^{\circ} \mathrm{C}$ to remove the chromosomal template. A portion $(5 \mu \mathrm{L})$ of the mixture was then introduced into chemically competent $E$. coli DH5 $\alpha$ cells. The resulting plasmids, pIBAstk1 and pIBAstk1kd, were inserted into E. coli BL21 Star (DE3) to express Stk1 and Stk1kd. Due to the difficulty of protein expression with anhydrotetracycline, the $s t k 1$ and the $s t k 1 k d$, including the sequences for a Strep-tag and a TEV cleavage site, were digested with restriction enzymes NheI and XhoI from both pIBAstk1 and pIBAskt1kd, respectively, and inserted into an expression vector pET24a to produce Nterminal Strep-tagged Stk1 and Stk1kd (pET24StStk1 and pET24StStk1kd). 
Construction of chimeric cap5A1ct/cap5B2 (A1ct/B2). Since the C-terminal 28 amino acids (Val194Asn222) of Cap5A1 are essential for the kinase activity of Cap5B2, ${ }^{20}$ the chimeric gene, in which the last 87 bases of cap5A1 (A1ct) are fused to the upstream of cap5B2 (B2), was constructed by PCR and NEBuilder ${ }^{\circledR}$ HiFi DNA Assembly Kit (NEB, Ipswich, MA). Briefly, the C-terminal segment of $A 1 c t$ (SAOUHSC_00114) and the intact B2 (SAOUHSC_02999) were amplified from the genomic DNA with pairs of primers capA1ctF/capA1ctB2ntR and capB2ntA1ctF/capB2R, respectively (Table S3). The expression vector pET28a was linearized with restriction enzymes NdeI and XhoI. The plasmid pET28NHisA1ctB2 was generated by assembling three fragments including the linearized vector, Alct and $B 2$ with NEBuilder ${ }^{\circledR}$ HiFi DNA Assembly Kit following the manufacturer's instruction. The resulting plasmid was introduced into E. coli BL21 Star (DE3) to express and purify N-terminal Histagged CapA1ct/Cap5B2.

Cloning of $\boldsymbol{r s} \boldsymbol{b} \boldsymbol{W}$ and $\boldsymbol{r s} \boldsymbol{b} \boldsymbol{V}$. The $r s b W$ (SAOUHSC_02299) and $r s b V$ (SAOUHSC_02300) genes were amplified from the genomic DNA of $S$. aureus NCTC8325 with pairs of primers $\mathrm{rsbWF} / \mathrm{rsbWR}$ and $\mathrm{rsbVF} / \mathrm{rsbVR}$, respectively (Table S3). ${ }^{21}$ For subcloning of the $r s b W$ gene, the PCR product and an expression vector, pET28a, were cut with restriction enzymes NcoI and XhoI and ligated with T4 ligase (NEB, Ipswich, MA). The restriction enzymes NdeI and XhoI were used for the $r s b V$ gene. The resulting plamids, pET28CHisRsbWand pET28NHisRsbV, were introduced E. coli BL21 Star (DE3) to express and purify C-terminal His-tagged RsbW and N-terminal His-tagged RsbV, respectively.

Expression and purification of proteins. Each overnight culture of E. coli BL21 Star (DE3) strains carrying each plasmid (pET24StStk1, pET24StStk1kd, pET28NHisA1ctB2, pET28CHisRsbW, or pET28NHisRsbv) were diluted 100-fold in a liter of fresh LB containing $30 \mathrm{mg} \mathrm{L}^{-1}$ kanamycin and grown until $\mathrm{OD}_{600}$ reached 0.6. In order to overexpress the proteins (Stk1, Stk1kd, CapA1ct/B2, RsbW and RsbV), isopropyl $\beta$-D-1-thiogalactopyranoside (IPTG) at the final concentration of $0.5 \mathrm{mM}$ was added to the cultures, followed by further incubation for $18 \mathrm{~h}$ at $16^{\circ} \mathrm{C}$. The cells were harvested at $6,000 \mathrm{~g}$ for 15 min at $4{ }^{\circ} \mathrm{C}$ and resuspended in $40 \mathrm{~mL}$ of lysis buffer. Depending on the affinity tag, the proteins were purified following either one of the two following methods. His-tagged proteins (CapA1ct/B2, RsbW and $\mathrm{RsbV}$ ) were lysed in $50 \mathrm{mM}$ Tris- $\mathrm{HCl}, \mathrm{pH} 8.0,300 \mathrm{mM} \mathrm{NaCl}$, followed by cell disruption by sonication on ice (10 x 2 min cycles with 2 min rest using a Branson 450 Sonifier). Unbroken cells were removed by centrifugation at $14,000 \mathrm{~g}$ for $1 \mathrm{~h}$ at $4{ }^{\circ} \mathrm{C}$. The supernatants were applied to $5 \mathrm{~mL}$ of Ni-NTA column (Macherey-Nagel, Düren, Germany) and the His-tagged proteins purified by eluting with a linear gradient of imidazole from $20 \mathrm{mM}$ to $500 \mathrm{mM}$. The Strep-tagged Stk1 and Stk1kd were resuspended in $100 \mathrm{mM}$ Tris-HCl, $\mathrm{pH} 8,150 \mathrm{mM} \mathrm{NaCl}, 0.05 \%$ Brij-35. After sonication and centrifugation, as mentioned above, the cleared lysate was loaded on $5 \mathrm{~mL}$ of Strep-Tactin resin (IBA Lifesciences, Göttingen, Germany) and the Strep-tagged proteins were elute with 3 column volumes of lysis buffer containing $2.5 \mathrm{mM}$ desthiobiotin. In all cases, the protein containing fractions were concentrated with Amicon Ultra Centrifugal Filters (Millipore-Sigma), and the purity of the proteins was confirmed with SDS-PAGE.

In vitro phosphorylation assay. This assay was used to assess the ability of compound $\mathbf{2 6}$, to inhibit the protein kinase activity of the three protein kinases Stk1, Cap5B2, and RsbW present in S. aureus. ${ }^{19-22}$ Recombinant kinases-Stk1, Stk1kd and Cap5A1/B2 except for RsbW-were evaluated for their autophosphorylation. For the protein phosphorylation by the kinases, myelin basic protein (MBP; Millipore-Sigma) was used as a substrate for Stk1, Stk1kd and Cap5A1/B2, and the purified RsbV for RsbW. The reactions were performed in a $1.5 \mathrm{~mL}$ microcentrifuge tube containing $25 \mathrm{mM}$ Tris $\cdot \mathrm{HCl} \mathrm{pH}$ 7.4 buffer, $10 \mathrm{mM} \mathrm{MgCl}_{2}, 1 \mathrm{mM}$ dithiothreitol (DTT), either 50 or $100 \mu \mathrm{M}$ of adjuvant, $1 \mu \mathrm{g}$ of purified protein, and $4 \mu \mathrm{g}$ of substrate protein (MBP or RsbV) in a final volume of $20 \mu \mathrm{L}$. The resulting mixtures were incubated with gentle shaking for $10 \mathrm{~min}$ at room temperature. After this time, the reactions were initiated by the addition of $4 \mu \mathrm{Ci}\left[\gamma^{32} \mathrm{P}\right]$-ATP $(20 \mu \mathrm{M}$ final $)$ and gently stirred for an additional $20 \mathrm{~min}$. The assays were stopped by the addition of $5 \times$ SDS-PAGE sample buffer. Autophosphorylation assay was 
carried out in the absence of substrate proteins. The samples were then boiled for 5 min, loaded, and run on an SDS-PAGE gel. The gel was dried and exposed to a phosphor screen overnight. The screen was processed with an Amersham Storm 840 Image Scanner. The data were visualized with ImageQuant software (Figure S3). 
Table S1. MIC in $\mathrm{mg} \cdot \mathrm{L}^{-1}$ against strain NRS70 for OXA at $20 \mu \mathrm{M}$ of the adjuvant (MIC OxA, column shaded $\tan )$, and the adjuvant alone $\left(\mathrm{MIC}_{\mathrm{ADJ}}\right)$. Panel A shows the initial development of compound 1, and panel $\mathrm{B}$ describes the importance of a bridging cyano-alkene between $\mathrm{SAR}^{1}$ and $\mathrm{SAR}^{2}$.

A:

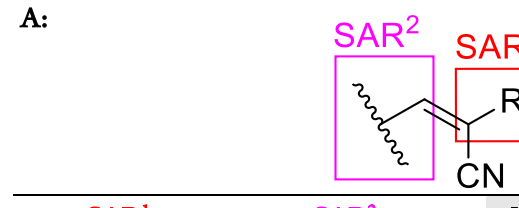

\begin{tabular}{|c|c|c|c|c|}
\hline & $\mathrm{SAR}^{1}$ & $\mathrm{SAR}^{2}$ & $\mathrm{MIC}_{\mathrm{oxA}^{2}}$ & $\mathrm{MIC}_{\mathrm{ADJ}}{ }^{2}$ \\
\hline \multicolumn{5}{|c|}{ Phenyl derivatives } \\
\hline 1 & $\mathrm{CN}$ & $3-\mathrm{OH}-4-\mathrm{NO}_{2}$ & 16 & 32 \\
\hline 84 & $\mathrm{CONH}_{2}$ & $3-\mathrm{OH}-4-\mathrm{NO}_{2}$ & 16 & 32 \\
\hline 85 & $\mathrm{CO}_{2} \mathrm{CH}_{3}$ & $3-\mathrm{OH}-4-\mathrm{NO}_{2}$ & 64 & $\geq 64$ \\
\hline 86 & $\mathrm{SO}_{2} \mathrm{CH}_{3}$ & $3-\mathrm{OH}-4-\mathrm{NO}_{2}$ & 64 & $\geq 64$ \\
\hline 87 & $\mathrm{CN}$ & $4-\mathrm{NO}_{2}$ & 64 & 32 \\
\hline 88 & $\mathrm{CN}$ & 3-OMe-4-F & 64 & $\geq 64$ \\
\hline 89 & $\mathrm{CN}$ & 3,4-OMe & 64 & $\geq 64$ \\
\hline 90 & $\mathrm{CN}$ & 3-OMe-4-Me & 64 & $\geq 64$ \\
\hline 91 & $\mathrm{CN}$ & 3-OMe-4-OH-5-Cl & 64 & $\geq 64$ \\
\hline 92 & $\mathrm{CN}$ & 3-COOH & 64 & $\geq 64$ \\
\hline 93 & $\mathrm{CN}$ & 3-OH-4-OMe & 64 & $\geq 64$ \\
\hline \multicolumn{5}{|c|}{ Other derivatives } \\
\hline 94 & $\mathrm{CN}$ & $b$ & 64 & $\geq 64$ \\
\hline
\end{tabular}

B:<smiles>[R]C=Cc1cc(Cc2ccc(Cl)c(Cl)c2)ccc1F</smiles>

III

\begin{tabular}{rcccc}
\hline & & $\mathrm{R}^{1}$ & MIC & MIC $^{a}$ \\
\hline 95 & I & $-\mathrm{OH}$ & 64 & $\geq 64$ \\
96 & I & $-\mathrm{SH}$ & 64 & $\geq 64$ \\
97 & I & $-\mathrm{SO}_{2} \mathrm{OH}$ & 64 & $\geq 64$ \\
98 & II & $\mathrm{COCH}_{3}$ & 64 & $\geq 64$ \\
99 & II & $\mathrm{SO}_{2} \mathrm{CH}_{3}$ & 64 & $\geq 64$ \\
100 & II & $\mathrm{NO}_{2}$ & 64 & $\geq 64$ \\
101 & II & $c$ & 64 & $\geq 64$ \\
102 & III & $\mathrm{COOH}$ & 64 & $\geq 64$
\end{tabular}

${ }^{a} \mathrm{MICOXA}$ and $\mathrm{MIC}_{\mathrm{ADJ}}$ determined in the presence and in the absence of $2 \% \mathrm{NaCl}$, respectively; ${ }^{b} 2$-(3-chlorophenyl)-5-furanyl; ${ }^{c}$ 1-morpholinoethanyl-1-one. 
Table S2. Reduced MIC of OXA against four MSSA strains in the presence of adjuvants at $20 \mu \mathrm{M} .^{a}$

\begin{tabular}{|c|c|c|c|c|}
\hline \multirow{2}{*}{ Adjuvant } & \multicolumn{4}{|c|}{$\operatorname{MIC}_{\text {OXA }}\left(\mathrm{mg} \cdot \mathrm{L}^{-1}\right)^{b}$} \\
\hline & ${\text { ATCC } 29213^{d}}$ & $\mathrm{NRS}_{1} 1^{d}$ & $\mathrm{NRS72}^{d}$ & $\mathrm{NRS77}^{e}$ \\
\hline None & 0.25 & 0.25 & 0.5 & 0.25 \\
\hline $17^{c}$ & (16) & (16) & (16) & (16) \\
\hline $20 \mu \mathrm{M}\left[8.9 \mathrm{mg} . \mathrm{L}^{-1}\right]$ & 0.25 & 0.25 & 0.25 & 0.06 \\
\hline $26^{c}$ & $(16)$ & (16) & $(16)$ & $(16)$ \\
\hline $20 \mu \mathrm{M}\left[9.0 \mathrm{mg} . \mathrm{L}^{-1}\right]$ & 0.06 & $\leq 0.03$ & 0.125 & $\leq 0.03$ \\
\hline $27^{c}$ & (32) & (8) & (32) & $(16)$ \\
\hline $20 \mu \mathrm{M}\left[7.7 \mathrm{mg} \cdot \mathrm{L}^{-1}\right]$ & 0.125 & $\leq 0.03$ & 0.06 & $\leq 0.03$ \\
\hline $28^{c}$ & (16) & $(16)$ & $(16)$ & $(16)$ \\
\hline $20 \mu \mathrm{M}\left[8.0 \mathrm{mg} . \mathrm{L}^{-1}\right]$ & 0.125 & 0.125 & 0.125 & 0.06 \\
\hline $29^{c}$ & (16) & (16) & (32) & (16) \\
\hline $20 \mu \mathrm{M}\left[7.4 \mathrm{mg} . \mathrm{L}^{-1}\right]$ & 0.25 & 0.25 & 0.25 & 0.06 \\
\hline
\end{tabular}

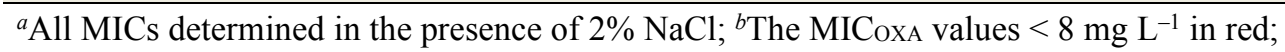
${ }^{c}$ The MICs of adjuvants alone in parentheses; ${ }^{d} \mathrm{blaZ}{ }^{+} ;{ }^{e}$ non-producer of BlaZ. 
Table S3. Primers used in this study

\begin{tabular}{ll}
\hline Primer & 5' to 3' sequence \\
\hline stk1F & CTTTATTTTCAGGGCGCCATGATAGGTAAAATAATAAATGAACGATATAAAATTG \\
stk1R & AGGGATCCCCGGGTACCTTAAATATCATCATAGCTGACTTCTTTTTCAG \\
stk1kdR & AGGGATCCCCGGGTACCTTACTTTCGTGTTGATTTCTTTTTAGGTTTTG \\
IBA17F & GGTACCCGGGGATCCCTCGAG \\
IBA17R & GGCGCCCTGAAAATAAAGATTCTCACC \\
capA1ctF & ACAGGCTAGCGTAATTTTCGATAAGCGAATTAAAG \\
capA1ctB2ntR & GATGTACTTCTTCGTGTATTCGTCATATTAAATTTTTGAATTGAACCC \\
capB2ntA1ctF & TGTATTGGGTTCAATTCAAAAATTTAATATGACGAATACACGAAGAAG \\
capB2R & CCAGCTCGAGTCATGATTCATCAGTC \\
rsbWF & ATATCCATGGAATCTAAAGAAGATTTTATCGAAATGC \\
rsbWR & ATATCTCGAGGCTGATTTCGACTCTTTCGC \\
rsbVF & ATATCATATGAATCTTAATATAGAAACAACCACTC \\
rsbVR & AATTCTCGAGTTATTCGACCTCCGTTCCTTCA \\
\hline
\end{tabular}



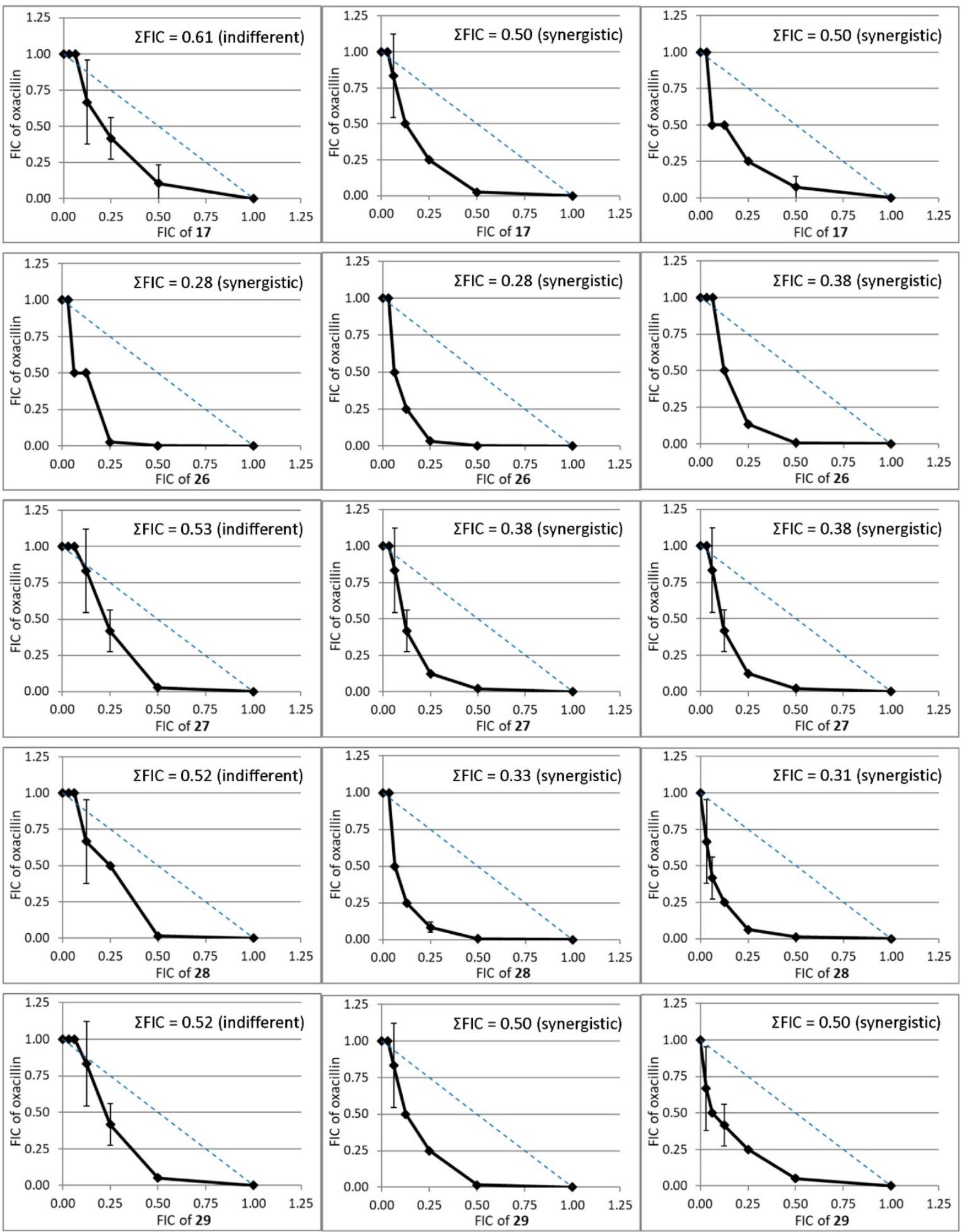

Figure S1. Assays for demonstration of synergy of adjuvants with oxacillin. Synergistic, $\Sigma$ FIC $\geq 0.5$; additive/indifferent, $0.5<\Sigma \mathrm{FIC}<4.0$; antagonistic, $\Sigma \mathrm{FIC} \leq 4.0 .^{15-17}$ 


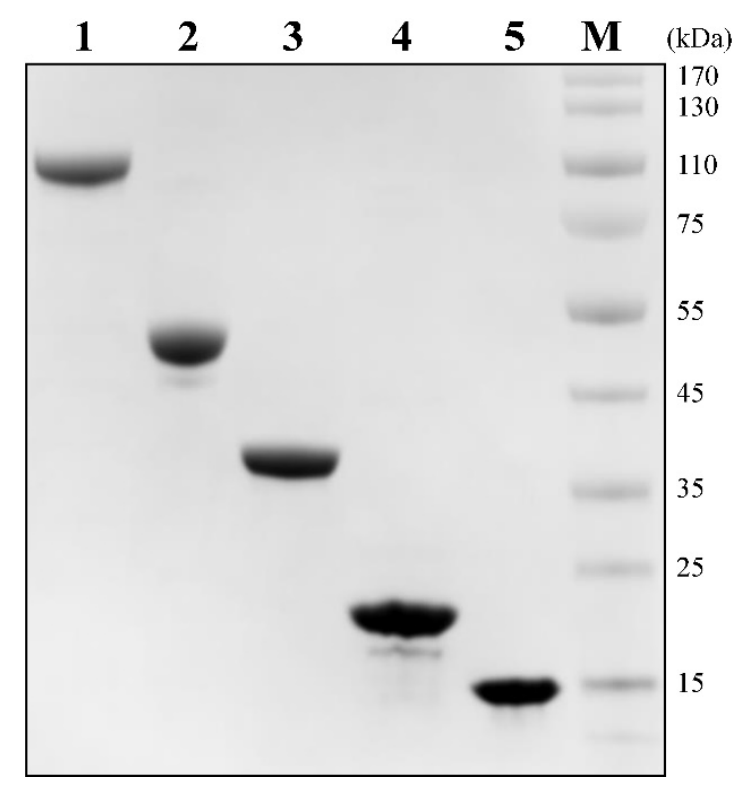

Figure S2. Purity of the purified kinases on SDS-PAGE. 1, full-length Stk1; 2, kinase domain of Stk1; 3, chimeric Cap5A1ct/B2; 4, RsbW; 5, RsbV; M, size markers.

\section{Stk1kd: $\quad$ Cap5A1ct/B2: RsbW:}

Auto-phosphorylation:

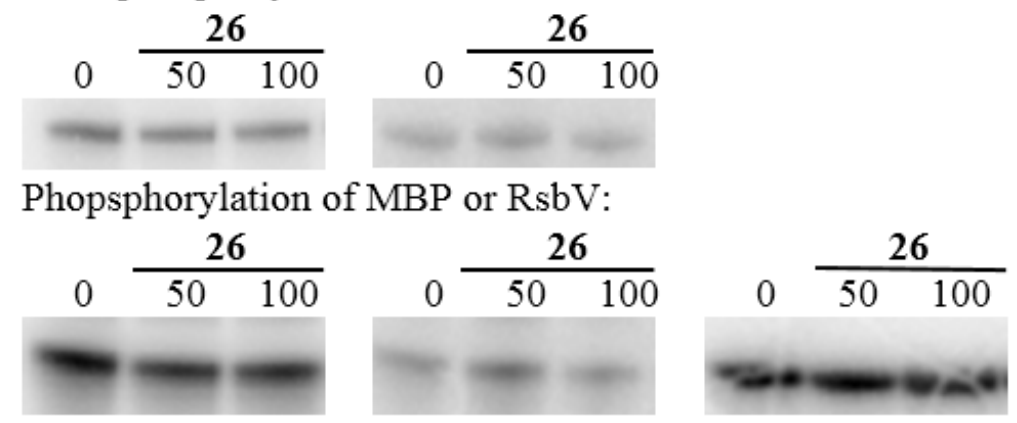

Figure S3. The influence of compound 26 (at 50 and $100 \mu \mathrm{M}$ ) on auto-phosphorylation of Stk1kd and Cap5A1ct/B2, and on phosphorylation of MBP (by Stk1kd and Cap5A1ct/B2) and RsbV (by RsbW). Fulllength Stk1 was not shown, but its result was the same as Stk1kd. 


\begin{tabular}{|c|c|}
\hline Structure & Experimental procedure and characterization data \\
\hline & 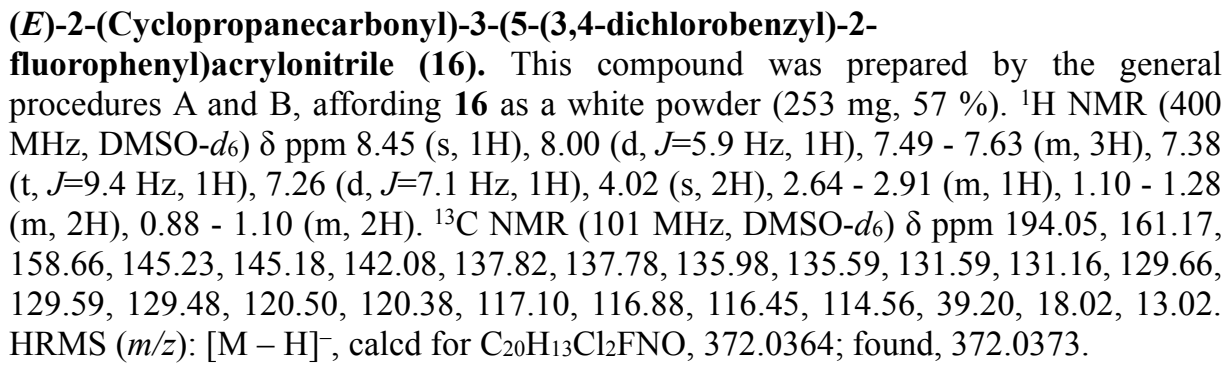 \\
\hline וס & 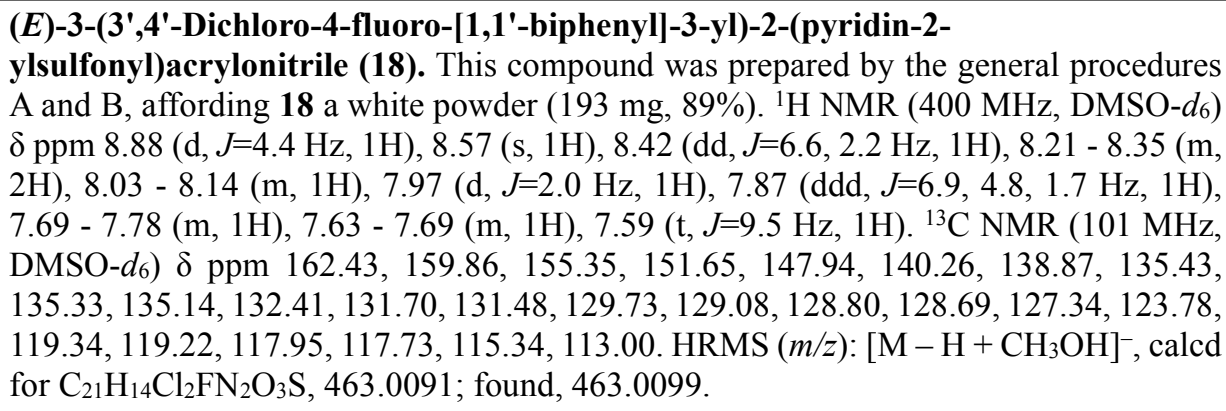 \\
\hline & 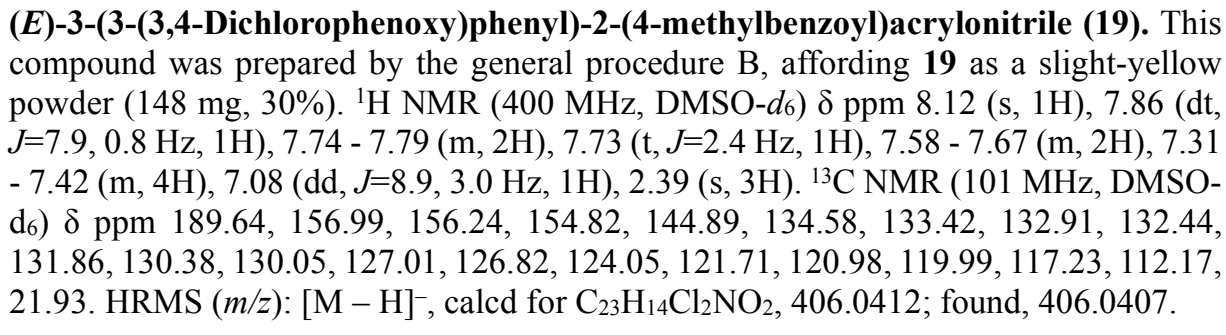 \\
\hline & $\begin{array}{l}\text { (Z)-3-(3-(3,4-Dichlorophenoxy)phenyl)-2-(pyridin-4-yl)acrylonitrile }(\mathbf{2 0}) \text {. This } \\
\text { compound was prepared by the general procedure B, affording } 20 \text { as an off-white } \\
\text { powder }(160 \mathrm{mg}, 46 \%) .{ }^{1} \mathrm{H} \text { NMR }\left(400 \mathrm{MHz}, \mathrm{DMSO}-d_{6}\right) \delta \mathrm{ppm} 8.69-8.81(\mathrm{~m}, 2 \mathrm{H}) \text {, } \\
8.42(\mathrm{~s}, 1 \mathrm{H}), 7.80-7.91(\mathrm{~m}, 3 \mathrm{H}), 7.56-7.70(\mathrm{~m}, 3 \mathrm{H}), 7.42(\mathrm{~d}, J=2.8 \mathrm{~Hz}, 1 \mathrm{H}), 7.28- \\
7.36(\mathrm{~m}, 1 \mathrm{H}), 7.11(\mathrm{dd}, J=2.8,9.1 \mathrm{~Hz}, 1 \mathrm{H}) .{ }^{13} \mathrm{C} \mathrm{NMR}\left(101 \mathrm{MHz}, \mathrm{DMSO}-d_{6}\right) \delta \mathrm{ppm} \\
157.12,156.27,149.81,146.87,143.15,135.71,132.96,132.51,131.85,126.89,126.05, \\
122.85,121.80,121.22,120.24,120.06,117.38,109.51 . \mathrm{HRMS}(\mathrm{m} / \mathrm{z}):[\mathrm{M}-\mathrm{H}]^{-} \text {, calcd } \\
\text { for } \mathrm{C}_{20} \mathrm{H}_{11} \mathrm{Cl}_{2} \mathrm{~N}_{2} \mathrm{O}, 365.0253 \text {; found, } 365.0259 \text {. }\end{array}$ \\
\hline & $\begin{array}{l}\text { (Z)-3-(3-(3,4-Dichlorophenoxy)phenyl)-2-(pyridin-2-yl)acrylonitrile }(\mathbf{2 1}) . \\
\text { compound was prepared by the general procedure B, affording } 21 \text { as an off-white } \\
\text { powder }(170 \mathrm{mg}, 59 \%) .{ }^{1} \mathrm{H} \text { NMR }\left(500 \mathrm{MHz}, \mathrm{DMSO}-\mathrm{d}_{6}\right) \delta \mathrm{ppm} 8.66(\mathrm{ddd}, J=0.7,1.7, \\
4.7 \mathrm{~Hz}, 1 \mathrm{H}), 8.45(\mathrm{~s}, 1 \mathrm{H}), 7.91-7.99(\mathrm{~m}, 1 \mathrm{H}), 7.80-7.88(\mathrm{~m}, 2 \mathrm{H}), 7.70(\mathrm{t}, J=2.0 \mathrm{~Hz}, \\
1 \mathrm{H}), 7.64(\mathrm{~d}, J=8.8 \mathrm{~Hz}, 1 \mathrm{H}), 7.60(\mathrm{t}, J=8.0 \mathrm{~Hz}, 1 \mathrm{H}), 7.45(\mathrm{ddd}, J=1.0,4.8,7.5 \mathrm{~Hz}, \\
1 \mathrm{H}), 7.39(\mathrm{~d}, J=2.9 \mathrm{~Hz}, 1 \mathrm{H}), 7.26(\mathrm{ddd}, J=0.9,2.5,8.2 \mathrm{~Hz}, 1 \mathrm{H}), 7.09(\mathrm{dd}, J=2.7,8.8 \\
\mathrm{Hz}, 1 \mathrm{H}) .{ }^{13} \mathrm{C} \mathrm{NMR}\left(125 \mathrm{MHz}, \mathrm{DMSO}-d_{6}\right) \delta \mathrm{ppm} 156.88,156.36,151.48,150.33, \\
144.64,138.50,135.82,132.86,132.37,131.66,126.64,126.10,124.80,122.28,121.57, \\
121.42,120.14,119.86,117.88,112.33 . \mathrm{HRMS}(\mathrm{m} / \mathrm{z}):[\mathrm{M}-\mathrm{H}]^{-} \text {, calcd for } \mathrm{C}_{20} \mathrm{H}_{11} \mathrm{Cl}_{2} \mathrm{~N}_{2} \mathrm{O} \text {, } \\
365.0253 \text {; found, } 365.0254 .\end{array}$ \\
\hline
\end{tabular}


<smiles>N#C/C(=C\c1cccc(Oc2ccc(Cl)c(Cl)c2)c1)c1cccs1</smiles>

(E)-3-(3-(3,4-Dichlorophenoxy)phenyl)-2-(thiophen-2-yl)acrylonitrile

(22). This compound was prepared by the general procedure B, affording 22 as affording an light-tan powder (148 mg, 40\%). ${ }^{1} \mathrm{H}$ NMR (400 MHz, DMSO- $\left.d 6\right) \delta \mathrm{ppm} 7.79(\mathrm{~s}, 1 \mathrm{H})$, $7.70-7.75(\mathrm{~m}, 1 \mathrm{H}), 7.68(\mathrm{dd}, J=5.1,1.2 \mathrm{~Hz}, 1 \mathrm{H}), 7.62(\mathrm{~d}, J=9.1 \mathrm{~Hz}, 1 \mathrm{H}), 7.51-7.59$ (m, 2H), $7.43(\mathrm{dd}, J=3.9,1.2 \mathrm{~Hz}, 1 \mathrm{H}), 7.36(\mathrm{~d}, J=2.8 \mathrm{~Hz}, 1 \mathrm{H}), 7.20$ (dt, $J=8.2,1.2 \mathrm{~Hz}$, $1 \mathrm{H}), 7.15$ (dd, $J=5.1,3.9 \mathrm{~Hz}, 1 \mathrm{H}), 7.06(\mathrm{dd}, J=8.9,2.95 \mathrm{~Hz}, 1 \mathrm{H}) .{ }^{13} \mathrm{C}$ NMR $(101 \mathrm{MHz}$, DMSO-d6) $\delta$ ppm 156.88, 156.45, 139.75, 138.82, 136.06, 132.87, 132.39, 131.61, 129.18, 128.94, 127.86, 126.62, 125.36, 121.71, 121.54, 119.86, 119.68, 117.43, 106.56. HRMS $(m / z):[\mathrm{M}-\mathrm{H}]^{-}$, calcd for $\mathrm{C}_{19} \mathrm{H}_{10} \mathrm{Cl}_{2} \mathrm{NOS}, 369.9865$; found, 369.9863 .

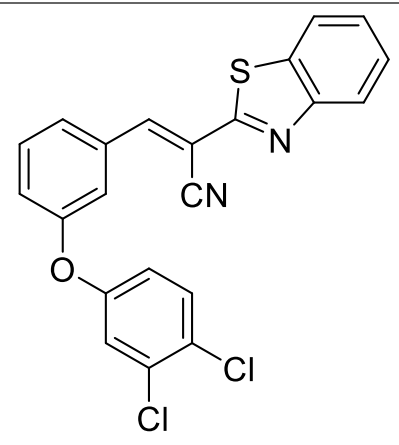

(E)-2-(Benzo[d] thiazol-2-yl)-3-(3-(3,4-dichlorophenoxy)phenyl)acrylonitrile (23). This compound was prepared by the general procedure B, affording $\mathbf{2 3}$ as a yellow powder (139 mg, 35\%). ${ }^{1} \mathrm{H}$ NMR (400 MHz, DMSO- $\left.d_{6}\right) \delta$ ppm 8.43 (br. s., $\left.1 \mathrm{H}\right), 8.02$ $8.28(\mathrm{~m}, 2 \mathrm{H}), 7.74-8.00(\mathrm{~m}, 2 \mathrm{H}), 7.48$ - $7.72(\mathrm{~m}, 4 \mathrm{H}), 7.26$ - 7.46 (m, 2H), 7.11 (br. s., $1 \mathrm{H}) .{ }^{13} \mathrm{C}$ NMR $\left(101 \mathrm{MHz}, \mathrm{DMSO}-d_{6}\right) \delta \mathrm{ppm} 162.81,156.22,155.48,152.71,147.17$, $134.29,134.22,132.11,131.65,131.07,127.09,126.37,126.00,125.61,123.14,122.54$, 122.43, 120.92, 119.92, 119.22, 115.76, 106.47. HRMS $(m / z):[\mathrm{M}+\mathrm{H}]^{+}$calcd for $\mathrm{C}_{22} \mathrm{H}_{13} \mathrm{Cl}_{2} \mathrm{~N}_{2} \mathrm{O}_{2} \mathrm{~S}, 423.0120$; found, 423.0115 .<smiles>N#C/C(=C\c1cccc(Oc2ccc(Cl)c(Cl)c2)c1)C(N)=O</smiles>

(E)-2-Cyano-3-(3-(3,4-dichlorophenoxy)phenyl)acrylamide (24). This compound was prepared by the general procedure B, affording 24 as a white powder $(410 \mathrm{mg}$, 52\%). ${ }^{1} \mathrm{H}$ NMR (400 MHz, DMSO-d6) $\delta$ ppm 8.18 (s, 1H), 7.93 (br. s., 1H), 7.82 (br. s., 1H), $7.71-7.78(\mathrm{~m}, 1 \mathrm{H}), 7.67(\mathrm{~d}, J=8.8 \mathrm{~Hz}, 1 \mathrm{H}), 7.57-7.65(\mathrm{~m}, 2 \mathrm{H}), 7.43(\mathrm{~d}, J=2.7$ $\mathrm{Hz}, 1 \mathrm{H}), 7.33$ (ddd, $J=0.7,2.5,8.3 \mathrm{~Hz}, 1 \mathrm{H}), 7.10(\mathrm{dd}, J=2.7,8.8 \mathrm{~Hz}, 1 \mathrm{H}) .{ }^{13} \mathrm{C} \mathrm{NMR}$ (101 MHz, DMSO-d6) $\delta$ ppm 162.91, 156.82, 155.94, 150.11, 134.37, 132.68, 132.21, $131.65,126.62,126.18,122.99,121.58,119.93,119.85,116.69,108.16$. HRMS $(\mathrm{m} / \mathrm{z})$ : $[\mathrm{M}-\mathrm{H}]^{-}$, calcd for $\mathrm{C}_{16} \mathrm{H}_{9} \mathrm{Cl}_{2} \mathrm{~N}_{2} \mathrm{O}_{2}, 331.0047$; found, 331.0074 .<smiles>N#C/C(=C\c1cccc(Oc2ccc(Cl)c(Cl)c2)c1)C(=O)O</smiles>

(E)-2-Cyano-3-(3-(3,4-dichlorophenoxy)phenyl)acrylic acid (25). 3-(3,4Dichlorophenoxy)benzaldehyde $(320 \mathrm{mg}, 1.2 \mathrm{mmol})$ in dry ethanol $(5 \mathrm{~mL})$ was added to an oven-dried $25 \mathrm{~mL}$ round bottom flask, under a nitrogen atmosphere. Right after, $t$-butyl cyanoacetate $(0.17 \mathrm{~mL}, 1.2 \mathrm{mmol})$ and L-proline $(69 \mathrm{mg}, 0.6 \mathrm{mmol})$ were added. The reaction was stirred overnight, the solvent was evaporate and the resulting crude sample was purified by column chromatography from EtOAc/Hexane 1:9 affording a white solid. The solid was then dissolved right away in $2 \mathrm{~mL}$ of trifluoroacetic acid (TFA) and the solution was stirred at room temperature for $2 \mathrm{~h}$. The solvent was removed in vacuo and the solid was washed with toluene affording a white solid (148 $\mathrm{mg}, 24 \%$ over two steps) ${ }^{1} \mathrm{H}$ NMR (400 MHz, DMSO- $\left.d_{6}\right) \delta$ ppm 14.01 (br. s., $\left.1 \mathrm{H}\right), 8.33(\mathrm{~s}, 1 \mathrm{H})$, 7.84 (d, J=7.9 Hz, 1H), 7.72 (s, 1H), $7.54-7.68$ (m, 2H), 7.39 (d, $J=2.8 \mathrm{~Hz}, 1 \mathrm{H}), 7.33$ (dd, $J=8.1,2.2 \mathrm{~Hz}, 1 \mathrm{H}), 7.07$ (dd, $J=8.9,3.0 \mathrm{~Hz}, 1 \mathrm{H}) .{ }^{13} \mathrm{C}$ NMR (101 MHz, DMSO-d $)$ $\delta$ ppm 163.69, 157.02, 156.18, 154.16, 134.22, 132.91, 132.43, 131.88, 126.92, 126.83, $123.95,121.73,120.97,120.00,116.53,105.61$. HRMS $(m / z):[\mathrm{M}-\mathrm{H}]^{-}$, calcd for $\mathrm{C}_{16} \mathrm{H}_{8} \mathrm{Cl}_{2} \mathrm{NO}_{3}, 331.9887$; found, 331.9877.<smiles>CS(=O)(=O)/C(C#N)=C/c1cccc(Cc2ccc(Cl)c(Cl)c2)c1F</smiles>

\section{(E)-3-(3-(3,4-Dichlorobenzyl)-2-fluorophenyl)-2-(methylsulfonyl)acrylonitrile}

(30). This compound was prepared by the general procedures A and B, affording $\mathbf{3 0}$ as a white powder $(245 \mathrm{mg}, 72 \%) .{ }^{1} \mathrm{H}$ NMR $\left(400 \mathrm{MHz}, \mathrm{DMSO}-d_{6}\right) \delta \mathrm{ppm} 8.31(\mathrm{~s}, 1 \mathrm{H})$, $8.06(\mathrm{dt}, J=8.1,2.0 \mathrm{~Hz}, 1 \mathrm{H}), 7.74(\mathrm{td}, J=7.5,1.5 \mathrm{~Hz}, 1 \mathrm{H}), 7.58(\mathrm{~d}, J=8.3 \mathrm{~Hz}, 1 \mathrm{H}), 7.56$ $(\mathrm{d}, J=2.0 \mathrm{~Hz}, 1 \mathrm{H}), 7.45$ (t, $J=7.7 \mathrm{~Hz}, 1 \mathrm{H}), 7.25$ (dd, $J=8.2,2.1 \mathrm{~Hz}, 1 \mathrm{H}), 4.09$ (s, 2H), $3.43(\mathrm{~s}, 3 \mathrm{H}) .{ }^{13} \mathrm{C}$ NMR $\left(101 \mathrm{MHz}, \mathrm{DMSO}-d_{6}\right) \delta \mathrm{ppm} 160.81,158.25,145.97,145.89$, $140.80,137.71,137.65,131.55,131.20,131.04,129.64,129.50,128.96,128.80,127.95$, $125.98,125.93,119.07,118.95,116.15,116.12,113.36,42.34,33.36$. HRMS $(m / z):[\mathrm{M}$ $-\mathrm{H}]^{-}$, calcd for $\mathrm{C}_{17} \mathrm{H}_{12} \mathrm{Cl}_{2} \mathrm{FNO}_{2} \mathrm{~S}, 381.9877$; found, 381.9884 . 


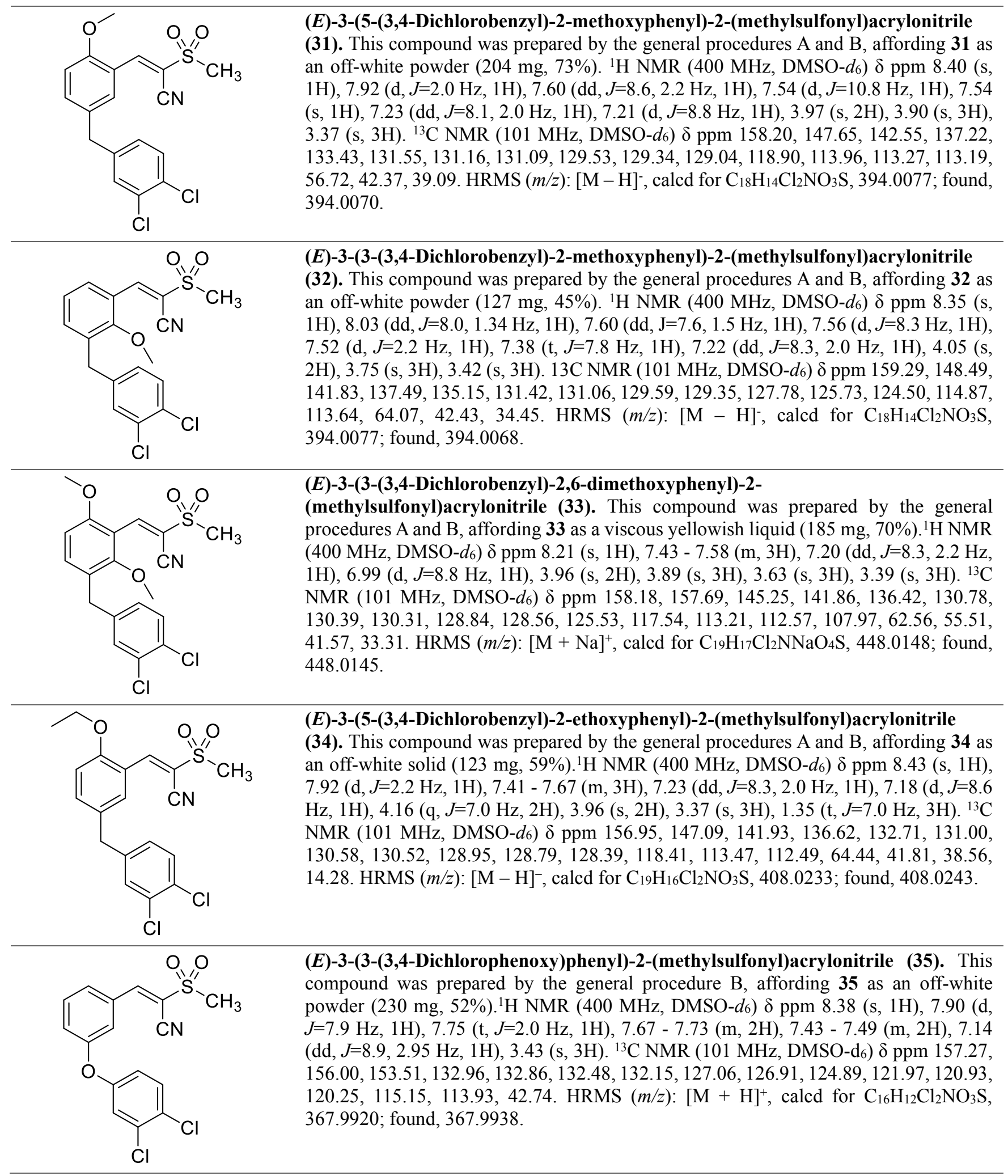


<smiles>CS(=O)(=O)/C(C#N)=C/c1cc(Cc2ccc(Cl)c(Cl)c2)ccc1N1CCOCC1</smiles><smiles>CS(=O)(=O)/C(C#N)=C/c1cc(Cc2ccc(C(F)(F)F)cc2)ccc1F</smiles>

(E)-3-(5-(3,4-Dichlorobenzyl)-2-morpholinophenyl)-2-

(methylsulfonyl)acrylonitrile (36). This compound was prepared by the general procedures A and B, affording 36 as a yellow powder (147 mg, 46\%). ${ }^{1} \mathrm{H}$ NMR (400 MHz, DMSO- $\left.d_{6}\right) \delta$ ppm $8.36(\mathrm{~s}, 1 \mathrm{H}), 7.74-7.99(\mathrm{~m}, 1 \mathrm{H}), 7.41-7.63(\mathrm{~m}, 3 \mathrm{H}), 7.11$ $7.32(\mathrm{~m}, 2 \mathrm{H}), 3.99(\mathrm{~s}, 2 \mathrm{H}), 3.73(\mathrm{dd}, J=5.5,3.6 \mathrm{~Hz}, 4 \mathrm{H}), 3.38(\mathrm{~s}, 3 \mathrm{H}), 2.79-2.98(\mathrm{~m}$, $4 \mathrm{H}) .{ }^{13} \mathrm{C}$ NMR $\left(101 \mathrm{MHz}, \mathrm{DMSO}-d_{6}\right) \delta \mathrm{ppm} 153.04,150.49,142.46,135.69,135.60$, $131.55,131.13,131.09,129.52,129.35,129.23,123.81,120.43,113.70,113.57,66.71$, 53.92, 42.64, 39.76. HRMS $(\mathrm{m} / \mathrm{z})$ : $[\mathrm{M}+\mathrm{H}]^{+}$, calcd for $\mathrm{C}_{21} \mathrm{H}_{21} \mathrm{Cl}_{2} \mathrm{~N}_{2} \mathrm{O}_{3} \mathrm{~S}, 451.0644$; found, 451.0617 .<smiles>COc1ccc(Cc2ccc(F)c(/C=C(\C#N)S(C)(=O)=O)c2)cc1C(F)(F)F</smiles><smiles>CS(=O)(=O)/C(C#N)=C/c1cc(Cc2ccc(F)c(C(F)(F)F)c2)ccc1F</smiles><smiles>CS(=O)(=O)/C(C#N)=C/c1cc(Cc2ccc(C(F)(F)F)c(F)c2)ccc1F</smiles>

(E)-3-(2-Fluoro-5-(4-(trifluoromethyl)benzyl)phenyl)-2-

(methylsulfonyl)acrylonitrile (37). This compound was prepared by the general procedures $\mathrm{A}$ and $\mathrm{B}$, affording 37 as a white powder $(82 \mathrm{mg}, 59 \%) .{ }^{1} \mathrm{H}$ NMR $(400 \mathrm{MHz}$, DMSO- $\left.d_{6}\right) \delta$ ppm $8.26(\mathrm{~s}, 1 \mathrm{H}), 7.99(\mathrm{dd}, J=6.9,2.2 \mathrm{~Hz}, 1 \mathrm{H}), 7.61-7.73(\mathrm{~m}, 3 \mathrm{H}), 7.49$ $(\mathrm{d}, J=8.1 \mathrm{~Hz}, 2 \mathrm{H}), 7.44(\mathrm{dd}, J=10.3,8.6 \mathrm{~Hz}, 1 \mathrm{H}), 4.14(\mathrm{~s}, 2 \mathrm{H}), 3.41$ (s, $3 \mathrm{H}) .{ }^{13} \mathrm{C}$ NMR (101 MHz, DMSO- $\left.d_{6}\right) \delta$ ppm 160.73, 158.20, 145.25, 145.20, 145.07, 137.68, 137.65, $136.68,136.59,129.43,128.96,127.19,126.87,125.59,125.43,125.39,125.35,122.89$, 118.27, 118.16, 116.81, 116.59, 115.68, 112.69, 41.72, 39.41. HRMS ( $m / z):[\mathrm{M}-\mathrm{H}]-$ calcd for $\mathrm{C}_{18} \mathrm{H}_{12} \mathrm{~F}_{4} \mathrm{NO}_{2} \mathrm{~S}, 382.0530$; found, 382.0523 .

\section{(E)-3-(2-Fluoro-5-(4-methoxy-3-(trifluoromethyl)benzyl)phenyl)-2-}

(methylsulfonyl)acrylonitrile (38). This compound was prepared by the general procedures $\mathrm{A}$ and $\mathrm{B}$, affording $\mathbf{3 8}$ as a white powder (130 mg, 63\%). ${ }^{1} \mathrm{H}$ NMR (400 MHz, DMSO- $\left.d_{6}\right) \delta$ ppm 8.26 (s, $\left.1 \mathrm{H}\right), 7.98$ (d, $\left.J=5.9 \mathrm{~Hz}, 1 \mathrm{H}\right), 7.65$ (br. s., $\left.1 \mathrm{H}\right), 7.47$ 7.57 (m, 2H), 7.42 (t, $J=9.4 \mathrm{~Hz}, 1 \mathrm{H}), 7.20$ (d, $J=8.3 \mathrm{~Hz}, 1 \mathrm{H}$ ), 4.04 (br. s., $2 \mathrm{H}$ ), 3.85 (s, $3 \mathrm{H}), 3.41(\mathrm{~s}, 3 \mathrm{H}) .{ }^{13} \mathrm{C}$ NMR (101 MHz, DMSO- $\left.d_{6}\right) \delta \mathrm{ppm} 161.46,158.93,156.34$, 146.00, 139.23, 139.20, 137.26, 137.17, 135.03, 132.99, 129.50, 127.55, 127.50, 125.74, $123.03,119.00,118.88,117.83,117.51,117.30,116.43,113.96,113.49,56.87,56.78$, 42.53, 42.51, 39.27. HRMS $(\mathrm{m} / \mathrm{z})$ : $[\mathrm{M}-\mathrm{H}]^{-}$, calcd for $\mathrm{C}_{19} \mathrm{H}_{14} \mathrm{~F}_{4} \mathrm{NO}_{3} \mathrm{~S}, 412.0636$; found, 412.0636 .

(E)-3-(2-Fluoro-5-(4-fluoro-3-(trifluoromethyl)benzyl)phenyl)-2-

(methylsulfonyl)acrylonitrile (39). This compound was prepared by the general procedures $\mathrm{A}$ and $\mathrm{B}$, affording 39 as a white powder (142 mg, 71\%). ${ }^{1} \mathrm{H}$ NMR (400 MHz, DMSO- $\left.d_{6}\right) \delta$ ppm $8.26(\mathrm{~s}, 1 \mathrm{H}), 7.96(\mathrm{dd}, J=6.7,2.0 \mathrm{~Hz}, 1 \mathrm{H}), 7.58-7.78(\mathrm{~m}, 3 \mathrm{H})$, $7.40-7.48(\mathrm{~m}, 2 \mathrm{H}), 4.13(\mathrm{~s}, 2 \mathrm{H}), 3.41(\mathrm{~s}, 3 \mathrm{H}) .{ }^{13} \mathrm{C}$ NMR (101 MHz, DMSO- $\left.d_{6}\right) \delta \mathrm{ppm}$. $161.53,159.58,158.99,157.08,145.97,138.61,138.59,138.15,138.12,137.33,137.24$, $136.22,136.13,129.58,128.00,127.96,124.67,121.97,118.95,118.22,118.02,117.57$, 117.45, 117.36, 117.26, 117.14, 116.52, 113.46, 71.26, 42.52, 42.49, 39.16. HRMS $(\mathrm{m} / \mathrm{z}):[\mathrm{M}-\mathrm{H}]^{-}$, calcd for $\mathrm{C}_{18} \mathrm{H}_{11} \mathrm{~F}_{5} \mathrm{NO}_{2} \mathrm{~S}, 400.0436$; found, 400.0439 .

\section{(E)-3-(2-Fluoro-5-(3-fluoro-4-(trifluoromethyl)benzyl)phenyl)-2-}

(methylsulfonyl)acrylonitrile (40). This compound was prepared by the general procedures A and B, affording 40 as a white powder (132 mg, 66\%). ${ }^{1} \mathrm{H}$ NMR (400 MHz, DMSO- $\left.d_{6}\right) \delta$ ppm $8.27(\mathrm{~s}, 1 \mathrm{H}), 7.97(\mathrm{dd}, J=6.7,2.0 \mathrm{~Hz}, 1 \mathrm{H}), 7.61-7.77(\mathrm{~m}, 2 \mathrm{H})$, $7.38-7.51(\mathrm{~m}, 2 \mathrm{H}), 7.31(\mathrm{~d}, J=8.3 \mathrm{~Hz}, 1 \mathrm{H}), 4.15(\mathrm{~s}, 2 \mathrm{H}), 3.41(\mathrm{~s}, 3 \mathrm{H}) .{ }^{13} \mathrm{C}$ NMR $(101$ MHz, DMSO- $\left.d_{6}\right) \delta$ ppm $161.58,160.94,159.04,158.43,149.35,149.27,146.02$, $145.95,137.83,137.79,137.43,137.34,129.85,128.28,128.25,128.20,128.15,127.51$, $126.05,126.02,124.80,122.09,120.12,119.12,119.09,117.88,117.62,117.40,116.71$, 115.81, 115.60, 115.48, 115.28, 115.16, 114.95, 114.83, 113.45, 42.52, 39.85. HRMS $(\mathrm{m} / \mathrm{z}):[\mathrm{M}-\mathrm{H}]^{-}$, calcd for $\mathrm{C}_{18} \mathrm{H}_{11} \mathrm{~F}_{5} \mathrm{NO}_{2} \mathrm{~S}, 400.0436$; found, 400.0417 . 


\begin{tabular}{|c|c|}
\hline $\mathrm{OCF}_{3}$ & 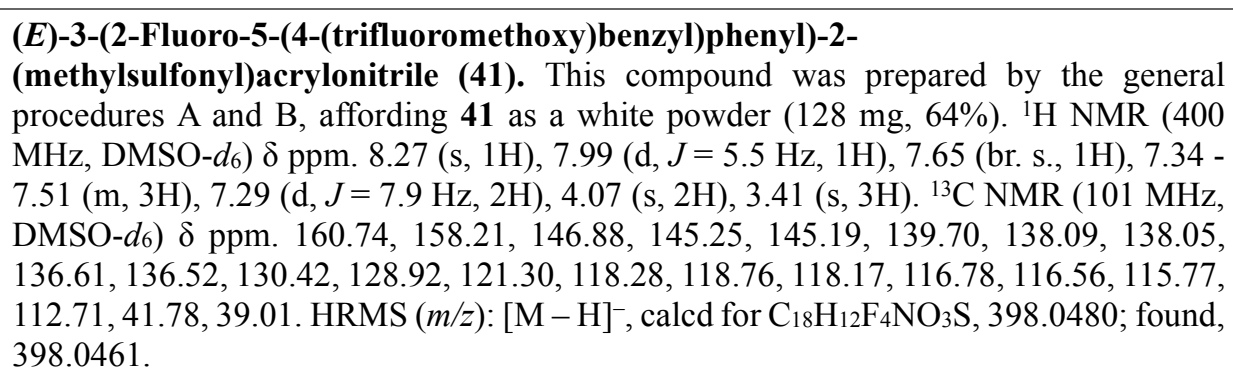 \\
\hline & $\begin{array}{l}\text { (E)-3-(2-Fluoro-5-(4-((trifluoromethyl)thio)benzyl)phenyl)-2- } \\
\text { (methylsulfonyl)acrylonitrile (42). This compound was prepared by the general } \\
\text { procedures A and B, affording 42 as a white powder }(137 \mathrm{mg}, 66 \%) .{ }^{1} \mathrm{H} \text { NMR }(400 \\
\left.\mathrm{MHz}, \mathrm{DMSO}-d_{6}\right) \delta \mathrm{ppm} 8.26(\mathrm{~s}, 1 \mathrm{H}), 7.95-8.07(\mathrm{~m}, 1 \mathrm{H}), 7.60-7.71(\mathrm{~m}, 3 \mathrm{H}), 7.34- \\
7.49(\mathrm{~m}, 3 \mathrm{H}), 4.10(\mathrm{~s}, 2 \mathrm{H}), 3.41(\mathrm{~s}, 3 \mathrm{H}) \cdot{ }^{13} \mathrm{C} \mathrm{NMR}\left(101 \mathrm{MHz}, \mathrm{DMSO}-\mathrm{d}_{6}\right) \delta \mathrm{ppm} 160.85 \text {, } \\
158.31,145.42,145.36,144.29,137.75,137.72,136.59,130.31,129.13,120.70,120.68 \text {, } \\
118.39,118.28,116.94,116.72,115.80,112.79,41.83 \text { 39.44. HRMS }(\mathrm{m} / \mathrm{z}):[\mathrm{M}-\mathrm{H}]^{-} \text {, } \\
\text { calcd for } \mathrm{C}_{18} \mathrm{H}_{12} \mathrm{~F}_{4} \mathrm{NO}_{2} \mathrm{~S}_{2}, 414.0251 \text {; found, } 414.0247 \text {. }\end{array}$ \\
\hline & $\begin{array}{l}\text { (E)-3-(5-(3,4-Dimethoxybenzyl)-2-(trifluoromethoxy)phenyl)-2- } \\
\text { (methylsulfonyl)acrylonitrile (43). This compound was prepared by the general } \\
\text { procedures A and B, affording } 43 \text { as a slightly yellow powder }(78 \mathrm{mg}, 49 \%) .{ }^{1} \mathrm{H} \text { NMR } \\
\left(400 \mathrm{MHz}, \mathrm{DMSO}-d_{6}\right) \delta \text { ppm } 8.31(\mathrm{~s}, 1 \mathrm{H}), 8.07(\mathrm{~d}, J=2.0 \mathrm{~Hz}, 1 \mathrm{H}), 7.69(\mathrm{dd}, J=8.7,2.0 \\
\mathrm{Hz}, 1 \mathrm{H}), 7.55(\mathrm{dd}, J=8.7,1.6 \mathrm{~Hz}, 1 \mathrm{H}), 6.91(\mathrm{~d}, J=2.0 \mathrm{~Hz}, 1 \mathrm{H}), 6.87(\mathrm{~d}, J=8.3 \mathrm{~Hz}, 1 \mathrm{H}), \\
6.77(\mathrm{dd}, J=8.3,2.0 \mathrm{~Hz}, 1 \mathrm{H}), 3.99(\mathrm{~s}, 2 \mathrm{H}), 3.73(\mathrm{~s}, 3 \mathrm{H}), 3.71(\mathrm{~s}, 3 \mathrm{H}), 3.43(\mathrm{~s}, 3 \mathrm{H}) .{ }^{3} \mathrm{C} \\
\mathrm{NMR}\left(101 \mathrm{MHz}, \mathrm{DMSO}-d_{6}\right) \delta \mathrm{ppm} 149.66,148.20,147.00,146.09,142.97,136.25 \text {, } \\
133.02,129.82,124.48,123.99,122.52,121.91,121.38,119.34,117.82,116.77,113.41 \text {, } \\
113.25,112.96,56.26,56.12,42.54,40.43 \mathrm{HRMS}(\mathrm{m} / \mathrm{z}):[\mathrm{M}+\mathrm{H}]^{+} \text {, calcd for } \\
\mathrm{C}_{20} \mathrm{H}_{19} \mathrm{~F}_{3} \mathrm{NO}_{5} \mathrm{~S}, 442.0931 \text {; found, } 442.0959 \text {. }\end{array}$ \\
\hline & $\begin{array}{l}(\boldsymbol{E})-3-(5-(B e n z o[d][1,3] \text { dioxol-5-ylmethyl)-2-(trifluoromethoxy)phenyl)-2- } \\
\text { (methylsulfonyl)acrylonitrile (44). This compound was prepared by the general } \\
\text { procedures A and B, affording 44 as a white powder }(148 \mathrm{mg}, 69 \%) .{ }^{1} \mathrm{H} \text { NMR }(400 \\
\left.\text { MHz, DMSO- } d_{6}\right) \delta \text { ppm } 8.29(\mathrm{~s}, 1 \mathrm{H}), 8.04(\mathrm{~d}, J=1.6 \mathrm{~Hz}, 1 \mathrm{H}), 7.66(\mathrm{dd}, J=8.3,2.0 \mathrm{~Hz} \text {, } \\
1 \mathrm{H}), 7.53(\mathrm{dd}, J=8.7,1.6 \mathrm{~Hz}, 1 \mathrm{H}), 6.82(\mathrm{~d}, J=7.9 \mathrm{~Hz}, 2 \mathrm{H}), 6.67-6.77(\mathrm{~m}, 1 \mathrm{H}), 5.94(\mathrm{~s}, \\
2 \mathrm{H}), 3.96(\mathrm{~s}, 2 \mathrm{H}), 3.41(\mathrm{~s}, 3 \mathrm{H}) .{ }^{13} \mathrm{C} \mathrm{NMR}\left(101 \mathrm{MHz}, \mathrm{DMSO}-d_{6}\right) \delta \mathrm{ppm} 148.24,146.93, \\
146.53,146.12,142.76,136.24,134.32,129.90,124.47,124.02,122.51,122.42,121.90, \\
119.33,117.89,116.76,113.22,109.85,109.05,101.51,42.54,40.40 . \mathrm{HRMS}(\mathrm{m} / \mathrm{z}):[\mathrm{M} \\
-\mathrm{H}]^{-} \text {, calcd for } \mathrm{C}_{19} \mathrm{H}_{13} \mathrm{~F}_{3} \mathrm{NO}_{5} \mathrm{~S}, 424.0472 \text {; found, } 424.0476 .\end{array}$ \\
\hline $\mathrm{CF}_{3}$ & 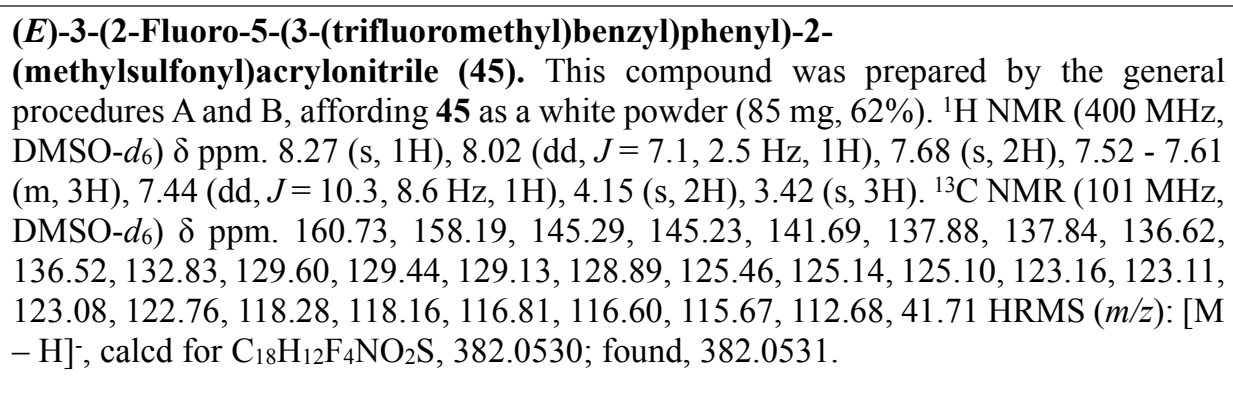 \\
\hline
\end{tabular}




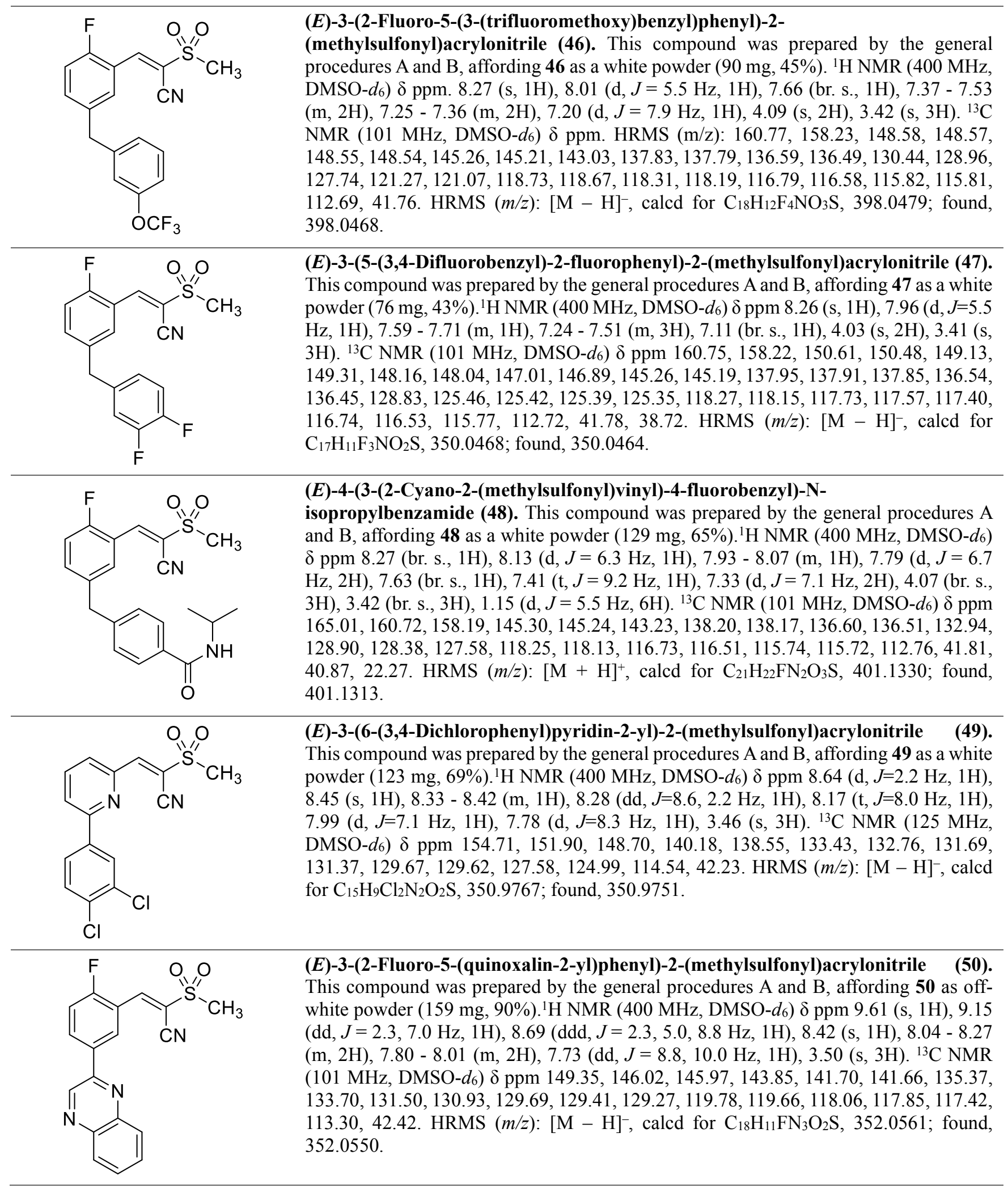




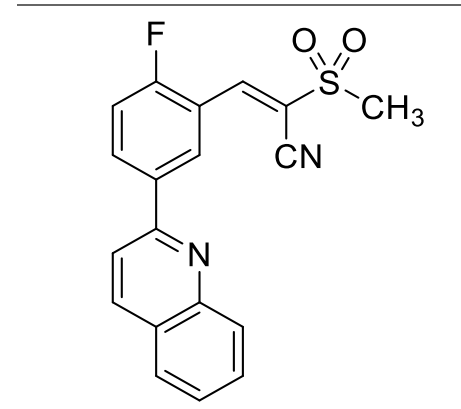

(E)-3-(2-Fluoro-5-(quinolin-2-yl)phenyl)-2-(methylsulfonyl)acrylonitrile (51). This compound was prepared by the general procedures $\mathrm{A}$ and $\mathrm{B}$, affording $\mathbf{5 1}$ as an off-white powder $(155 \mathrm{mg}, 88 \%) .{ }^{1} \mathrm{H}$ NMR $\left(400 \mathrm{MHz}, \mathrm{DMSO}-d_{6}\right) \delta \mathrm{ppm} 9.13(\mathrm{dd}, J=2.2,6.9$ $\mathrm{Hz}, 1 \mathrm{H}), 8.61$ (ddd, $J=2.3,5.1,8.7 \mathrm{~Hz}, 1 \mathrm{H}), 8.53$ (d, $J=8.6 \mathrm{~Hz}, 1 \mathrm{H}), 8.40(\mathrm{~s}, 1 \mathrm{H}), 8.16$ $(\mathrm{d}, J=8.8 \mathrm{~Hz}, 1 \mathrm{H}), 7.98-8.10(\mathrm{~m}, 2 \mathrm{H}), 7.82(\mathrm{ddd}, J=1.3,6.9,8.4 \mathrm{~Hz}, 1 \mathrm{H}), 7.55-7.72$ $(\mathrm{m}, 2 \mathrm{H}), 3.49(\mathrm{~s}, 3 \mathrm{H}) .{ }^{13} \mathrm{C}$ NMR $\left(101 \mathrm{MHz}\right.$, DMSO- $\left.d_{6}\right) \delta \mathrm{ppm} 162.86,160.28,153.69$, $147.38,145.55,145.50,137.75,135.73,134.73,134.63,130.32,129.09,128.25,127.90$, 127.09, 126.94, 118.90, 118.78, 118.27, 117.26, 117.05, 116.43, 112.93, 41.97. HRMS $(\mathrm{m} / \mathrm{z}):[\mathrm{M}-\mathrm{H}]^{-}$, calcd for $\mathrm{C}_{19} \mathrm{H}_{12} \mathrm{FN}_{2} \mathrm{O}_{2} \mathrm{~S}, 351.0609$, found, 351.0594 .<smiles>CS(=O)(=O)/C(C#N)=C/c1cc(-c2ccnc3ccccc23)ccc1F</smiles>

(E)-3-(2-Fluoro-5-(quinolin-4-yl)phenyl)-2-(methylsulfonyl)acrylonitrile (52). This compound was prepared by the general procedures $\mathrm{A}$ and $\mathrm{B}$, affording $\mathbf{5 2}$ as an off-white powder (120 mg, 68\%). ${ }^{1} \mathrm{H}$ NMR (400 MHz, DMSO- $\left.d_{6}\right) \delta \mathrm{ppm} 9.01(\mathrm{~d}, J=4.4 \mathrm{~Hz}, 1 \mathrm{H})$, $8.42(\mathrm{~s}, 1 \mathrm{H}), 8.30$ (dd, $J=6.7,2.1 \mathrm{~Hz}, 1 \mathrm{H}), 8.15(\mathrm{~d}, J=8.1 \mathrm{~Hz}, 1 \mathrm{H}), 7.93-8.02(\mathrm{~m}, 1 \mathrm{H})$, $7.91(\mathrm{~d}, J=8.3 \mathrm{~Hz}, 1 \mathrm{H}), 7.84(\mathrm{td}, J=7.6,1.1 \mathrm{~Hz}, 1 \mathrm{H}), 7.72(\mathrm{dd}, J=10.0,8.7 \mathrm{~Hz}, 1 \mathrm{H}), 7.59$ - $7.67(\mathrm{~m}, 1 \mathrm{H}), 7.53(\mathrm{~d}, J=4.4 \mathrm{~Hz}, 1 \mathrm{H}), 3.45(\mathrm{~s}, 3 \mathrm{H}) .{ }^{13} \mathrm{C}$ NMR $\left(101 \mathrm{MHz}\right.$, DMSO- $\left.d_{6}\right) \delta$ ppm $162.51,159.95,150.72,150.61,148.61,146.44,145.88,145.44,137.58,137.49$, $134.80,134.74,130.80,130.26,130.15,127.90,127.44,125.95,125.54,122.17,119.35$, 119.23, 117.85, 117.63, 117.42, 113.29, 41.42. HRMS $(\mathrm{m} / \mathrm{z})$ : $[\mathrm{M}-\mathrm{H}]^{-}$, calcd for $\mathrm{C}_{19} \mathrm{H}_{12} \mathrm{FN}_{2} \mathrm{O}_{2} \mathrm{~S}, 351.0609$; found, 351.0598 .<smiles>N#CC(C#N)=Cc1cc(Cc2ccc(Cl)c(Cl)c2)ccc1F</smiles>

2-(5-(3,4-Dichlorobenzyl)-2-fluorobenzylidene)malononitrile (53). This compound was prepared by the general procedures $\mathrm{A}$ and $\mathrm{B}$, affording $\mathbf{5 3}$ as an off-white powder (323 mg, 78\%). ${ }^{1} \mathrm{H}$ NMR (400 MHz, DMSO- $d_{6}$ ) $\delta \mathrm{ppm} 8.55$ (s, $1 \mathrm{H}$ ), 7.88 (dd, $J=6.7$, $1.6 \mathrm{~Hz}, 1 \mathrm{H}), 7.60-7.70(\mathrm{~m}, 1 \mathrm{H}), 7.50-7.59(\mathrm{~m}, 2 \mathrm{H}), 7.40(\mathrm{dd}, J=10.0,8.8 \mathrm{~Hz}, 1 \mathrm{H})$, $7.24(\mathrm{dd}, J=8.2,1.8 \mathrm{~Hz}, 1 \mathrm{H}), 4.02(\mathrm{~s}, 2 \mathrm{H}) .{ }^{13} \mathrm{C}$ NMR $\left(101 \mathrm{MHz}, \mathrm{DMSO}-d_{6}\right) \delta \mathrm{ppm}$ $160.65,158.62,154.77,154.74,142.15,138.27,138.24,137.40,137.33,131.84,131.41$, 129.81, 129.74, 120.20, 120.10, 117.51, 117.34, 114.38, 113.31, 85.78, 39.30. HRMS $(\mathrm{m} / \mathrm{z})$ : $[\mathrm{M}-\mathrm{H}]^{-}$, calcd for $\mathrm{C}_{17} \mathrm{H}_{9} \mathrm{Cl}_{2} \mathrm{FN}_{2}, 329.0054$; found, 329.0052 .<smiles>N#CC(C#N)=Cc1cccc(Cc2ccc(Cl)c(Cl)c2)c1F</smiles>

2-(3-(3,4-Dichlorobenzyl)-2-fluorobenzylidene)malononitrile (54). This compound was prepared by the general procedures A and B, affording $\mathbf{5 4}$ as an off-white powder (262 mg, 65\%). ${ }^{1} \mathrm{H}$ NMR (400 MHz, DMSO- $\left.d_{6}\right) \delta \mathrm{ppm} 8.60(\mathrm{~s}, 1 \mathrm{H}), 7.89-8.02(\mathrm{~m}$, $1 \mathrm{H}), 7.72(\mathrm{td}, J=7.6,1.7 \mathrm{~Hz}, 1 \mathrm{H}), 7.58(\mathrm{~d}, J=8.3 \mathrm{~Hz}, 1 \mathrm{H}), 7.55(\mathrm{~d}, J=2.0 \mathrm{~Hz}, 1 \mathrm{H}), 7.42$ (t, $J=7.7 \mathrm{~Hz}, 1 \mathrm{H}), 7.23$ (dd, $J=8.2,2.1 \mathrm{~Hz}, 1 \mathrm{H}), 4.07$ (s, 2H). ${ }^{13} \mathrm{C}$ NMR $(101 \mathrm{MHz}$, DMSO-d6) $\delta$ ppm 160.16, 157.60, 154.53, 154.46, 140.78, 137.74, 137.68, 131.54, 131.22, 131.06, 129.64, 129.50, 128.90, 128.74, 128.05, 125.85, 125.81, 120.23, 120.11, 114.23, 113.21, 85.48, 33.33. HRMS ( $m / z)$ : $[\mathrm{M}-\mathrm{H}]^{-}$, calcd for $\mathrm{C}_{17} \mathrm{H}_{9} \mathrm{Cl}_{2} \mathrm{FN}_{2}, 329.0054$; found, 329.0070 .<smiles>COc1ccc(Cc2ccc(Cl)c(Cl)c2)cc1C=C(C#N)C#N</smiles>
2-(5-(3,4-Dichlorobenzyl)-2-methoxybenzylidene)malononitrile (55). This compound was prepared by the general procedures $\mathrm{A}$ and $\mathrm{B}$, affording $\mathbf{5 5}$ as a faintyellow powder $(330 \mathrm{mg}, 77 \%)$. ${ }^{1} \mathrm{H}$ NMR $\left(400 \mathrm{MHz}, \mathrm{DMSO}-d_{6}\right) \delta \mathrm{ppm} 8.43(\mathrm{~s}, 1 \mathrm{H})$, $7.80(\mathrm{~d}, \mathrm{~J}=2.20 \mathrm{~Hz}, 1 \mathrm{H}), 7.58(\mathrm{dd}, \mathrm{J}=8.56,2.20 \mathrm{~Hz}, 1 \mathrm{H}), 7.54(\mathrm{~d}, \mathrm{~J}=8.07 \mathrm{~Hz}, 1 \mathrm{H}), 7.52$ $(\mathrm{d}, \mathrm{J}=1.96 \mathrm{~Hz}, 1 \mathrm{H}), 7.22(\mathrm{dd}, \mathrm{J}=8.19,2.08 \mathrm{~Hz}, 1 \mathrm{H}), 7.18(\mathrm{~d}, \mathrm{~J}=8.56 \mathrm{~Hz}, 1 \mathrm{H}), 3.95$ (s, $2 \mathrm{H}), 3.88(\mathrm{~s}, 3 \mathrm{H}) .{ }^{13} \mathrm{C}$ NMR $\left(101 \mathrm{MHz}, \mathrm{DMSO}-d_{6}\right) \delta \mathrm{ppm} 157.11,156.56,142.54$, 137.25, 133.32, 131.53, 131.13, 131.04, 129.49, 129.30, 120.40, 114.86, 113.68, 113.19, 82.26, 56.64, 39.07. HRMS ( $m / z)$ : [M - H] -, calcd for $\mathrm{C}_{18} \mathrm{H}_{12} \mathrm{Cl}_{2} \mathrm{~N}_{2} \mathrm{O}, 341.0253$; found, 341.0246 . 
<smiles>N#CC(C#N)=Cc1cccc(Oc2ccc(Cl)c(Cl)c2)c1</smiles><smiles>N#CC(C#N)Cc1cccc(Oc2ccc(Cl)c(Cl)c2)c1</smiles>

2-(3-(3,4-Dichlorophenoxy)benzylidene)malononitrile (56). This compound was prepared by the general procedure B, affording $\mathbf{5 6}$ as an off-white powder $(170 \mathrm{mg}$, 92\%). ${ }^{1} \mathrm{H}$ NMR (400 MHz, DMSO-d6) $\delta \mathrm{ppm} 8.52(\mathrm{~s}, 1 \mathrm{H}), 7.74(\mathrm{~d}, J=8.3 \mathrm{~Hz}, 1 \mathrm{H})$, $7.61-7.68(\mathrm{~m}, 2 \mathrm{H}), 7.57$ (t, $J=2.2 \mathrm{~Hz}, 1 \mathrm{H}), 7.38-7.44(\mathrm{~m}, 2 \mathrm{H}), 7.09$ (dd, $J=9.1,2.8$ $\mathrm{Hz}, 1 \mathrm{H}) .{ }^{13} \mathrm{C}$ NMR (101 MHz, DMSO-d6) $\delta \mathrm{ppm} 161.26,157.22,155.84,133.75$, 133.00, 132.48, 132.17, 127.17, 126.62, 125.04, 121.97, 120.41, 120.24, 114.64, 113.64, 83.52. HRMS $(\mathrm{m} / \mathrm{z})$ : [M $-\mathrm{H}]^{-}$, calcd for $\mathrm{C}_{16} \mathrm{H}_{7} \mathrm{Cl}_{2} \mathrm{~N}_{2} \mathrm{O}, 312.9941$; found, 312.9951 .

2-(3-(3,4-Dichlorophenoxy)benzyl)malononitrile (57). Ethidine (88 $\mathrm{mg}, 0.4)$ and $\mathbf{5 6}$ (100 mg, $0.3 \mathrm{mmol}$ ) in $5 \mathrm{~mL}$ of methanol were added to an oven-dried $25-\mathrm{mL}$ round bottom flask, under a nitrogen atmosphere. The reaction was stirred overnight at room temperature, the solvent was evaporated under reduced pressure and the crude was purified by silica-gel column chromatography from EtOAc/Hexane 1:9 to EtOAc/Hexane 1:0, affording an colorless oil (62 mg, 61\%). ${ }^{1} \mathrm{H}$ NMR (400 MHz, $\left.\mathrm{CDCl}_{3}\right) \delta \mathrm{ppm} 7.43(\mathrm{~d}, J=8.7 \mathrm{~Hz}, 1 \mathrm{H}), 7.41(\mathrm{~d}, J=9.1 \mathrm{~Hz}, 1 \mathrm{H}), 7.10-7.17(\mathrm{~m}, 2 \mathrm{H}), 7.01$ - $7.07(\mathrm{~m}, 1 \mathrm{H}), 6.98(\mathrm{t}, J=2.0 \mathrm{~Hz}, 1 \mathrm{H}), 6.89(\mathrm{dd}, J=8.7,2.8 \mathrm{~Hz}, 1 \mathrm{H}), 3.93(\mathrm{t}, J=6.9 \mathrm{~Hz}$, $1 \mathrm{H}), 3.28(\mathrm{~d}, J=7.9 \mathrm{~Hz}, 2 \mathrm{H}) .{ }^{13} \mathrm{C}$ NMR $\left(101 \mathrm{MHz}, \mathrm{CDCl}_{3}\right) \delta \mathrm{ppm} 156.60,156.14,137.68$, $132.53,132.08,131.07,125.95,125.91,120.82,120.48,119.25,119.19,114.46,34.55$, 24.64. HRMS (m/z): [M - H] , calcd for $\mathrm{C}_{16} \mathrm{H}_{9} \mathrm{Cl}_{2} \mathrm{~N}_{2} \mathrm{O}, 315.0097$; found, 315.0098.

2-(3-(3,4-Dichlorobenzyl)benzylidene)malononitrile (58). This compound was prepared by the general procedures $\mathrm{A}$ and $\mathrm{B}$, affording $\mathbf{5 8}$ as a white solid powder (131 mg, 90\%). ${ }^{1} \mathrm{H}$ NMR (400 MHz, DMSO-d6) $\delta \mathrm{ppm} 8.51$ (s, $\left.1 \mathrm{H}\right), 7.82$ (dt, $J=7.4,1.4 \mathrm{~Hz}$, $1 \mathrm{H}), 7.73-7.79(\mathrm{~m}, 1 \mathrm{H}), 7.59(\mathrm{~m}, J=8.1 \mathrm{~Hz}, 4 \mathrm{H}), 7.20-7.27(\mathrm{~m}, 1 \mathrm{H}), 4.05(\mathrm{~s}, 2 \mathrm{H})$. ${ }^{13} \mathrm{C}$ NMR (101 MHz, DMSO-d6) $\delta$ ppm 161.94, 142.27, 142.01, 135.22, 132.10, 131.57, 131.24, 131.20, 130.29, 129.70, 129.49, 128.69, 114.64, 113.66, 82.27, 39.77. HRMS $(\mathrm{m} / \mathrm{z}):[\mathrm{M}-\mathrm{H}]^{-}$, calcd for $\mathrm{C}_{17} \mathrm{H}_{9} \mathrm{~N}_{2} \mathrm{Cl}_{2}, 311.0148$; found, 311.0137 .

2-(1-(3-(3,4-Dichlorobenzyl)phenyl)ethylidene)malononitrile (59). This compound was prepared by the general procedures A and B, affording $\mathbf{5 9}$ as an off-white powder (139 mg, 49\%). ${ }^{1} \mathrm{H}$ NMR (400 MHz, DMSO- $\left.d_{6}\right) \delta \mathrm{ppm} 7.62(\mathrm{~s}, 1 \mathrm{H}), 7.56(\mathrm{~d}, J=2.0 \mathrm{~Hz}$, $1 \mathrm{H}), 7.51-7.55(\mathrm{~m}, 2 \mathrm{H}), 7.46-7.51(\mathrm{~m}, 2 \mathrm{H}), 7.26(\mathrm{dd}, J=8.3,2.0 \mathrm{~Hz}, 1 \mathrm{H}), 4.02(\mathrm{~s}$, $2 \mathrm{H}), 2.61(\mathrm{~s}, 3 \mathrm{H}) .{ }^{13} \mathrm{C}$ NMR (101 MHz, DMSO- $\left.d_{6}\right) \delta \mathrm{ppm} 177.75,142.52,141.81$, 137.04, 133.10, 131.74, 131.37, 131.30, 129.91, 129.80, 129.61, 128.62, 126.39, 114.05, 113.88, 84.12, 25.07. HRMS (m/z): [M - H] $]^{-}$, calcd for $\mathrm{C}_{18} \mathrm{H}_{11} \mathrm{Cl}_{2} \mathrm{~N}_{2}$, 325.0304; found, 325.0304 .<smiles>COc1ccc(C=C(C#N)C#N)cc1Oc1ccc(Cl)c(Cl)c1</smiles><smiles>CCC(C)NCCOc1ccc(C=O)cc1Oc1ccc(Cl)c(Cl)c1</smiles> 
(1.00 g, $6.6 \mathrm{mmol})$, copper (II) acetate $(1.19 \mathrm{~g}, 6.6 \mathrm{mmol})$, triethylamine $(4.58 \mathrm{~mL}, 33.0$ $\mathrm{mmol})$, and dry DCM $(60 \mathrm{~mL})$ were added to an oven-dried $250 \mathrm{~mL}$ round-bottom flask loaded with activated 4A molecular sieves. After stirring the solution overnight at room temperature, the insoluble materials were filtered through a pad of celite and the flow through was evaporated under reduced pressure. The crude was purified by silica gel column chromatography EtOAc/Hexane 1:9 to EtOAc/Hexane 1:0 affording a colorless liquid (547 mg, $28 \%$ ). ${ }^{1} \mathrm{H}$ NMR (400 MHz, $\left.\mathrm{CDCl}_{3}\right) \delta \mathrm{ppm} 9.86(\mathrm{~s}, 1 \mathrm{H}), 7.74$ (dd, $J=8.3$, $2.0 \mathrm{~Hz}, 1 \mathrm{H}), 7.53$ (d, $J=2.0 \mathrm{~Hz}, 1 \mathrm{H}), 7.36(\mathrm{~d}, J=8.7 \mathrm{~Hz}, 1 \mathrm{H}), 7.13$ (d, $J=8.3 \mathrm{~Hz}, 1 \mathrm{H})$, $7.01(\mathrm{~d}, J=2.8 \mathrm{~Hz}, 1 \mathrm{H}), 6.81(\mathrm{dd}, J=9.1,2.8 \mathrm{~Hz}, 1 \mathrm{H}), 3.92(\mathrm{~s}, 3 \mathrm{H}) .{ }^{13} \mathrm{C}$ NMR $(101 \mathrm{MHz}$, $\left.\mathrm{CDCl}_{3}\right) \delta \mathrm{ppm} 160.30,156.72,156.58,144.95,133.45,131.22,130.58,129.42,126.76$, 121.26, 119.32, 117.01, 112.66, 56.52. HRMS $(\mathrm{m} / \mathrm{z}):[\mathrm{M}+\mathrm{H}]^{+}$, calcd for $\mathrm{C}_{14} \mathrm{H}_{11} \mathrm{Cl}_{2} \mathrm{O}_{3}$, 297.0080; found, 297.0098.

2-(3-(3,4-Dichlorophenoxy)-4-methoxybenzylidene)malononitrile $\quad(60) . \quad$ This compound was prepared by the general procedures B, using $\mathbf{6 0 . A}$, affording 60 as an off-white powder (136 mg, 33\%). ${ }^{1} \mathrm{H}$ NMR (400 MHz, $\left.\mathrm{CDCl}_{3}\right) \delta \mathrm{ppm} 3.94(\mathrm{~s}, 3 \mathrm{H}) .6 .81$ $(\mathrm{dd}, J=8.7,2.8 \mathrm{~Hz}, 1 \mathrm{H}), 7.01(\mathrm{~d}, J=2.8 \mathrm{~Hz}, 1 \mathrm{H}), 7.13(\mathrm{~d}, J=8.7 \mathrm{~Hz}, 1 \mathrm{H}), 7.38(\mathrm{~d}, J=8.7$ $\mathrm{Hz}, 1 \mathrm{H}), 7.60(\mathrm{~d}, J=2.4 \mathrm{~Hz}, 1 \mathrm{H}), 7.63(\mathrm{~s}, 1 \mathrm{H}), 7.82(\mathrm{dd}, J=8.9,2.16 \mathrm{~Hz}, 1 \mathrm{H}),{ }^{13} \mathrm{C}$ NMR $\left(101 \mathrm{MHz}, \mathrm{CDCl}_{3}\right) \delta \mathrm{ppm} \mathrm{158.19}, 156.77,156.17,144.88,133.57,131.33,130.21$, 127.11, 124.62, 123.22, 119.27, 116.96, 114.18, 113.43, 113.12, 80.55, 56.67. HRMS $(\mathrm{m} / \mathrm{z})$ : $[\mathrm{M}-\mathrm{H}]^{-}$, calcd for $\mathrm{C}_{17} \mathrm{H}_{9} \mathrm{Cl}_{2} \mathrm{~N}_{2} \mathrm{O}_{2}, 343.0047$; found, 343.0073 .

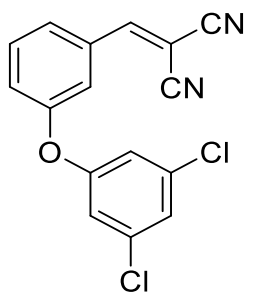

2-(3-(3,5-Dichlorophenoxy)benzylidene)malononitrile (61). This compound was prepared by the general procedure B, affording 61 as a white powder $(25 \mathrm{mg}, 7 \%) .{ }^{1} \mathrm{H}$ NMR (400 MHz, DMSO- $\left.d_{6}\right) \delta$ ppm $8.53(\mathrm{~s}, 1 \mathrm{H}), 7.77(\mathrm{~d}, J=7.9 \mathrm{~Hz}, 1 \mathrm{H}), 7.67$ (t, $J=8.1$ $\mathrm{Hz}, 1 \mathrm{H}), 7.60(\mathrm{~s}, 1 \mathrm{H}), 7.37-7.51(\mathrm{~m}, 2 \mathrm{H}), 7.18(\mathrm{~d}, J=1.6 \mathrm{~Hz}, 2 \mathrm{H}) .{ }^{13} \mathrm{C}$ NMR $(101 \mathrm{MHz}$, DMSO-d $\left._{6}\right) \delta$ ppm 161.24, 158.07, 156.69, 135.86, 133.83, 132.29, 127.01, 125.43, 124.70, 120.85, 118.75, 114.66, 113.67, 83.65. HRMS $(\mathrm{m} / \mathrm{z}):[\mathrm{M}-\mathrm{H}]^{-}$, calcd for $\mathrm{C}_{16} \mathrm{H}_{7} \mathrm{Cl}_{2} \mathrm{~N}_{2} \mathrm{O}, 312.9930$; found, 312.9941 .<smiles>N#CC(C#N)=Cc1cccc(Sc2ccc(Cl)c(Cl)c2)c1</smiles>

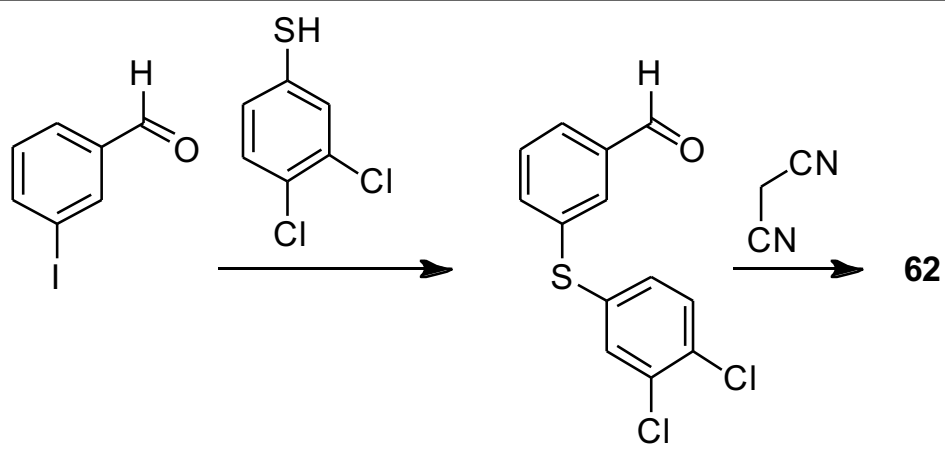

62.A

3-((3,4-Dichlorophenyl)thio)benzaldehyde (62.A). To a round-bottom flask were added 3-iodobenzaldehyde $(1.50 \mathrm{~g}, 6.5 \mathrm{mmol}), 3$,4-dichlorothiophenol (1.16 g, 6.4 $\mathrm{mmol})$, copper (I) iodide (124 mg, $0.7 \mathrm{mmol})$, ethylene glycol (0.78 mL, $12.9 \mathrm{mmol})$, potassium carbonate $(1.78 \mathrm{~g}, 12.9 \mathrm{mmol})$, and isopropanol $(25 \mathrm{~mL})$. The mixture was refluxed for $48 \mathrm{~h}$ : The reaction was then diluted with DCM $(50 \mathrm{ml})$ and filtered through a pad of celite. The filtrate was concentrated in vacuo and the crude was purified by silica-gel column chromatography EtOAc/Hexane 1:9 to EtOAc/Hexane 1:0, affording a faint-yellow oil $(628 \mathrm{mg}, 34 \%) .{ }^{1} \mathrm{H}$ NMR $\left(400 \mathrm{MHz}, \mathrm{CDCl}_{3}\right) \delta \mathrm{ppm} 9.97(\mathrm{~s}, 1 \mathrm{H}), 7.83$ $(\mathrm{t}, J=2.0 \mathrm{~Hz}, 1 \mathrm{H}), 7.75-7.81(\mathrm{~m}, 1 \mathrm{H}), 7.57(\mathrm{td}, J=1.5,7.7 \mathrm{~Hz}, 1 \mathrm{H}), 7.50(\mathrm{t}, J=7.7$ $\mathrm{Hz}, 1 \mathrm{H}), 7.42(\mathrm{~d}, J=2.4 \mathrm{~Hz}, 1 \mathrm{H}), 7.39(\mathrm{~d}, J=8.7 \mathrm{~Hz}, 1 \mathrm{H}), 7.11-7.20(\mathrm{~m}, 1 \mathrm{H}){ }^{13} \mathrm{C}$ NMR

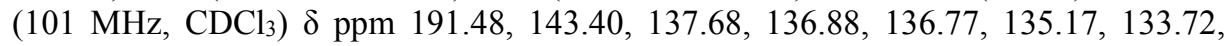
$132.89,132.05,131.40,130.68,130.37,129.10$. HRMS $(\mathrm{m} / \mathrm{z}):[\mathrm{M}+\mathrm{H}]^{+}$, calcd for $\mathrm{C}_{13} \mathrm{H}_{9} \mathrm{Cl}_{2} \mathrm{OS}, 282.9746$; found, 282.9727. 
2-(3-((3,4-Dichlorophenyl)thio)benzylidene)malononitrile (62). This compound was prepared by the general procedure B, using $62 . \mathbf{A}$, affording 62 as an off-yellow powder (363 mg, 62\%). ${ }^{1} \mathrm{H}$ NMR (400 MHz, $\left.\mathrm{CDCl}_{3}\right) \delta \mathrm{ppm} 7.80(\mathrm{td}, J=1.6,7.5 \mathrm{~Hz}, 1 \mathrm{H}), 7.70$ $(\mathrm{s}, 1 \mathrm{H}), 7.69(\mathrm{t}, J=2.0 \mathrm{~Hz}, 1 \mathrm{H}), 7.39-7.55(\mathrm{~m}, 4 \mathrm{H}), 7.20-7.28(\mathrm{~m}, 1 \mathrm{H}) .{ }^{13} \mathrm{C}$ NMR $(101$ $\left.\mathrm{MHz}, \mathrm{CDCl}_{3}\right) \delta$ ppm 158.95, 139.67, 138.52, 135.72, 134.01, 133.61, 133.21, 132.34, $131.78,131.68,130.73,129.04,113.50,112.35,84.66,63.49$. HRMS $(m / z):[\mathrm{M}-\mathrm{H}]^{-}$, calcd for $\mathrm{C}_{16} \mathrm{H}_{7} \mathrm{Cl}_{2} \mathrm{~N}_{2} \mathrm{~S}, 328.9712$; found, 328.9699.<smiles>N#CC(C#N)=Cc1cccc(S(=O)(=O)c2ccc(Cl)c(Cl)c2)c1</smiles>

2-(3-((3,4-Dichlorophenyl)sulfonyl)benzylidene)malononitrile (63). 62 (200 mg, $0.60 \mathrm{mmol}$ ) was added to oven-dried $25 \mathrm{~mL}$ round-bottom flask with $2 \mathrm{~mL}$ of acetic acid and $0.5 \mathrm{~mL}$ of hydrogen peroxide. The reaction was stirred overnight at room temperature. It was evaporated and the crude was purified by silica-gel column chromatography EtOAc/Hexane 1:9 to EtOAc/Hexane 1:0, affording a white powder (158 mg, 72\%). ${ }^{1} \mathrm{H}$ NMR (400 MHz, DMSO- $\left.d_{6}\right) \delta$ ppm $8.04-8.27$ (m, $\left.3 \mathrm{H}\right), 7.85$ - 7.97 $(\mathrm{m}, 2 \mathrm{H}), 7.68-7.85(\mathrm{~m}, 2 \mathrm{H}), 5.52(\mathrm{~s}, 1 \mathrm{H}) .{ }^{13} \mathrm{C}$ NMR (101 MHz, DMSO- $\left.d_{6}\right) \delta \mathrm{ppm}$ 141.42, 141.13, 138.20, 133.61, 133.14, 132.96, 132.07, 131.23, 130.39, 129.94, 128.29, 127.33, 113.16, 111.97, 64.64, 63.47. HRMS $(m / z)$ : $[\mathrm{M}-\mathrm{H}]^{-}$, calcd for $\mathrm{C}_{16} \mathrm{H}_{7} \mathrm{Cl}_{2} \mathrm{~N}_{2} \mathrm{O}_{2} \mathrm{~S}$, 360.9611 ; found, 360.9585 .<smiles>Nc1ccc(Cl)c(Cl)c1</smiles><smiles>CC(C#N)(C#N)CCC#N</smiles>

64.A<smiles>N#CC(C#N)=Cc1cccc(C(=O)Nc2ccc(Cl)c(Cl)c2)c1</smiles>

$\mathrm{N}$-(3,4-Dichlorophenyl)-3-formylbenzamide (64.A). To a solution of 3-formylbenzoic acid $(500 \mathrm{mg}, 3.3 \mathrm{mmol})$ in dry DMF $(10 \mathrm{~mL}), 1$-[bis(dimethylamino)methylene-1H1,2,3-triazolo[4,5-b]pyridinium 3-oxid hexafluorophosphate (HATU, $1.39 \mathrm{gr}, 3.7 \mathrm{mmol}$ ) was added and the solution was stirred for $10 \mathrm{~min}$. 3,4-Dichloroaniline (1.08 g, 6.7 mmol) was then added and the solution was stirred for another $20 \mathrm{~min}$. Finally, DIPEA $(1.74 \mathrm{~mL}, 10.00 \mathrm{mmol})$ was added and the solution was stirred at room temperature overnight. The solvent was evaporated in vacuo and the residue was dissolved in diethyl ether $(20 \mathrm{~mL})$. The organic solution was washed with water $(15 \mathrm{~mL})$, the layers were separated and the organic solution was dried over anhydrous $\mathrm{Na}_{2} \mathrm{SO}_{4}$. The suspention was filtered and the filtrate was evaporation under reduced pressure. The crude product was purified with a gradient column chromatography on silica gel from EtOAc/Hexane 3:7 to EtOAc/Hexane 1:1 affording a white solid (488 mg, 50\%). ${ }^{1} \mathrm{H}$ NMR (400 MHz, DMSO- $\left.d_{6}\right) \delta \mathrm{ppm} 10.70(\mathrm{~s}, 1 \mathrm{H}), 10.11(\mathrm{~s}, 1 \mathrm{H}), 8.47(\mathrm{t}, J=2.0 \mathrm{~Hz}, 1 \mathrm{H}), 8.25(\mathrm{td}, J=1.6$, $7.9 \mathrm{~Hz}, 1 \mathrm{H}), 8.07-8.19(\mathrm{~m}, 2 \mathrm{H}), 7.70-7.84(\mathrm{~m}, 2 \mathrm{H}), 7.62(\mathrm{~d}, J=8.7 \mathrm{~Hz}, 1 \mathrm{H}){ }^{13} \mathrm{C}$ NMR $\left(101 \mathrm{MHz}, \mathrm{DMSO}-d_{6}\right) \delta \mathrm{ppm} 193.52,165.56,139.81,136.99,135.82,134.12,133.50$, 131.64, 131.30, 130.19, 129.17, 126.13, 122.29, 121.00. HRMS $(\mathrm{m} / \mathrm{z}):[\mathrm{M}+\mathrm{H}]^{+}$, calcd for $\mathrm{C}_{14} \mathrm{H}_{10} \mathrm{Cl}_{2} \mathrm{NO}_{2}$, 294.0083; found, 294.0057 .

$\boldsymbol{N}$-(3,4-Dichlorophenyl)-3-(2,2-dicyanovinyl)benzamide (64). This compound was prepared by the general procedure B, using 64.A, affording 64 as a white powder (186 mg, 64\%). ${ }^{1} \mathrm{H}$ NMR (400 MHz, DMSO- $\left.d_{6}\right) \delta \mathrm{ppm} 10.78(\mathrm{~s}, 1 \mathrm{H}), 8.65(\mathrm{~s}, 1 \mathrm{H}), 8.45$ (s, $1 \mathrm{H}), 8.24$ (d, $J=7.6 \mathrm{~Hz}, 1 \mathrm{H}), 8.07-8.20$ (m, 2H), 7.79 (t, $J=7.8 \mathrm{~Hz}, 1 \mathrm{H}), 7.74$ (dd, $J=8.8$, $2.0 \mathrm{~Hz}, 1 \mathrm{H}), 7.62(\mathrm{~d}, J=8.8 \mathrm{~Hz}, 1 \mathrm{H}) \cdot{ }^{13} \mathrm{C}$ NMR $\left(101 \mathrm{MHz}, \mathrm{DMSO}-d_{6}\right) \delta \mathrm{ppm} 165.13$, 161.24, 139.48, 135.93, 133.29, 133.13, 132.02, 131.41, 131.12, 130.85, 130.14, 125.91, 

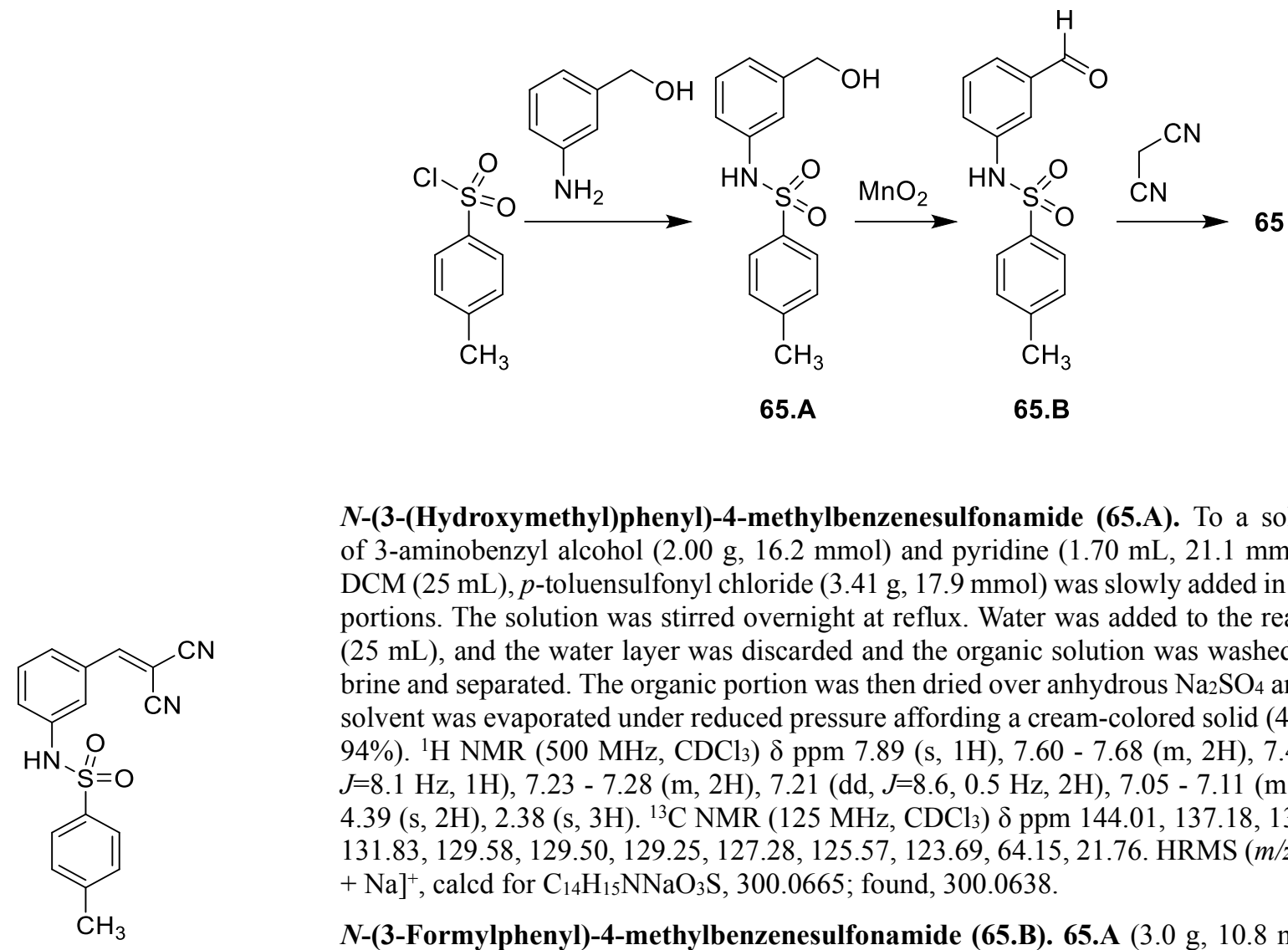

N-(3-(Hydroxymethyl)phenyl)-4-methylbenzenesulfonamide (65.A). To a solution of 3-aminobenzyl alcohol $(2.00 \mathrm{~g}, 16.2 \mathrm{mmol})$ and pyridine $(1.70 \mathrm{~mL}, 21.1 \mathrm{mmol})$ in DCM (25 mL), p-toluensulfonyl chloride (3.41 g, $17.9 \mathrm{mmol})$ was slowly added in small portions. The solution was stirred overnight at reflux. Water was added to the reaction $(25 \mathrm{~mL})$, and the water layer was discarded and the organic solution was washed with brine and separated. The organic portion was then dried over anhydrous $\mathrm{Na}_{2} \mathrm{SO}_{4}$ and the solvent was evaporated under reduced pressure affording a cream-colored solid $(4.25 \mathrm{~g}$, 94\%). ${ }^{1} \mathrm{H}$ NMR $\left(500 \mathrm{MHz}, \mathrm{CDCl}_{3}\right) \delta \mathrm{ppm} 7.89(\mathrm{~s}, 1 \mathrm{H}), 7.60-7.68(\mathrm{~m}, 2 \mathrm{H}), 7.43(\mathrm{~d}$, $J=8.1 \mathrm{~Hz}, 1 \mathrm{H}), 7.23-7.28(\mathrm{~m}, 2 \mathrm{H}), 7.21(\mathrm{dd}, J=8.6,0.5 \mathrm{~Hz}, 2 \mathrm{H}), 7.05-7.11(\mathrm{~m}, 2 \mathrm{H})$, 4.39 (s, 2H), $2.38(\mathrm{~s}, 3 \mathrm{H}) .{ }^{13} \mathrm{C}$ NMR $\left(125 \mathrm{MHz}, \mathrm{CDCl}_{3}\right) \delta \mathrm{ppm} 144.01,137.18,136.63$, $131.83,129.58,129.50,129.25,127.28,125.57,123.69,64.15,21.76$. HRMS $(\mathrm{m} / z):[\mathrm{M}$ $+\mathrm{Na}^{+}$, calcd for $\mathrm{C}_{14} \mathrm{H}_{15} \mathrm{NNaO}_{3} \mathrm{~S}, 300.0665$; found, 300.0638 .

$\boldsymbol{N}$-(3-Formylphenyl)-4-methylbenzenesulfonamide (65.B). 65.A (3.0 g, $10.8 \mathrm{mmol})$ was dissolved in DCM $(100 \mathrm{~mL})$ and at the resulting solution was mixed with manganese dioxide $(11.75 \mathrm{~g}, 135.2 \mathrm{mmol})$. The reaction mixture was stirred for $72 \mathrm{~h}$ and then the solid was filtrate through a pad of celite. The resulting clear solution was concentrated under reduced pressure, affording a yellowish solid $(2.8 \mathrm{~g}, 94 \%) .{ }^{1} \mathrm{H} \mathrm{NMR}$ $\left(500 \mathrm{MHz}, \mathrm{CDCl}_{3}\right) \delta$ ppm 10.79 (br. s., $\left.1 \mathrm{H}\right), 9.83$ (s, 1H), 7.78 (d, J=8.3 Hz, 2H), 7.69 (d, $J=8.3 \mathrm{~Hz}, 1 \mathrm{H}), 7.59$ (dd, $J=7.6,1.5 \mathrm{~Hz}, 1 \mathrm{H}), 7.51$ (ddd, $J=8.6,7.2,1.6 \mathrm{~Hz}, 1 \mathrm{H}), 7.20$ - $7.30(\mathrm{~m}, 2 \mathrm{H}), 7.16(\mathrm{td}, J=7.6,1.0 \mathrm{~Hz}, 1 \mathrm{H}), 2.37$ (s, 3H). ${ }^{13} \mathrm{C} \mathrm{NMR}\left(125 \mathrm{MHz}, \mathrm{CDCl}_{3}\right)$ $\delta$ ppm 195.19, 144.38, 140.18, 136.64, 136.31, 136.02, 129.97, 127.49, 123.13, 122.09, 117.99, 21.75. HRMS $(m / z):[\mathrm{M}+\mathrm{Na}]^{+}$, calcd for $\mathrm{C}_{14} \mathrm{H}_{13} \mathrm{NNaO}_{3} \mathrm{~S}, 298.0508$; found, 298.0526.

N-(3-(2,2-Dicyanovinyl)phenyl)-4-methylbenzenesulfonamide (65). This compound was prepared by the general procedure B, using 65.B, affording 65 as faint-orange solid (236 mg, 61\%). ${ }^{1} \mathrm{H}$ NMR (400 MHz, DMSO- $\left.d_{6}\right) \delta$ ppm 10.50 (br. s., $\left.1 \mathrm{H}\right), 8.46(\mathrm{~s}, 1 \mathrm{H})$, $7.64-7.77(\mathrm{~m}, 3 \mathrm{H}), 7.56(\mathrm{~d}, \mathrm{~J}=7.9 \mathrm{~Hz}, 1 \mathrm{H}), 7.44(\mathrm{t}, \mathrm{J}=8.1 \mathrm{~Hz}, 1 \mathrm{H}), 7.32$ (d, J=7.9 Hz, 3H), $2.30(\mathrm{~s}, 3 \mathrm{H}) .{ }^{13} \mathrm{C}$ NMR (101 MHz, DMSO-d $) \delta \mathrm{ppm} 161.72,144.30,139.67$, 137.00, 132.79, 131.12, 130.50, 127.49, 126.64, 125.61, 125.61, 120.93, 114.78, 113.52, 82.99, 46.48. HRMS $(\mathrm{m} / z)$ : $[\mathrm{M}-\mathrm{H}]^{-}$, calcd for $\mathrm{C}_{17} \mathrm{H}_{12} \mathrm{~N}_{3} \mathrm{O}_{2} \mathrm{~S}, 322.0656$; found, 322.0680 .<smiles>N#CC(C#N)=Cc1cccc(Oc2ccccc2)c1</smiles>

2-(3-Phenoxybenzylidene)malononitrile (66). This compound was prepared by the general procedure B, affording 65 as an off-white powder $(231 \mathrm{mg}, 39 \%)$. ${ }^{1} \mathrm{H}$ NMR (400 MHz, DMSO-d6) $\delta$ ppm $8.51(\mathrm{~s}, 1 \mathrm{H}), 7.68(\mathrm{~d}, J=7.9 \mathrm{~Hz}, 1 \mathrm{H}), 7.60(\mathrm{t}, J=7.9 \mathrm{~Hz}, 1 \mathrm{H})$, $7.54(\mathrm{t}, J=2.0 \mathrm{~Hz}, 1 \mathrm{H}), 7.36-7.46(\mathrm{~m}, 2 \mathrm{H}), 7.26-7.35(\mathrm{~m}, 1 \mathrm{H}), 7.20(\mathrm{t}, J=7.5 \mathrm{~Hz}, 1 \mathrm{H})$, 7.07 (dd, J=8.7, $0.8 \mathrm{~Hz}, 2 \mathrm{H}) .{ }^{13} \mathrm{C}$ NMR (101 MHz, DMSO-d 6 ) $\delta$ ppm 161.45, 158.12, 156.22, 133.60, 131.97, 131.00, 126.01, 125.06, 124.63, 119.94, 119.82, 114.71, 113.65, 83.24. HRMS $(\mathrm{m} / \mathrm{z})$ : $[\mathrm{M}-\mathrm{H}]^{-}$, calcd for $\mathrm{C}_{16} \mathrm{H}_{9} \mathrm{~N}_{2} \mathrm{O}, 245.0720$; found, 245.0785 . 
<smiles>N#CC(C#N)=Cc1cccc(Oc2ccc(Cl)cc2)c1</smiles><smiles>N#CC(C#N)=Cc1ccc(Oc2ccc(Cl)cc2)cc1</smiles>

2-(3-(4-Chlorophenoxy)benzylidene)malononitrile (67). This compound was prepared by the general procedure B, affording 67 as an off-white powder (482 $\mathrm{mg}$, 72\%). ${ }^{1} \mathrm{H}$ NMR (400 MHz, DMSO-d $) \delta \mathrm{ppm} 8.51(\mathrm{~s}, 1 \mathrm{H}), 7.71(\mathrm{~d}, J=7.9 \mathrm{~Hz}, 1 \mathrm{H}), 7.62$ (t, $J=8.1 \mathrm{~Hz}, 1 \mathrm{H}), 7.54(\mathrm{~s}, 1 \mathrm{H}), 7.45$ (d, J=9.1 Hz, 2H), 7.35 (dd, J=7.5, $2.4 \mathrm{~Hz}, 1 \mathrm{H})$, $7.10(\mathrm{~d}, J=9.1 \mathrm{~Hz}, 2 \mathrm{H}) .{ }^{13} \mathrm{C}$ NMR $\left(101 \mathrm{MHz}, \mathrm{DMSO}-\mathrm{d}_{6}\right) \delta \mathrm{ppm} 161.36,157.78,155.18$, 133.67, 132.08, 130.85, 128.93, 126.24, 124.77, 121.75, 119.99, 114.68, 113.65, 83.39. HRMS $(m / z):[\mathrm{M}-\mathrm{H}]^{-}$, calcd for $\mathrm{C}_{16} \mathrm{H}_{8} \mathrm{ClN}_{2} \mathrm{O}, 279.0331$; found, 279.0344 .

2-(4-(4-Chlorophenoxy)benzylidene)malononitrile (68). This compound was prepared by the general procedure B, affording $\mathbf{6 8}$ as an off-white powder $(222 \mathrm{mg}$, 33\%). ${ }^{1} \mathrm{H}$ NMR (400 MHz, DMSO- $\left.d_{6}\right) \delta \mathrm{ppm} 7.04-7.32(\mathrm{~m}, 4 \mathrm{H}) 7.51(\mathrm{~d}, J=8.65 \mathrm{~Hz}$, 2H) $7.99(\mathrm{~d}, J=8.65 \mathrm{~Hz}, 2 \mathrm{H}) 8.46(\mathrm{~s}, 1 \mathrm{H}) .{ }^{13} \mathrm{C}$ NMR $(101 \mathrm{MHz}$, DMSO-d 6$) \delta \mathrm{ppm}$ $162.55,161.00,154.03,134.11,131.02,129.84,126.94,122.80,118.83,115.20,114.23$, 79.80. HRMS $(\mathrm{m} / \mathrm{z})$ : $[\mathrm{M}-\mathrm{H}]^{-}$, calcd for $\mathrm{C}_{16} \mathrm{H}_{8} \mathrm{ClN}_{2} \mathrm{O}, 279.0331$; found, 279.0358.<smiles>N#CC(C#N)=Cc1cccc(Oc2cccc(C(F)(F)F)c2)c1</smiles>

2-(3-(3-(Trifluoromethyl)phenoxy)benzylidene)malononitrile (69). This compound was prepared by the general procedure B, affording 69 as a yellowish powder $(156 \mathrm{mg}$, 38\%). ${ }^{1} \mathrm{H}$ NMR $\left(400 \mathrm{MHz}, \mathrm{CDCl}_{3}\right) \delta \mathrm{ppm} 7.74(\mathrm{~s}, 1 \mathrm{H}), 7.68(\mathrm{~d}, J=7.8 \mathrm{~Hz}, 1 \mathrm{H}), 7.48-$ $7.58(\mathrm{~m}, 3 \mathrm{H}), 7.39-7.47(\mathrm{~m}, 1 \mathrm{H}), 7.25-7.31(\mathrm{~m}, 2 \mathrm{H}), 7.23(\mathrm{~d}, J=8.3 \mathrm{~Hz}, 1 \mathrm{H}) .{ }^{13} \mathrm{C}$ NMR $\left(125 \mathrm{MHz}, \mathrm{CDCl}_{3}\right) \delta$ ppm 159.06, 157.79, 156.39, 132.79, 131.50, 131.04, 126.05, $124.74,122.79,121.41,121.37,121.34,121.31,116.61,116.56,116.53,116.50,113.55$, 112.36, 84.46. HRMS $(\mathrm{m} / z)$ : $[\mathrm{M}-\mathrm{H}]^{-}$, calcd for $\mathrm{C}_{17} \mathrm{H}_{8} \mathrm{~F}_{3} \mathrm{~N}_{2} \mathrm{O}, 313.0594$; found, 313.0599 .

2-(3-(p-Tolyloxy)benzylidene)malononitrile (70). This compound was prepared by the general procedure B, affording 70 as a white powder $(150 \mathrm{mg}, 62 \%) .{ }^{1} \mathrm{H}$ NMR (400 MHz, DMSO-d6) $\delta$ ppm. $8.52(\mathrm{~s}, 1 \mathrm{H}), 7.67(\mathrm{~d}, J=7.9 \mathrm{~Hz}, 1 \mathrm{H}), 7.60(\mathrm{t}, J=8.1 \mathrm{~Hz}, 1 \mathrm{H})$, $7.51(\mathrm{t}, J=2.0 \mathrm{~Hz}, 1 \mathrm{H}), 7.29(\mathrm{dd}, J=2.1,7.7 \mathrm{~Hz}, 1 \mathrm{H}), 7.19-7.26(\mathrm{~m}, J=8.7 \mathrm{~Hz}, 2 \mathrm{H})$, 6.93 - $7.03(\mathrm{~m}, 2 \mathrm{H}), 2.30(\mathrm{~s}, 3 \mathrm{H}){ }^{13} \mathrm{C} \mathrm{NMR}\left(101 \mathrm{MHz}, \mathrm{DMSO}-\mathrm{d}_{6}\right) \delta \mathrm{ppm} 161.69,158.73$, $153.89,134.50,133.74,132.00,131.32,125.56,124.20,120.11,119.50,114.73,113.75$, 83.30, 21.05. HRMS (m/z): [M-H] $]^{-}$, calcd for $\mathrm{C}_{17} \mathrm{H}_{11} \mathrm{~N}_{2} \mathrm{O}, 259.0877$; found, 259.0881.

2-(3-(4-Fluorophenoxy)benzylidene)malononitrile (71). This compound was prepared by the general procedure B, affording 71 as a white powder $(51 \mathrm{mg}, 42 \%) .{ }^{1} \mathrm{H}$ NMR (400 MHz, DMSO-d6) $\delta$ ppm $8.53(\mathrm{~s}, 1 \mathrm{H}), 7.66-7.71(\mathrm{~m}, 1 \mathrm{H}), 7.62(\mathrm{t}, J=7.8$ $\mathrm{Hz}, 1 \mathrm{H}), 7.51(\mathrm{t}, J=2.1 \mathrm{~Hz}, 1 \mathrm{H}), 7.33$ (ddd, $J=1.0,2.5,8.1 \mathrm{~Hz}, 1 \mathrm{H}), 7.23$ - 7.30 (m,

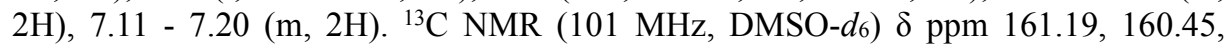
$158.38,158.06,151.81,151.79,133.33,131.77,125.70,123.90,122.08,121.99$, 118.779, 117.49, 117.25, 114.48, 113.43, 83.00. HRMS $(\mathrm{m} / z)$ : $[\mathrm{M}-\mathrm{H}]^{-}$, calcd for $\mathrm{C}_{16} \mathrm{H}_{8} \mathrm{FN}_{2} \mathrm{O}$, 263.0626; found, 263.0626.

2-(3-(3-Chlorobenzyl)benzylidene)malononitrile (72). This compound was prepared by the general procedures $\mathrm{A}$ and $\mathrm{B}$, affording 72 as a white powder $(323 \mathrm{mg}, 73 \%) .{ }^{1} \mathrm{H}$ NMR (400 MHz, DMSO-d6) $\delta$ ppm $8.50(\mathrm{~s}, 1 \mathrm{H}), 7.73$ - $7.89(\mathrm{~m}, 2 \mathrm{H}), 7.48$ - $7.67(\mathrm{~m}$, 2H), $7.29-7.38(\mathrm{~m}, 2 \mathrm{H}), 7.26(\mathrm{~d}, J=8.1 \mathrm{~Hz}, 1 \mathrm{H}), 7.21(\mathrm{~d}, J=7.6 \mathrm{~Hz}, 1 \mathrm{H}), 4.03(\mathrm{~s}, 2 \mathrm{H})$. ${ }^{13} \mathrm{C}$ NMR $\left(101 \mathrm{MHz}, \mathrm{DMSO}-d_{6}\right) \delta$ ppm $162.17,143.63,142.85,135.39,133.84,132.28$, $131.51,131.15,130.47,129.23,128.81,128.24,127.05,114.93,113.90,82.46,40.73$. HRMS $(m / z):[\mathrm{M}-\mathrm{H}]^{-}$, calcd for $\mathrm{C}_{17} \mathrm{H}_{10} \mathrm{ClN}_{2}, 277.0538$; found, 277.0534. 


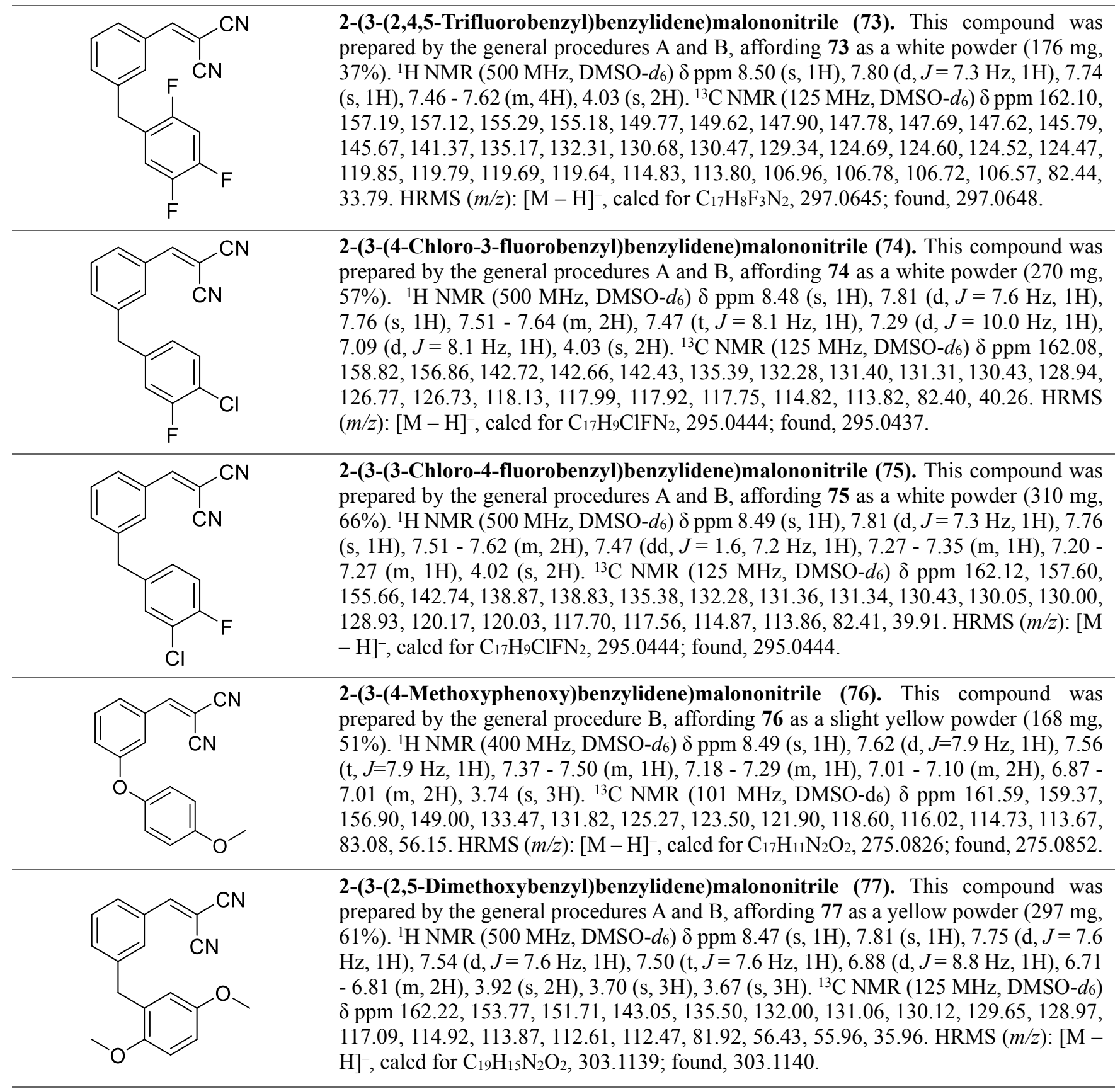<smiles>N#CC(C#N)=Cc1cccc(Oc2ccc(Cl)nn2)c1</smiles>

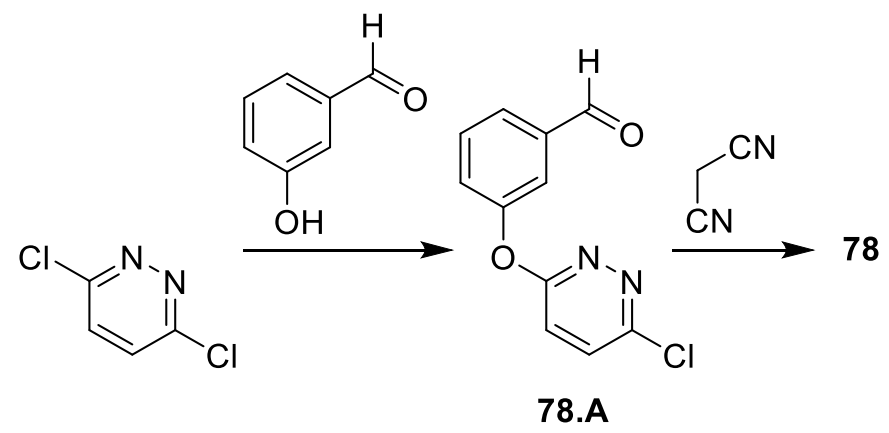

3-((6-Chloropyridazin-3-yl)oxy)benzaldehyde (78.A). To a solution of 3hydroxybenzaldehyde $(1.00 \mathrm{~g}, 8.2 \mathrm{mmol})$ in $15 \mathrm{~mL}$ of dry DMF was added potassium $t$ - 
butoxide $(918 \mathrm{mg}, 8.2 \mathrm{mmol})$ and the resulting solution was let stirring at room temperature for $30 \mathrm{~min}$. A solution of 1,6-dichloropyridazine $(2.44 \mathrm{~g}, 16.4 \mathrm{mmol})$ in 5 $\mathrm{mL}$ of dry DMF was added and the reaction was stirred at room temperature overnight. The DMF was removed under reduced pressure and the residue was diluted with ethyl acetate $(15 \mathrm{~mL})$ and was washed with water two times. The organic portion was then separated, dried over anhydrous $\mathrm{Na}_{2} \mathrm{SO}_{4}$ and was purified with a silica-gel column chromatography EtOAc/Hexane 1:9 to EtOAc/Hexane 1:0, obtaining a white powder (1.24 g, $65 \%$ ). ${ }^{1} \mathrm{H}$ NMR (500 MHz, $\left.\mathrm{CDCl}_{3}\right) \delta \mathrm{ppm} 10.00$ (d, $\left.J=1.2 \mathrm{~Hz}, 1 \mathrm{H}\right), 7.77$ (dd, $J=7.61 .5 \mathrm{~Hz}, 1 \mathrm{H}), 7.72(\mathrm{dt}, J=2.5,1.4 \mathrm{~Hz}, 1 \mathrm{H}), 7.60(\mathrm{t}, J=7.6 \mathrm{~Hz}, 1 \mathrm{H}), 7.54$ (dd, $J=9.1$, $1.2 \mathrm{~Hz}, 1 \mathrm{H}), 7.45-7.51(\mathrm{~m}, 1 \mathrm{H}), 7.20-7.29(\mathrm{~m}, 1 \mathrm{H}) .{ }^{13} \mathrm{C} \mathrm{NMR}\left(125 \mathrm{MHz}, \mathrm{CDCl}_{3}\right) \delta$ ppm 191.33, 164.80, 153.84, 152.83, 138.30, 132.03, 130.74, 127.51, 127.45, 121.75, 120.53 .

2-(3-((6-Chloropyridazin-3-yl)oxy)benzylidene)malononitrile (78). This compound was prepared by the general procedure $\mathrm{B}$, using $\mathbf{7 8 . A}$, affording $\mathbf{7 8}$ as a white powder $(178 \mathrm{mg}, 68 \%) .{ }^{1} \mathrm{H}$ NMR $\left(400 \mathrm{MHz}, \mathrm{CDCl}_{3}\right) \delta \mathrm{ppm} .7 .79-7.83(\mathrm{~m}, 1 \mathrm{H}), 7.74-7.79$ $(\mathrm{m}, 2 \mathrm{H}), 7.60(\mathrm{t}, J=7.9 \mathrm{~Hz}, 1 \mathrm{H}), 7.56(\mathrm{~d}, J=9.1 \mathrm{~Hz}, 1 \mathrm{H}), 7.51$ (ddd, $J=1.0,2.3,8.2$ $\mathrm{Hz}, 1 \mathrm{H}), 7.25(\mathrm{~d}, J=4.3 \mathrm{~Hz}, 1 \mathrm{H}){ }^{13} \mathrm{C}$ NMR $\left(101 \mathrm{MHz}, \mathrm{CDCl}_{3}\right) \delta \mathrm{ppm} 164.50,158.95$, 153.86, 153.10, 132.59, 132.13, 131.14, 128.26, 127.65, 123.01, 120.58, 113.59, 112.45, 84.41. HRMS $(\mathrm{m} / \mathrm{z})$ : [M - H] $]^{-}$, calcd for $\mathrm{C}_{14} \mathrm{H}_{6} \mathrm{ClN}_{4} \mathrm{O}, 281.0236$; found, 281.0257.<smiles>N#CC(C#N)=Cc1cccc(Oc2ncc(Cl)c(Cl)n2)c1</smiles>

2-(3-((4,5-Dichloropyrimidin-2-yl)oxy)benzylidene)malononitrile (79). This compound was prepared by the general procedure for $\mathbf{7 8}$, affording $\mathbf{7 9}$ as a white powder (162 mg, 55\%). ${ }^{1} \mathrm{H}$ NMR (400 MHz, DMSO- $\left.d_{6}\right) \delta \mathrm{ppm} 8.88(\mathrm{~s}, 1 \mathrm{H}), 8.58(\mathrm{~s}, 1 \mathrm{H}), 7.94$ $(\mathrm{d}, J=7.8 \mathrm{~Hz}, 1 \mathrm{H}), 7.82(\mathrm{t}, J=2.0 \mathrm{~Hz}, 1 \mathrm{H}), 7.77(\mathrm{t}, J=8.0 \mathrm{~Hz}, 1 \mathrm{H}), 7.70$ (ddd, $J=0.9$, $2.2,8.2 \mathrm{~Hz}, 1 \mathrm{H}) .{ }^{13} \mathrm{C}$ NMR $\left(101 \mathrm{MHz}, \mathrm{DMSO}-\mathrm{d}_{6}\right) \delta \mathrm{ppm} 164.48,160.09,159.29$, 156.01, 151.52, 132.84, 131.11, 128.21, 127.42, 123.01, 116.69, 113.85, 112.78, 83.20. HRMS $(m / z)$ : [M - $\mathrm{H}^{-}$, calcd for $\mathrm{C}_{14} \mathrm{H}_{5} \mathrm{Cl}_{2} \mathrm{~N}_{4} \mathrm{O}, 314.9846$; found, 314.9865 .<smiles>N#C/C(=C\c1ccc([N+](=O)[O-])c(O)c1)C(N)=O</smiles>

(E)-2-Cyano-3-(3-hydroxy-4-nitrophenyl)acrylamide (84). This compound was prepared by the general procedure B, affording 84 as a yellow powder $(68 \mathrm{mg}, 12 \%) .{ }^{1} \mathrm{H}$ NMR (400 MHz, DMSO- $\left.d_{6}\right) \delta$ ppm 11.47 (s, $\left.1 \mathrm{H}\right), 8.14(\mathrm{~s}, 1 \mathrm{H}), 8.01(\mathrm{~d}, J=8.65 \mathrm{~Hz}, 2 \mathrm{H})$, 7.87 (br. s., $1 \mathrm{H}), 7.63$ (d, $J=1.6 \mathrm{~Hz}, 1 \mathrm{H}), 7.43$ (dd, $J=8.7,2.0 \mathrm{~Hz}, 1 \mathrm{H}) .{ }^{13} \mathrm{C}$ NMR $(101$ MHz, DMSO-d6) $\delta 162.88,152.37,149.09,139.32,138.29,126.54,121.16,120.27$, 116.34, 110.74. HRMS $(\mathrm{m} / \mathrm{z})$ : $\left[\mathrm{M}-\mathrm{H}^{-}\right.$, calcd for $\mathrm{C}_{10} \mathrm{H}_{6} \mathrm{~N}_{3} \mathrm{O}_{4}, 232.0364$; found, 232.0361 .<smiles>COC(=O)/C(C#N)=C/c1ccc([N+](=O)[O-])c(O)c1</smiles>

Methyl (E)-2-cyano-3-(3-hydroxy-4-nitrophenyl)acrylate (85). This compound was prepared by the general procedure B, affording $\mathbf{8 5}$ as a yellow powder (122 $\mathrm{mg}, 21 \%)$. ${ }^{1} \mathrm{H}$ NMR $\left(400 \mathrm{MHz}\right.$, DMSO- $\left.d_{6}\right) \delta$ ppm 11.54 (br. s., $\left.1 \mathrm{H}\right), 8.41(\mathrm{~s}, 1 \mathrm{H}), 8.02(\mathrm{~d}, J=8.3$ $\mathrm{Hz}, 1 \mathrm{H}), 7.75$ (d, $J=2.0 \mathrm{~Hz}, 1 \mathrm{H}), 7.54$ (dd, $J=8.5,1.8 \mathrm{~Hz}, 1 \mathrm{H}), 3.88$ (s, 3H). ${ }^{13} \mathrm{C}$ NMR (101 MHz, DMSO-d6) $\delta$ ppm 162.46, 153.74, 152.21, 139.99, 137.38, 126.45, 122.02, 120.82, 115.55, 106.46. HRMS (m/z): [M - $\mathrm{H}^{-}$, calcd for $\mathrm{C}_{11} \mathrm{H}_{7} \mathrm{~N}_{2} \mathrm{O}_{5}, 247.0360$; found, 247.0353 .<smiles>CS(=O)(=O)/C(C#N)=C/c1ccc([N+](=O)[O-])c(O)c1</smiles>

(E)-3-(3-Hydroxy-4-nitrophenyl)-2-(methylsulfonyl)acrylonitrile (86). This compound was prepared by the general procedure $\mathrm{B}$, affording $\mathbf{8 6}$ as a yellow powder (135 mg, 21\%). ${ }^{1} \mathrm{H}$ NMR (400 MHz, DMSO- $\left.d_{6}\right) \delta \mathrm{ppm} 9.81(\mathrm{~s}, 1 \mathrm{H}), 8.26(\mathrm{~s}, 1 \mathrm{H}), 7.52$ (d, $J=2.4 \mathrm{~Hz}, 1 \mathrm{H}), 7.42$ (dd, $J=8.5,2.2 \mathrm{~Hz}, 1 \mathrm{H}), 7.14(\mathrm{~d}, J=8.7 \mathrm{~Hz}, 1 \mathrm{H}), 3.87(\mathrm{~s}, 3 \mathrm{H})$. ${ }^{13} \mathrm{C}$ NMR (101 MHz, DMSO-d6) $\delta$ ppm 161.40, 154.57, 147.68, 127.07, 125.06, 116.00, $115.69,114.63,112.91,76.92,56.68$.

2-(4-Nitrobenzylidene)malononitrile (87). This compound was prepared by the<smiles>N#CC(C#N)=Cc1ccc([N+](=O)[O-])cc1</smiles>
general procedure B, affording 87 as a yellow powder (308 mg, 31\%). ${ }^{1} \mathrm{H}$ NMR (500 MHz, DMSO- $\left.d_{6}\right) \delta$ ppm 8.71 (s, $\left.1 \mathrm{H}\right), 8.41$ (d, $\left.J=8.8 \mathrm{~Hz}, 2 \mathrm{H}\right), 8.12$ (d, $\left.J=8.8 \mathrm{~Hz}, 2 \mathrm{H}\right)$. ${ }^{13} \mathrm{C}$ NMR (125 MHz, DMSO-d 6 ) $\delta 159.30,149.71,136.69,131.45,124.41,113.64$, 112.53, 85.96. HRMS (m/z): [M - H]-, calcd for $\mathrm{C}_{10} \mathrm{H}_{4} \mathrm{~N}_{3} \mathrm{O}_{2}, 198.0309$; found, 198.0309. 
<smiles>COc1cc(C=C(C#N)C#N)ccc1F</smiles>

2-(4-Fluoro-3-hydroxybenzylidene)malononitrile (88). This compound was prepared by the general procedure B, affording 88 as a faint-yellow powder $(104 \mathrm{mg}, 22 \%) .{ }^{1} \mathrm{H}$ NMR (400 MHz, DMSO- $\left.d_{6}\right) \delta 8.48(\mathrm{~s}, 1 \mathrm{H}), 7.76$ (dd, $\left.J=8.3,2.0 \mathrm{~Hz}, 1 \mathrm{H}\right), 7.59$ (ddd, $J=8.6,4.4,2.0 \mathrm{~Hz}, 1 \mathrm{H}), 7.42-7.54(\mathrm{~m}, 1 \mathrm{H}), 3.87(\mathrm{~s}, 3 \mathrm{H}) .{ }^{13} \mathrm{C}$ NMR $(101 \mathrm{MHz}$, DMSO$\left.\mathrm{d}_{6}\right) \delta 160.60,160.58,156.20,153.64,147.80,147.69,128.53,128.50,125.13,125.04$, $117.47,117.28,115.58,115.54,114.30,113.43,81.38,56.31$. HRMS $(m / z):\left[\mathrm{M}-\mathrm{H}^{-}\right.$, calcd for $\mathrm{C}_{11} \mathrm{H}_{6} \mathrm{FN}_{2} \mathrm{O}, 201.0470$; found, 201.0467.<smiles>COc1ccc(C=C(C#N)C#N)cc1OC</smiles>

2-(3,4-Dimethoxybenzylidene)malononitrile (89). This compound was prepared by the general procedure $\mathrm{B}$, affording $\mathbf{8 9}$ as a yellow powder (186 mg, 36\%). ${ }^{1} \mathrm{H}$ NMR (400 MHz, DMSO- $\left.d_{6}\right) \delta$ ppm $8.30(\mathrm{~s}, 1 \mathrm{H}), 7.59(\mathrm{~d}, J=2.0 \mathrm{~Hz}, 1 \mathrm{H}), 7.53-7.58(\mathrm{~m}, 1 \mathrm{H}), 7.17$ (d, $J=8.7 \mathrm{~Hz}, 1 \mathrm{H}), 3.87$ (s, 3H), 3.77 (s, 3H). ${ }^{13} \mathrm{C}$ NMR (101 MHz, DMSO-d 6 ) $\delta \mathrm{ppm}$ 161.26, 149.47, 128.04, 124.84, 115.50, 114.73, 112.65, 112.56, 77.30, 56.73, 56.14 . $\operatorname{HRMS}(\mathrm{m} / \mathrm{z}):$ [M - H] $]^{-}$, calcd for $\mathrm{C}_{12} \mathrm{H}_{9} \mathrm{~N}_{2} \mathrm{O}_{2}, 213.0670$; found, 213.0662 .

2-(3-Methoxy-4-methylbenzylidene)malononitrile (90). This compound was<smiles>COc1cc(C=C(C#N)C#N)ccc1C</smiles>
prepared by the general procedure B, affording $\mathbf{9 0}$ as a bright-yellow powder (153 $\mathrm{mg}$, $32 \%) .{ }^{1} \mathrm{H}$ NMR $\left(500 \mathrm{MHz}, \mathrm{DMSO}-d_{6}\right) \delta \mathrm{ppm} 8.44(\mathrm{~s}, 1 \mathrm{H}), 7.53(\mathrm{~s}, 1 \mathrm{H}), 7.46$ (dd, $J=7.7$, $1.3 \mathrm{~Hz}, 1 \mathrm{H}), 7.38(\mathrm{~d}, J=7.8 \mathrm{~Hz}, 1 \mathrm{H}), 3.82(\mathrm{~s}, 3 \mathrm{H}), 2.23(\mathrm{~s}, 3 \mathrm{H}) .{ }^{13} \mathrm{C} \mathrm{NMR}(101 \mathrm{MHz}$, DMSO-d6) $\delta$ ppm 162.15, 158.22, 134.84, 131.99, 131.04, 124.46, 115.08, 114.26, 111.79, 80.67, 56.09, 17.17. HRMS $(\mathrm{m} / \mathrm{z})$ : $[\mathrm{M}-\mathrm{H}]^{-}$, calcd for $\mathrm{C}_{12} \mathrm{H}_{9} \mathrm{~N}_{2} \mathrm{O}, 197.0720$; found, 197.00725 .

2-(3-Chloro-4-hydroxy-5-methoxybenzylidene)malononitrile (91). This compound was prepared by the general procedure B, affording 91 as a yellow powder $(136 \mathrm{mg}$, 24\%). ${ }^{1} \mathrm{H}$ NMR (400 MHz, DMSO- $d_{6}$ ) $\delta$ ppm 11.24 (br. s., $\left.1 \mathrm{H}\right), 8.28(\mathrm{~s}, 1 \mathrm{H}), 7.61(\mathrm{~d}$, $J=2.0 \mathrm{~Hz}, 1 \mathrm{H}), 7.64$ (d, $J=2.0 \mathrm{~Hz}, 1 \mathrm{H}), 3.86(\mathrm{~s}, 3 \mathrm{H}) .{ }^{13} \mathrm{C}$ NMR (101 MHz, DMSO-d 6 ) $\delta$ ppm 160.31, 149.91, 149.31, 127.33, 123.43, 121.14, 115.32, 114.54, 112.16, 78.22, 57.00. HRMS $(\mathrm{m} / \mathrm{z})$ : [M - H] $]^{-}$, calcd for $\mathrm{C}_{11} \mathrm{H}_{6} \mathrm{ClN}_{2} \mathrm{O}_{2}, 233.0123$; found, 233.0135.

3-(2,2-Dicyanovinyl)benzoic acid (92). This compound was prepared by the general procedure B, affording 92 as an off-white powder $(23 \mathrm{mg}, 15 \%)$. ${ }^{1} \mathrm{H}$ NMR (400 MHz, DMSO-d6) $\delta$ ppm $13.42(\mathrm{~s}, 1 \mathrm{H}), 8.54(\mathrm{~s}, 1 \mathrm{H}), 8.64(\mathrm{~s}, 1 \mathrm{H}), 8.18(\mathrm{~d}, J=7.5 \mathrm{~Hz}, 1 \mathrm{H}), 8.14$ $(\mathrm{d}, J=7.5 \mathrm{~Hz}, 1 \mathrm{H}), 7.74(\mathrm{t}, J=7.9 \mathrm{~Hz}, 1 \mathrm{H}) .{ }^{13} \mathrm{C}$ NMR $(101 \mathrm{MHz}, \mathrm{DMSO}-\mathrm{d} 6) \delta \mathrm{ppm}$ $166.87,161.40,135.05,134.98,132.65,132.31,131.74,130.69,114.71,113.65,83.69$. HRMS (m/z): [M - H] $]^{-}$, calcd for $\mathrm{C}_{11} \mathrm{H}_{5} \mathrm{~N}_{2} \mathrm{O}_{2}, 197.0357$; found, 197.0361 .

2-(3-Hydroxy-4-methoxybenzylidene)malononitrile (93). This compound was prepared by the general procedure B, affording 93 as a yellow powder (107 $\mathrm{mg}, 24 \%)$.<smiles>COc1ccc(C=C(C#N)C#N)cc1O</smiles>
${ }^{1} \mathrm{H}$ NMR (400 MHz, DMSO- $\left.d_{6}\right) \delta$ ppm 11.64 (br. s., $\left.1 \mathrm{H}\right), 8.34$ (s, $\left.1 \mathrm{H}\right), 8.05$ (d, $J=8.7$ $\mathrm{Hz}, 1 \mathrm{H}), 7.75$ (d, $J=1.6 \mathrm{~Hz}, 1 \mathrm{H}), 7.55$ (dd, $J=8.7,1.6 \mathrm{~Hz}, 1 \mathrm{H}), 3.44$ (s, 3H). ${ }^{13} \mathrm{C}$ NMR $\left(101 \mathrm{MHz}, \mathrm{DMSO}-\mathrm{d}_{6}\right) \delta$ ppm $152.49,152.18,140.54,136.11,126.61,122.06,120.81$, 117.24, 113.44, 94.04, 42.61. HRMS $(\mathrm{m} / \mathrm{z})$ : [M - H] -, calcd for $\mathrm{C}_{11} \mathrm{H}_{8} \mathrm{~N}_{2} \mathrm{O}_{2}, 199.0513$; found, 199.0540 .

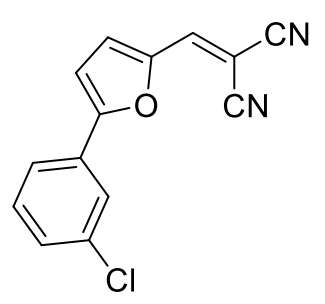

\section{2-((5-(3-Chlorophenyl)furan-2-yl)methylene)malononitrile (94).}

This compound was prepared by the general procedure B, affording 94 as a yellow powder (436 mg, 72\%). ${ }^{1} \mathrm{H}$ NMR (400 MHz, DMSO- $\left.d_{6}\right) \delta \mathrm{ppm} 8.25(\mathrm{~s}, 1 \mathrm{H}), 7.95(\mathrm{t}$, $J=1.6 \mathrm{~Hz}, 1 \mathrm{H}), 7.83(\mathrm{dt}, J=7.2,1.5 \mathrm{~Hz}, 1 \mathrm{H}), 7.42-7.62(\mathrm{~m}, 4 \mathrm{H}) .{ }^{13} \mathrm{C}$ NMR $(101 \mathrm{MHz}$, DMSO-d $\left._{6}\right) \delta$ ppm 158.90, 148.53, 144.02, 134.88, 131.92, 130.68, 128.88, 125.52, 124.37, 115.42, 114.75, 112.51, 75.07. HRMS $(\mathrm{m} / \mathrm{z}):[\mathrm{M}-\mathrm{H}]^{-}$, calcd for $\mathrm{C}_{14} \mathrm{H}_{6} \mathrm{ClN}_{2} \mathrm{O}$, 253.0174; found, 253.0178 . 


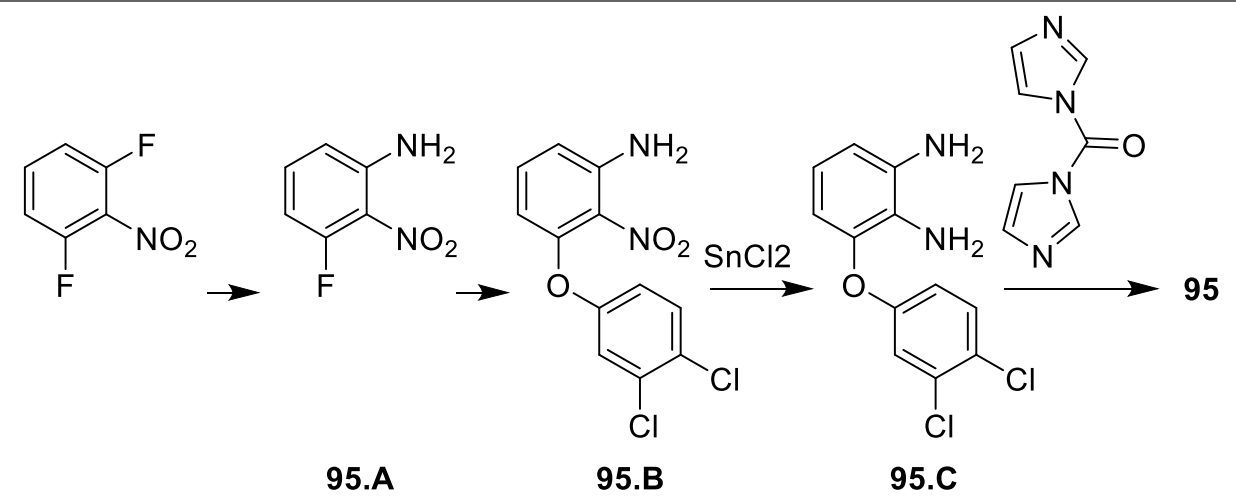

3-Fluoro-2-nitroaniline (95.A). To a solution of 2,5-difluoronitrobenzene $(20.00 \mathrm{~g}$, $15.57 \mathrm{mmol})$ in ethanol $(200 \mathrm{~mL})$ was added $34 \%$ aq. ammonia solution $(200 \mathrm{~mL})$ and the resulting mixture was heated at $75{ }^{\circ} \mathrm{C}$ overnight. The excess of ammonia used, allowed the reaction to be run in an open flask with the aid of a reflux condenser. The solution was let cool to room temperature and was concentrated to dryness in vacuo. The residue was dissolved in EtOAc $(100 \mathrm{~mL})$, washed with water $(75 \mathrm{~mL})$ and brine $(75 \mathrm{~mL})$. The organic layer was then dried over anhydrous $\mathrm{Na}_{2} \mathrm{SO}_{4}$, the solid was filtered and the organic solution was concentrated, affording a brown solid $(19.00 \mathrm{~g}, 97 \%) .{ }^{1} \mathrm{H}$ NMR (400 MHz, $\left.\mathrm{CDCl}_{3}\right) \delta \mathrm{ppm} 7.19-7.28(\mathrm{~m}, 1 \mathrm{H}), 6.59(\mathrm{td}, J=1.4,8.6 \mathrm{~Hz}, 1 \mathrm{H}), 6.47$ (ddd, $J=1.2,7.9,11.4 \mathrm{~Hz}, 1 \mathrm{H}), 5.68$ (br. s., $2 \mathrm{H}) .{ }^{13} \mathrm{C} \mathrm{NMR}\left(101 \mathrm{MHz}, \mathrm{CDCl}_{3}\right) \delta \mathrm{ppm}$ 159.03, 156.41, 145.16, 135.68, 134.51, 134.37, 113.68, 113.64, 105.08, 104.86. HRMS $(\mathrm{m} / \mathrm{z}):[\mathrm{M}+\mathrm{H}]^{+}$, calcd for $\mathrm{C}_{6} \mathrm{H}_{6} \mathrm{FN}_{2} \mathrm{O}_{2}, 157.0408$; found, 157.0380 .

3-(3,4-Dichlorophenoxy)-2-nitroaniline (95.B). To a solution of 3,4-dichlorophenol $(18.79 \mathrm{~g}, 115.3 \mathrm{mmol})$ in $70 \mathrm{~mL}$ of dry DMF was added potassium $t$-butoxide $(12.9 \mathrm{~g}$, $115.3 \mathrm{mmol}$ ) and the resulting solution was let stirring at room temperature for $30 \mathrm{~min}$. A solution of 95.A (12.0 g, $76.9 \mathrm{mmol})$ in $50 \mathrm{~mL}$ of dry DMF was stirred into the reaction mixture and the resulting solution was stirred at $80{ }^{\circ} \mathrm{C}$ overnight. The solvent was removed under reduced pressure and the residue was diluted with ethyl acetate $(100 \mathrm{~mL})$ and washed with water two times. The organic portion was separated, dried over anhydrous $\mathrm{Na}_{2} \mathrm{SO}_{4}$, evaporated under reduced pressure affording a crude sample. This was purified by silica-gel column chromatography EtOAc/Hexane 1:9 to EtOAc/Hexane 1:0, affording a yellow powder $(10.65 \mathrm{~g}, 46 \%) .{ }^{1} \mathrm{H} \mathrm{NMR}\left(400 \mathrm{MHz}, \mathrm{CDCl}_{3}\right) \delta \mathrm{ppm} 7.40$ $(\mathrm{d}, J=8.7 \mathrm{~Hz}, 1 \mathrm{H}), 7.21(\mathrm{t}, J=8.3 \mathrm{~Hz}, 1 \mathrm{H}), 7.13(\mathrm{~d}, J=2.8 \mathrm{~Hz}, 1 \mathrm{H}), 6.90(\mathrm{dd}, J=2.8$, $8.7 \mathrm{~Hz}, 1 \mathrm{H}), 6.61(\mathrm{dd}, J=1.0,8.5 \mathrm{~Hz}, 1 \mathrm{H}), 6.30$ (dd, $J=1.0,8.1 \mathrm{~Hz}, 1 \mathrm{H}), 5.25$ (br. s., $2 \mathrm{H}) .{ }^{13} \mathrm{C}$ NMR $\left(101 \mathrm{MHz}, \mathrm{CDCl}_{3}\right) \delta \mathrm{ppm} 157.10,155.58,137.66,132.48,132.21$, 131.78, 125.08, 122.03, 121.83, 119.41, 117.54, 112.78, 106.25. $\operatorname{HRMS}(\mathrm{m} / \mathrm{z}):[\mathrm{M}+\mathrm{H}]^{+}$, calcd for $\mathrm{C}_{12} \mathrm{H}_{9} \mathrm{Cl}_{2} \mathrm{~N}_{2} \mathrm{O}_{3}, 298.9985$; found, 298.9995 .

3-(3,4-Dichlorophenoxy)benzene-1,2-diamine (95.C). Tin(II) chloride dihydrate $(22.63 \mathrm{~g}, 100.3 \mathrm{mmol})$ and 95.B $(6.00 \mathrm{~g}, 20.1 \mathrm{mmol})$ were suspended in $\mathrm{MeOH}$ (150 $\mathrm{mL}$ ) and heated at reflux overnight. The mixture was allowed to cool to room temperature and the solvent was removed in vacuo and the resulting solid diluted with EtOAc $(200 \mathrm{~mL})$ The organic solvent was vigorously shaken with a $10 \%$ aqueous solution of $\mathrm{Na}_{2} \mathrm{CO}_{3}(250 \mathrm{~mL})$. The solvent mixture was filtered through a pad of celite. The pad was rinsed with $200 \mathrm{~mL}$ of EtOAc. The organic layer was saved. The water layer was extracted again with EtOAc $(200 \mathrm{~mL})$. The combined organic fractions were dried $\left(\mathrm{Na}_{2} \mathrm{SO}_{4}\right)$ and the solvent was removed in vacuo affording a dark-yellow semisolid paste $(3.22 \mathrm{~g}, 60 \%)$. ${ }^{1} \mathrm{H}$ NMR $\left(400 \mathrm{MHz}, \mathrm{CDCl}_{3}\right) \delta \mathrm{ppm} 7.35(\mathrm{~d}, J=9.1 \mathrm{~Hz}, 1 \mathrm{H})$, $7.07(\mathrm{~d}, J=3.2 \mathrm{~Hz}, 1 \mathrm{H}), 6.78-6.89(\mathrm{~m}, 1 \mathrm{H}), 6.69(\mathrm{t}, J=8.1 \mathrm{~Hz}, 1 \mathrm{H}), 6.59$ (dd, $J=1.6$, $7.9 \mathrm{~Hz}, 1 \mathrm{H}), 6.44$ (dd, $J=1.4,8.1 \mathrm{~Hz}, 1 \mathrm{H}), 3.49$ (br s., 4H). ${ }^{13} \mathrm{C} \mathrm{NMR}\left(101 \mathrm{MHz}, \mathrm{CDCl}_{3}\right)$ $\delta$ ppm 157.08, 143.74, 136.89, 133.39, 131.13, 127.35, 126.19, 119.86, 119.06, 116.78, 113.31, 111.75. HRMS $(\mathrm{m} / \mathrm{z}):[\mathrm{M}+\mathrm{H}]^{+}$, calcd for $\mathrm{C}_{12} \mathrm{H}_{11} \mathrm{Cl}_{2} \mathrm{~N}_{2} \mathrm{O}, 269.0243$; found, 269.0258 . 
4-(3,4-Dichlorophenoxy)-1H-benzo[d] imidazol-2-ol (95). Solid 95.C (250 mg, 0.9 mmole) was dissolved in THF (3 mL) and subsequentially 1,1'-carbonyldiimidazole (151 mg, $0.9 \mathrm{mmole}$ ) was added. The resulting solution was stirred at room temperature overnight. The solvent was concentrated under reduced pressure and the crude product was purified by silica-gel column chromatography EtOAc/Hexane 1:9 to EtOAc/Hexane 1:0, affording a white solid (193 mg, 70\%). ${ }^{1} \mathrm{H}$ NMR (400 MHz, DMSO- $d 6$ ) $\delta$ ppm 10.91 - $11.05(\mathrm{~m}, 1 \mathrm{H}), 10.75-10.91(\mathrm{~m}, 1 \mathrm{H}), 7.59(\mathrm{~d}, J=8.8 \mathrm{~Hz}, 1 \mathrm{H}), 7.23(\mathrm{~d}, J=2.9 \mathrm{~Hz}$, $1 \mathrm{H}), 6.94-7.02(\mathrm{~m}, 1 \mathrm{H}), 6.91(\mathrm{dd}, J=2.9,8.8 \mathrm{~Hz}, 1 \mathrm{H}), 6.85(\mathrm{~d}, J=7.8 \mathrm{~Hz}, 1 \mathrm{H}), 6.69$ (dd, $J=1.0,8.3 \mathrm{~Hz}, 1 \mathrm{H}) .{ }^{13} \mathrm{C}$ NMR (101 MHz, DMSO-d6) $\delta \mathrm{ppm} \mathrm{156.02,} \mathrm{151.15,}$ $144.14,133.65,133.53,131.28,127.53,120.43,118.07,113.82,109.32$. HRMS $(m / z)$ : $[\mathrm{M}+\mathrm{H}]^{+}$, calcd for $\mathrm{C}_{13} \mathrm{H}_{9} \mathrm{Cl}_{2} \mathrm{~N}_{2} \mathrm{O}_{2}$, 295.0036; found, 295.0060.<smiles>Sc1nc2c(Oc3ccc(Cl)c(Cl)c3)cccc2[nH]1</smiles>

4-(3,4-Dichlorophenoxy)-1H-benzo[d]imidazole-2-thiol (96). This compound was prepared by the general procedure for 96 affording a yellow powder $(956 \mathrm{mg}, 41 \%),{ }^{1} \mathrm{H}$ NMR (400 MHz, DMSO- $d_{6}$ ) $\delta$ ppm 12.88 (br. s., $1 \mathrm{H}$ ), 12.72 (br. s., $\left.1 \mathrm{H}\right), 7.59$ (d, $J=9.1$ $\mathrm{Hz}, 1 \mathrm{H}), 7.27(\mathrm{~d}, J=2.8 \mathrm{~Hz}, 1 \mathrm{H}), 7.14(\mathrm{t}, J=8.3 \mathrm{~Hz}, 1 \mathrm{H}), 7.03(\mathrm{~d}, J=7.9 \mathrm{~Hz}, 1 \mathrm{H}), 6.91$ (dd, $J=2.8,9.1 \mathrm{~Hz}, 1 \mathrm{H}), 6.85(\mathrm{~d}, J=7.1 \mathrm{~Hz}, 1 \mathrm{H}) .{ }^{13} \mathrm{C}$ NMR $(101 \mathrm{MHz}$, DMSO-d 6$) \delta$ ppm 169.71, 157.23, 138.44, 135.46, 132.48, 132.01, 125.64, 125.23, 124.10, 120.04, 117.97, 114.30, 107.22. HRMS $(\mathrm{m} / \mathrm{z}):[\mathrm{M}+\mathrm{H}]^{+}$, calcd for $\mathrm{C}_{13} \mathrm{H}_{9} \mathrm{Cl}_{2} \mathrm{~N}_{2} \mathrm{OS}, 310.9807$; found, 310.9835 .<smiles>O=S(=O)(O)c1nc2c(Oc3ccc(Cl)c(Cl)c3)cccc2[nH]1</smiles>

4-(3,4-Dichlorophenoxy)-1H-benzo[d] imidazole-2-sulfonic acid (97). Compound 95 $(120 \mathrm{mg}, 1.0 \mathrm{mmol})$ was added to a solution of hydrogen peroxide $30 \%(1 \mathrm{~mL})$ diluted with $3 \mathrm{~mL}$ of water, and $0.4 \mathrm{~mL}$ of a $10 \%$ solution of $\mathrm{NaOH}$ in water. The reaction was stirred overnight, by which time the starting material completely went into solution. The $\mathrm{pH}$ of the solution was adjusted to 3.0 by the addition of $10 \% \mathrm{HCl}$. The white precipitate was filtered and dried under high vacuum $(120 \mathrm{mg}, 36 \%) .14 .13$ (br. s., $2 \mathrm{H}), 7.63$ (d, $J$ $=9.1 \mathrm{~Hz}, 1 \mathrm{H}), 7.46-7.59(\mathrm{~m}, 2 \mathrm{H}), 7.40(\mathrm{~d}, J=2.7 \mathrm{~Hz}, 1 \mathrm{H}), 7.20(\mathrm{dd}, J=3.4,5.1 \mathrm{~Hz}$, $1 \mathrm{H}), 7.02$ (dd, $J=2.7,8.8 \mathrm{~Hz}, 1 \mathrm{H}) .{ }^{13} \mathrm{C}$ NMR $\left(101 \mathrm{MHz}, \mathrm{DMSO}-\mathrm{d}_{6}\right) \delta \mathrm{ppm} 156.70$, 154.31, 143.14, 133.76, 132.41, 131.91, 127.71, 126.01, 125.30, 120.30, 118.32, 116.53, 111.43. HRMS $(m / z):[\mathrm{M}-\mathrm{H}]^{+}$, calcd for $\mathrm{C}_{13} \mathrm{H}_{7} \mathrm{Cl}_{2} \mathrm{~N}_{2} \mathrm{O}_{4} \mathrm{~S}, 356.9509$; found, 356.9492 .

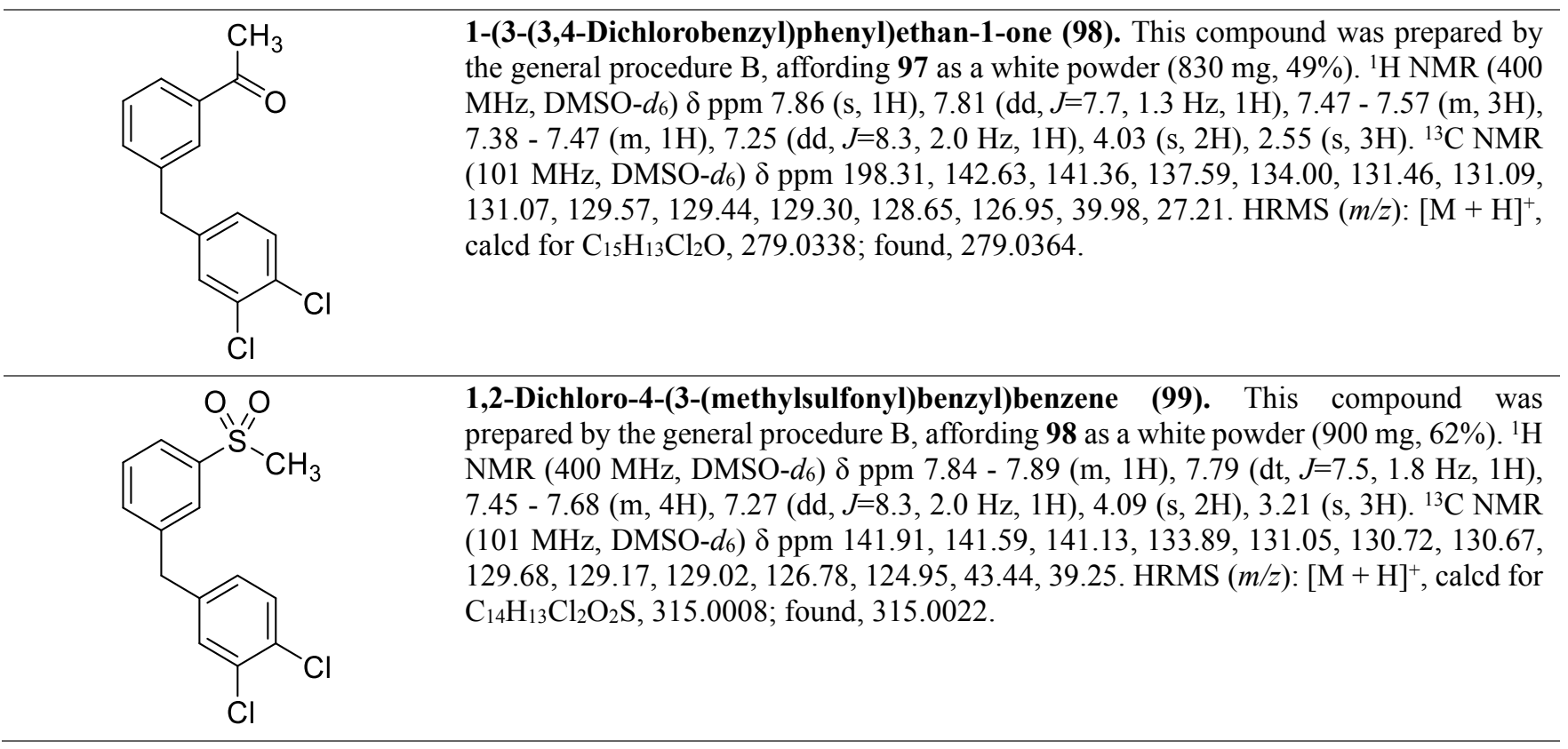




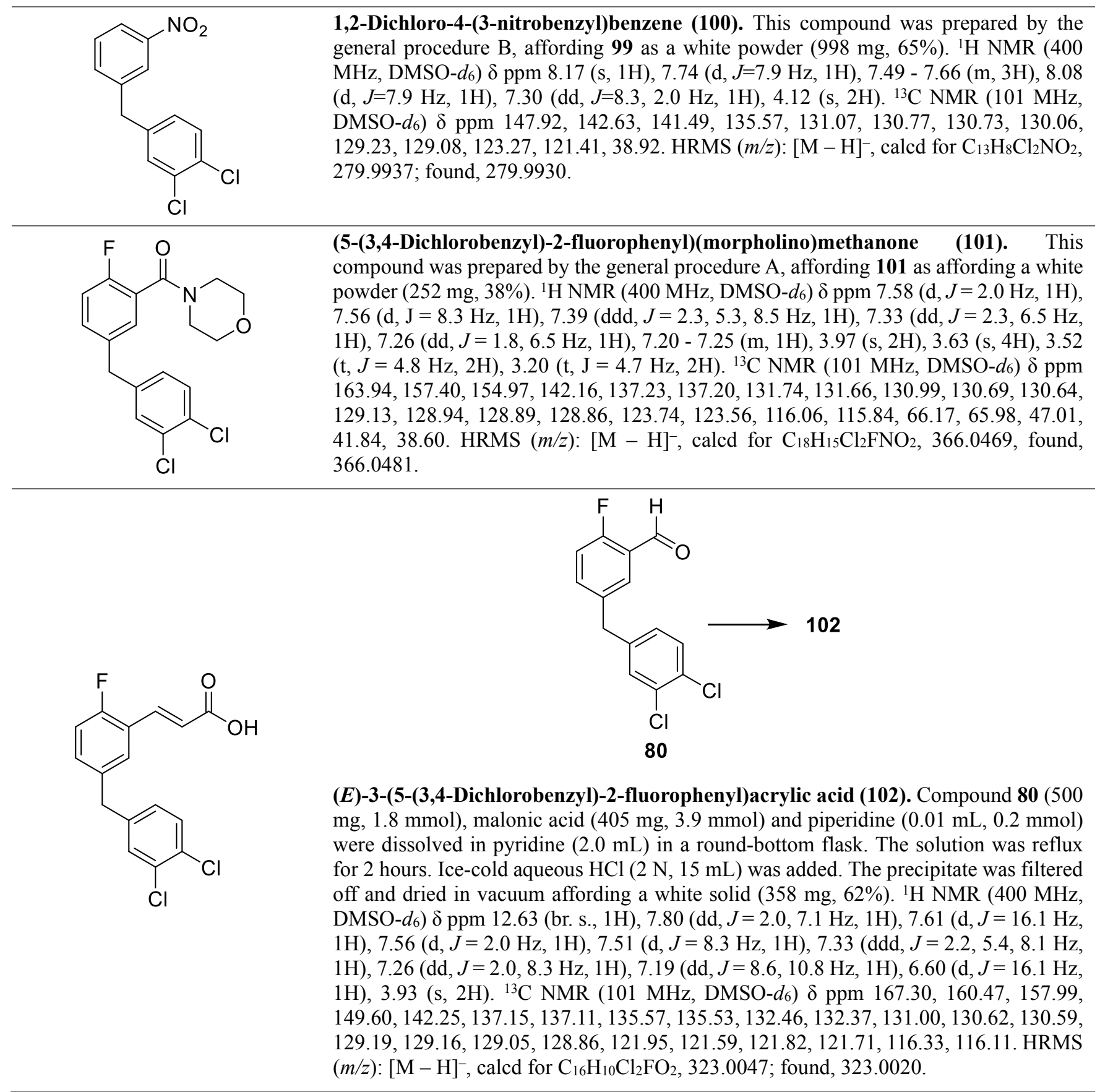


${ }^{1} \mathrm{H}$ and ${ }^{13} \mathrm{C}$ NMR and MS for compounds 17, 26, 27, 28 and 29. NMR spectra are in DMSO- $d_{6}$ solution. (E)-3-(5-(3,4-Dichlorobenzyl)-2-fluorophenyl)-2-(pyridin-2-ylsulfonyl)acrylonitrile (17)<smiles>N/C(=C\c1cc(Cc2ccc(Cl)c(Cl)c2)ccc1F)S(=O)(=O)c1ccccn1</smiles>
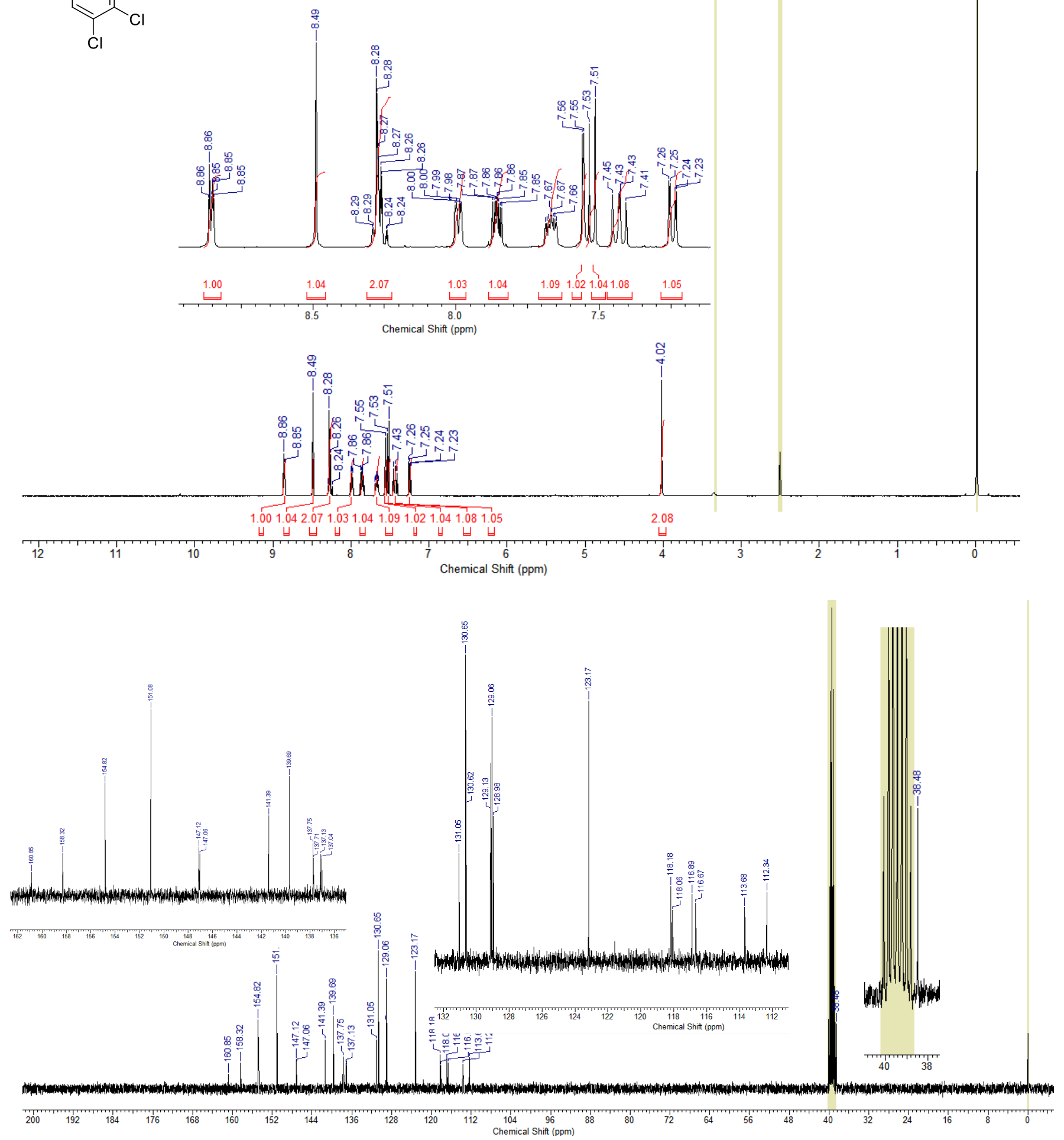

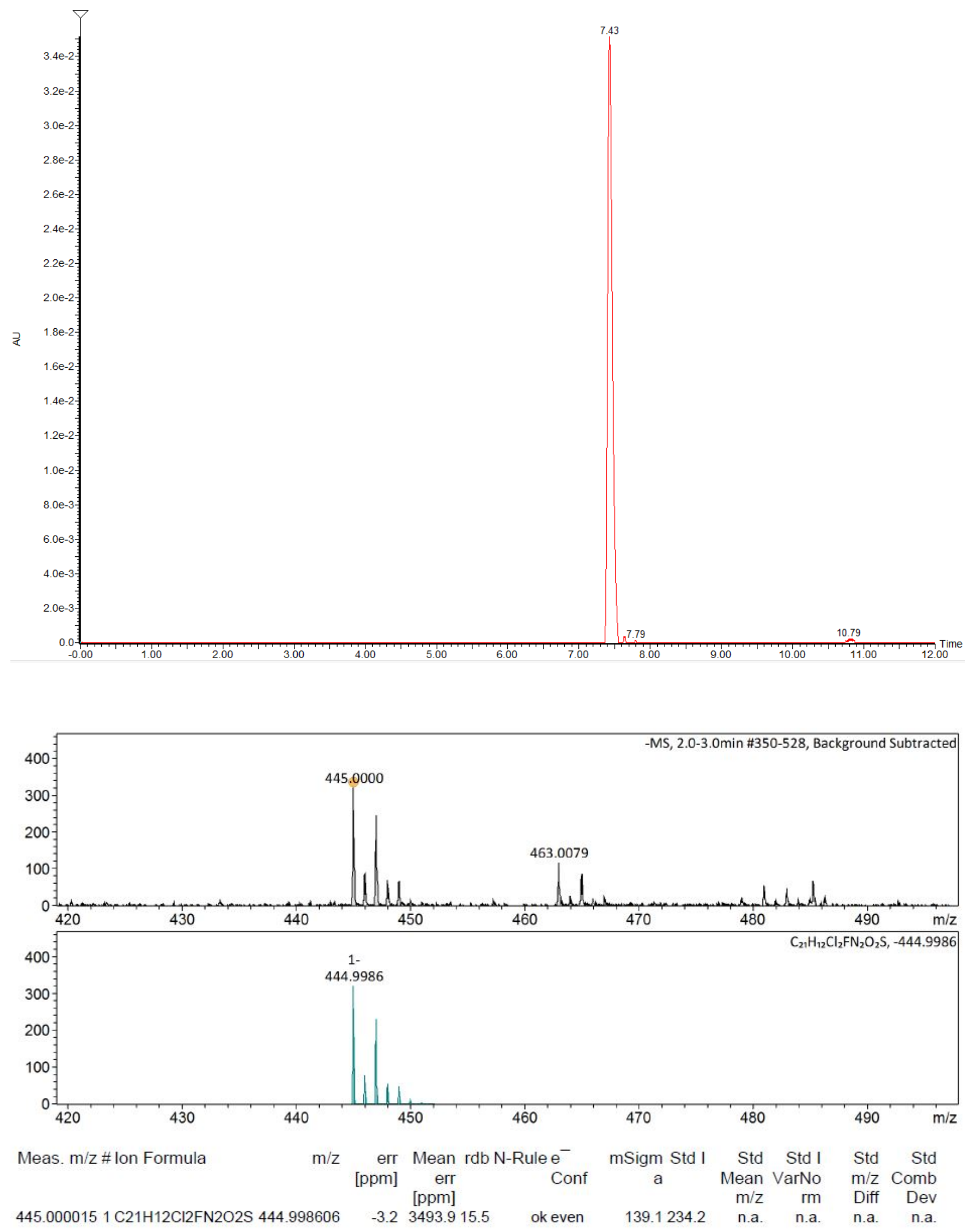
(E)-3-(5-(3,4-Dichlorobenzyl)-2-(trifluoromethoxy)phenyl)-2-(methylsulfonyl)acrylonitrile (26)<smiles>COc1ccc(Cc2ccc(Cl)c(Cl)c2)cc1/C=C(\C#N)S(C)(=O)=O</smiles>
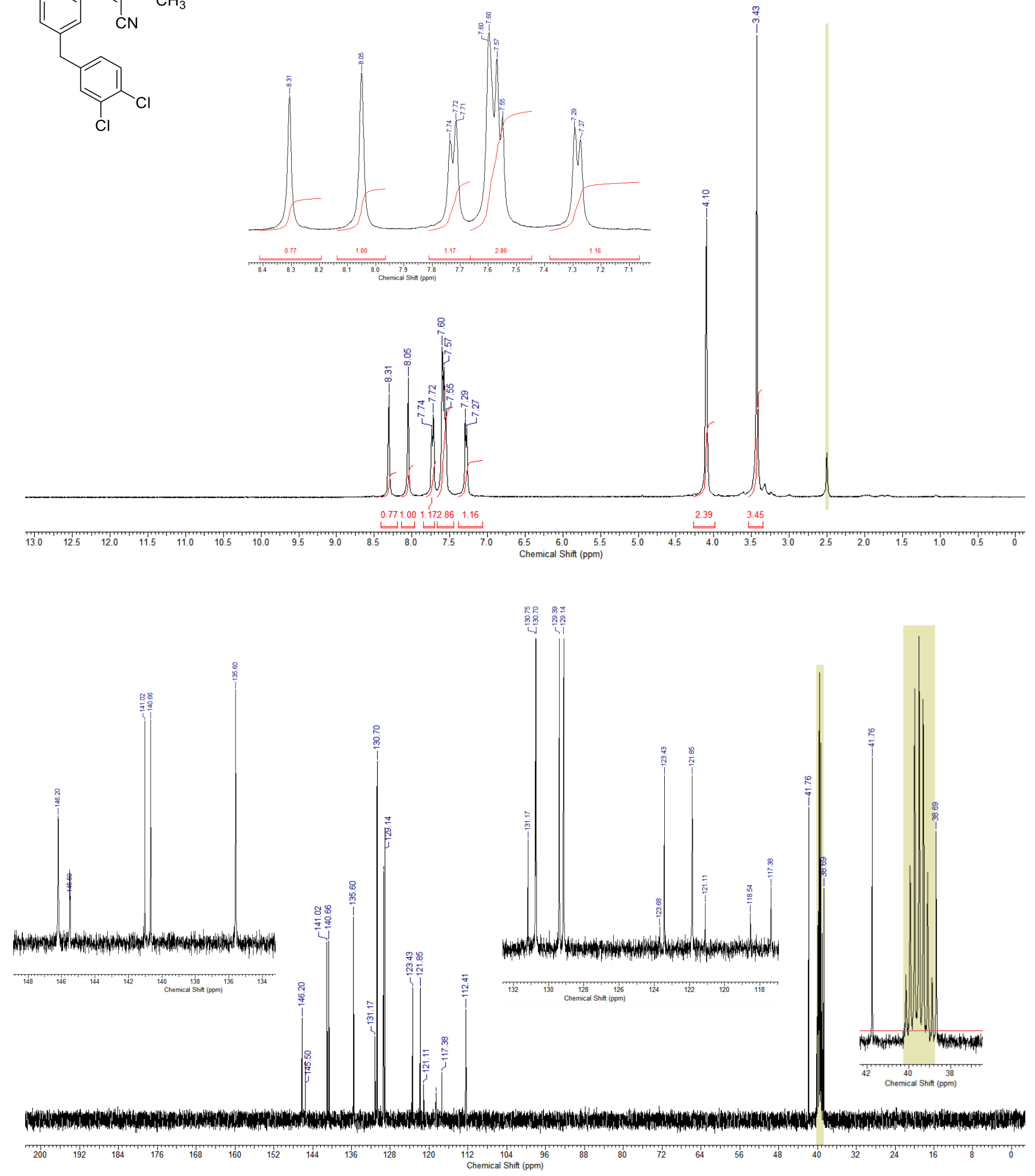

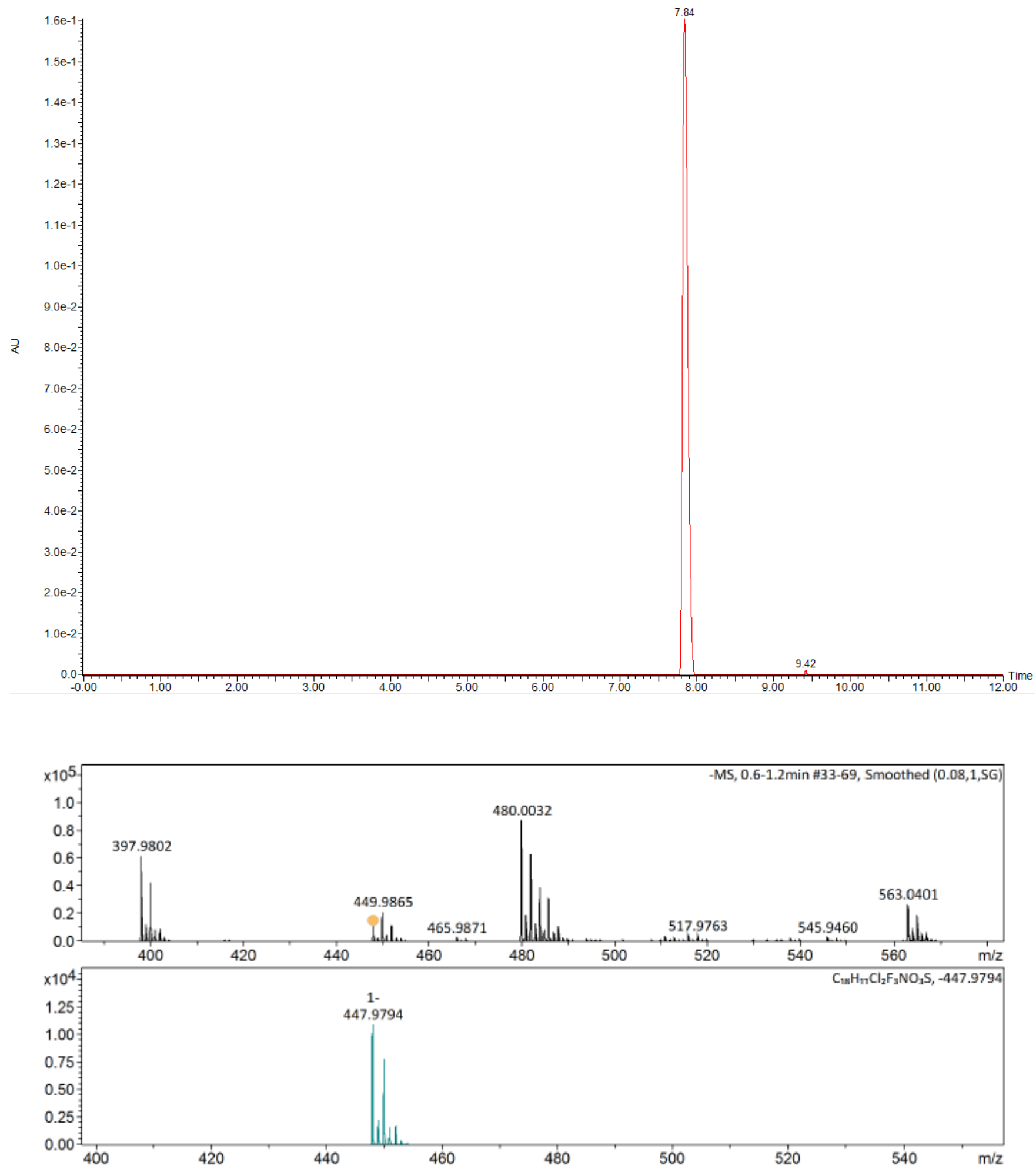

Meas. $\mathrm{m} / \mathrm{z}$ \# Ion Formula

$\mathrm{m} / \mathrm{z}$ err Mean rdb N-Rule $\mathrm{e}^{-}$

mSigm Std I Std Std I Std Std

[ppm] err Conf [ppm]

447.976554 1 C18H11Cl2F3NO3S 447.979428

6.44148 .311 .5 ok even

a Mean VarNo $\mathrm{m} / \mathrm{z}$ Comb

$\begin{array}{ccccc} & \mathrm{m} / \mathrm{z} & \mathrm{rm} & \text { Diff } & \mathrm{Dev} \\ 303.0503 .9 & \text { n.a. } & \text { n.a. } & \text { n.a. } & \text { n.a. }\end{array}$ 
(E)-3-(5-(3,4-Dichlorobenzyl)-2-fluorophenyl)-2-(methylsulfonyl)acrylonitrile (27)
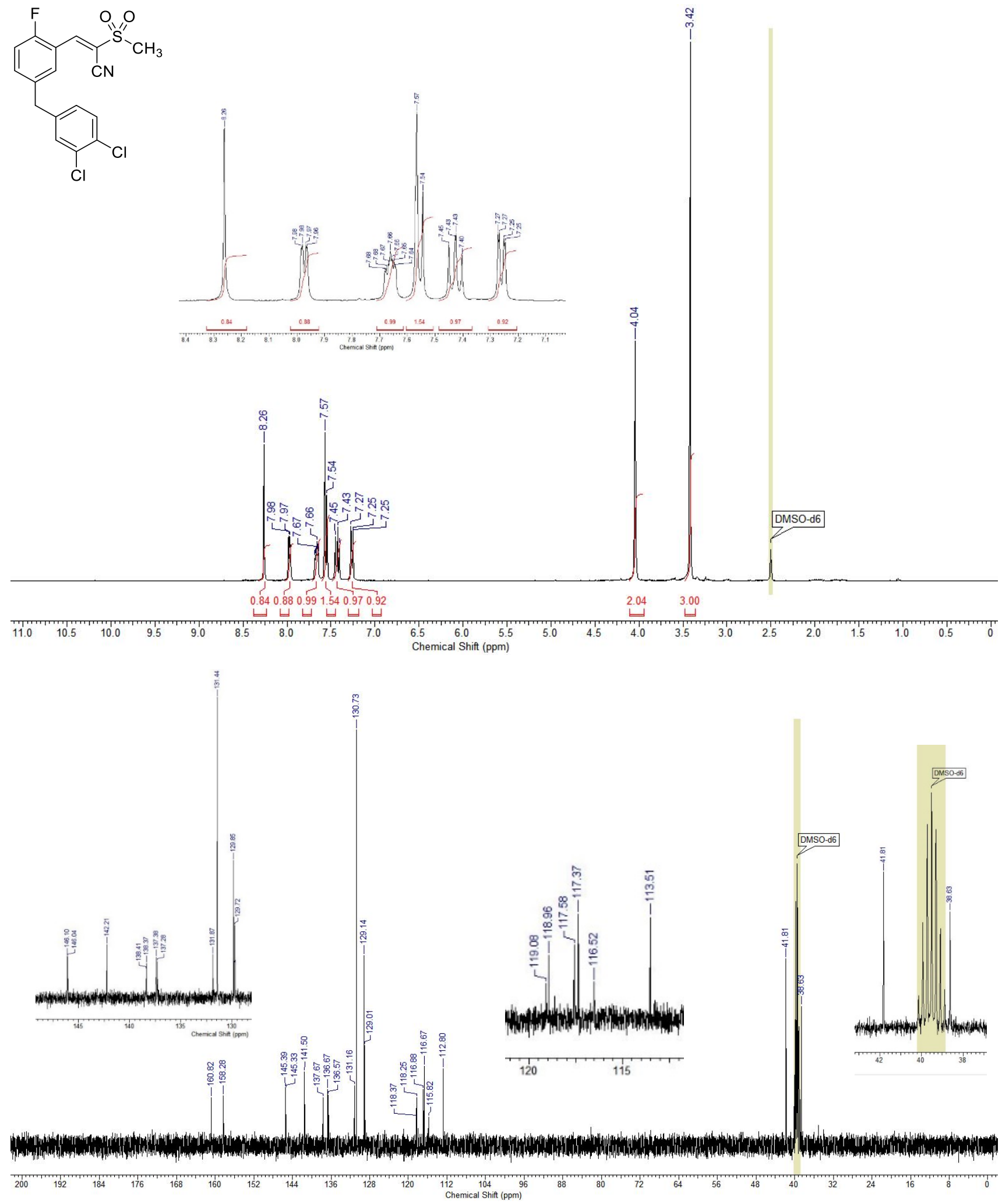

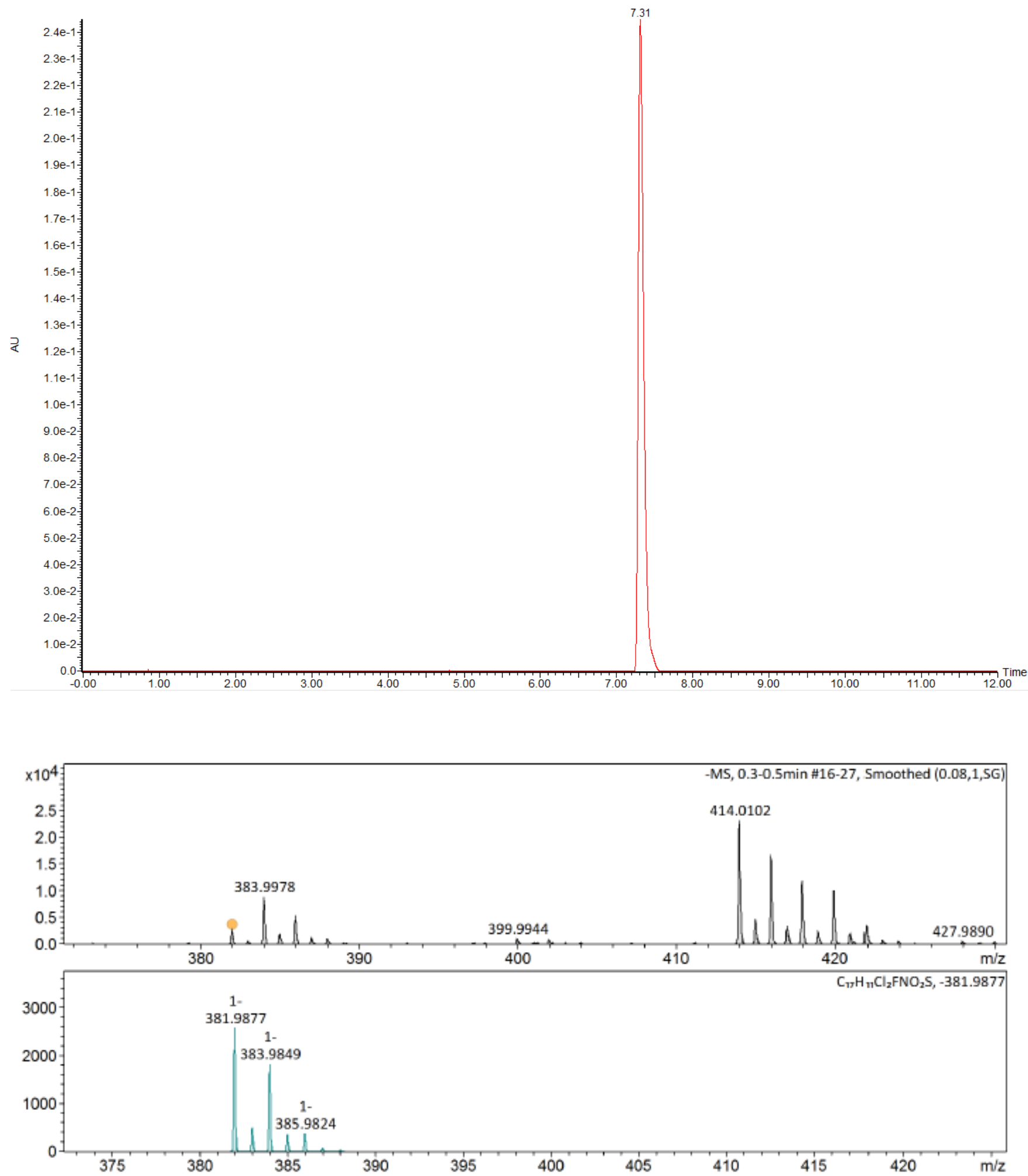

Meas. $\mathrm{m} / \mathrm{z}$ \# Ion Formula

$\mathrm{m} / \mathrm{z}$ err Mean rdb N-Rule $\mathrm{e}^{-}$ [ppm] err

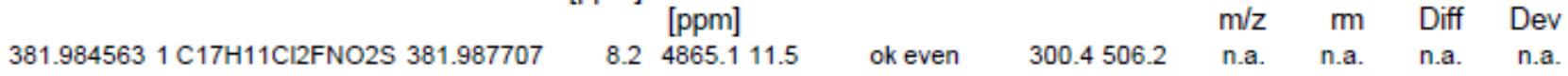
mSigm Std I Std Std I Std Std Conf a Mean VarNo $\mathrm{m} / \mathrm{z}$ Comb 
(E)-3-(3-(3,4-Dichlorobenzyl)-2,6-difluorophenyl)-2-(methylsulfonyl)acrylonitrile (28)<smiles>CS(C)(=O)(O)/C(C#N)=C/c1c(F)ccc(Cc2ccc(Cl)c(Cl)c2)c1F</smiles>
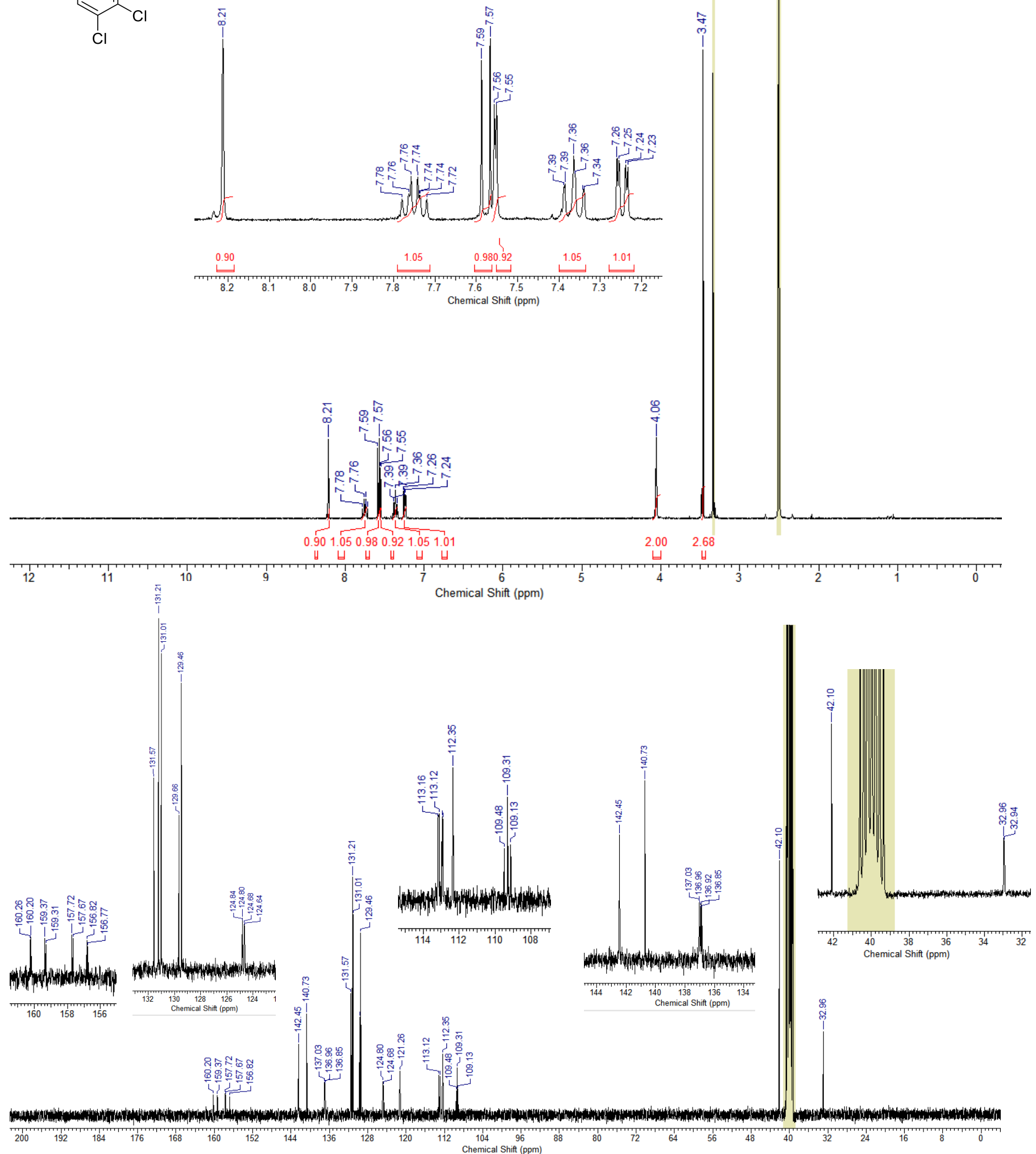

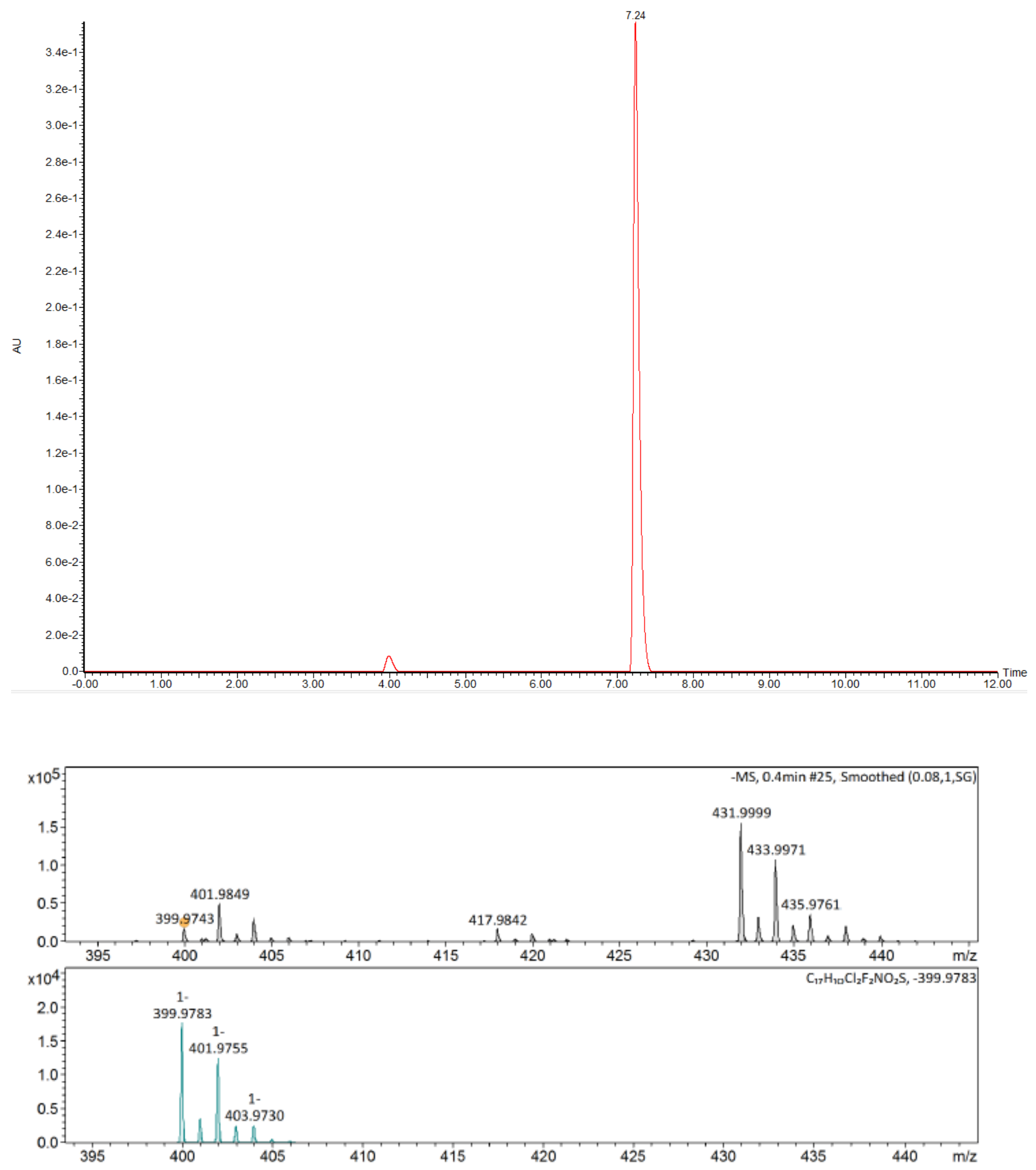

Meas. $\mathrm{m} / \mathrm{z}$ \# Ion Formula

$\mathrm{m} / \mathrm{z}$ err Mean $\mathrm{rdb} \mathrm{N}-\mathrm{Rule}^{-}$

mSigm Std I Std Std I Std Std

[ppm] err Conf

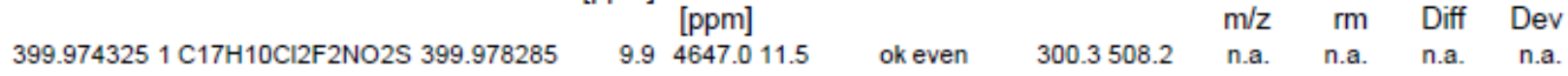

a Mean VarNo $\mathrm{m} / \mathrm{z}$ Comb 
(E)-3-(3',4'-Dichloro-4-fluoro-[1,1'-biphenyl-3-yl)-2-(methylsulfonyl)acrylonitrile (29)<smiles>CS(=O)(=O)/C(C#N)=C/c1cc(-c2ccc(Cl)c(Cl)c2)ccc1F</smiles>
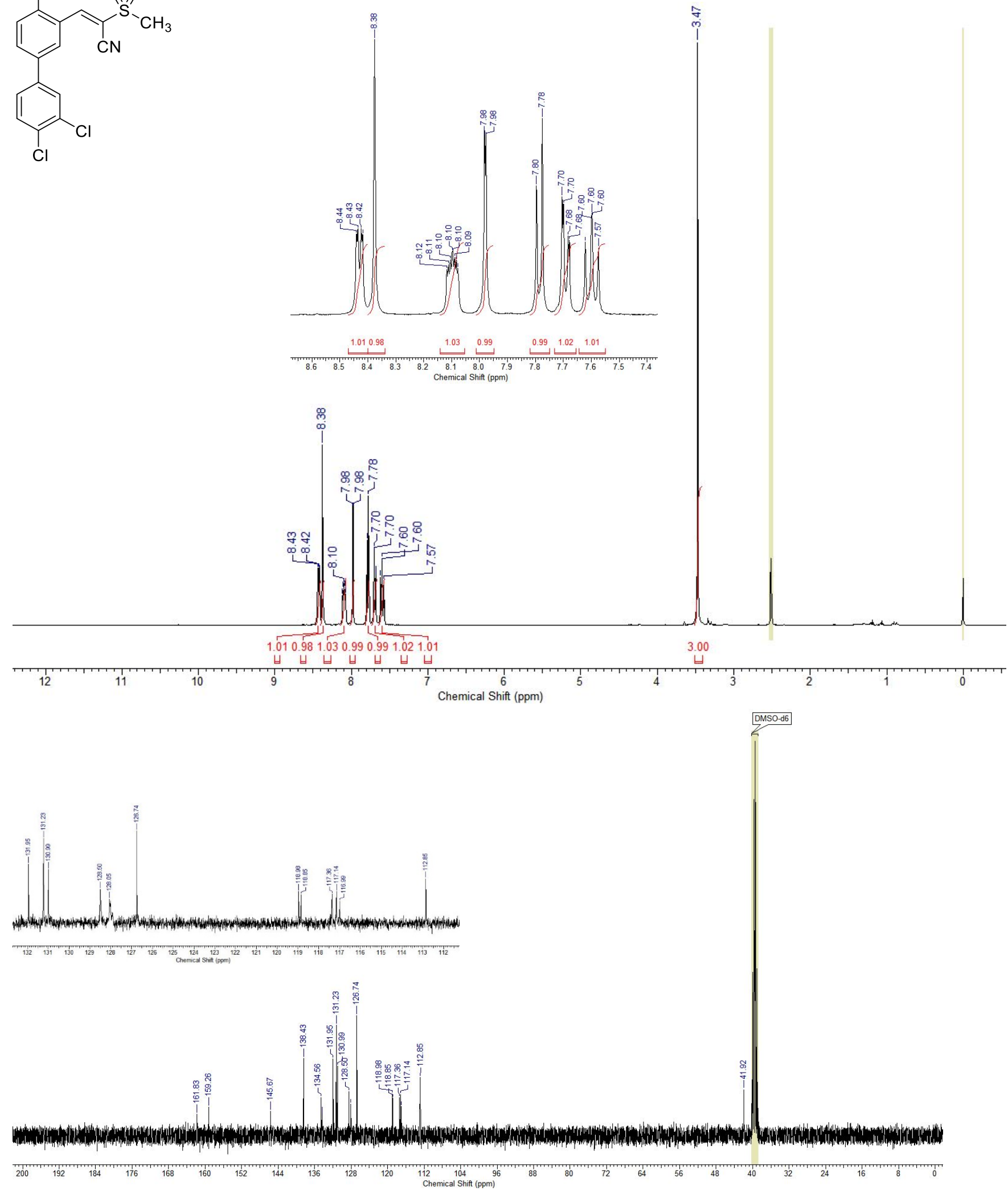

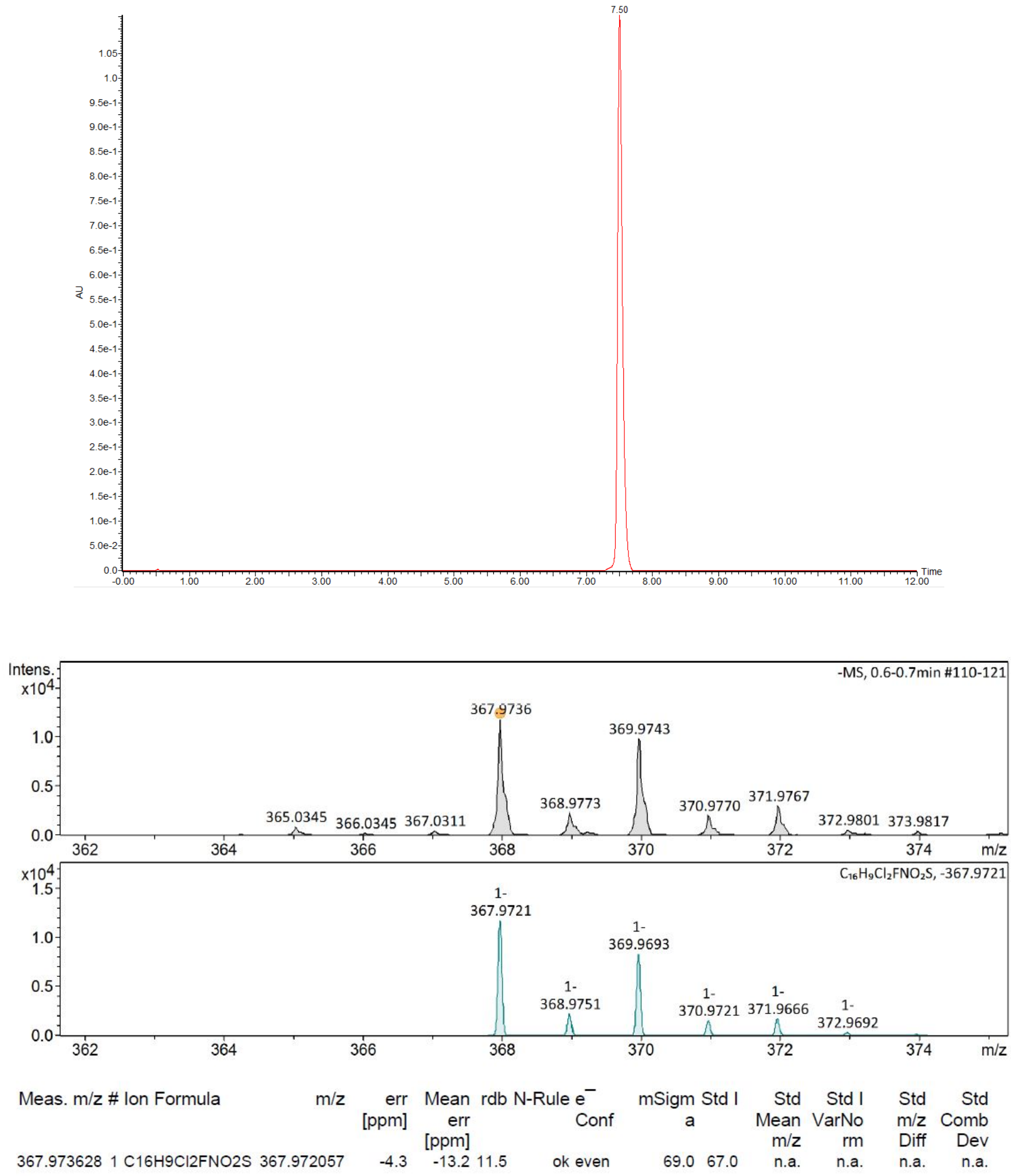

The dominant molecular ion envelope seen in these ESI- mass spectra is that of $[\mathrm{M}+\mathrm{H}]^{-}$ions, as a consequence of the electron deficiency of the cyanovinyl functional group. ${ }^{23}$ 


\section{References}

1. Hayashi, T. Studies on geometric isomerism by NMR. III. Stereochemistry of $\alpha$-cyanocinnamic esters. $J$. Org. Chem. 1966, 31, 3253-3258.

2. Lasri, J.; Charmier, M. A. J.; Haukka, M.; Pombeiro, A. J. L. Stereospecific synthesis of polysubstituted $E$-olefins by reaction of acyclic nitrones with free and $\mathrm{Pt}(\mathrm{II})$ coordinated organonitriles. J. Org. Chem. 2007, 72, 750-755.

3. Hiller, N. J.; Silva, N. A. A. E.; Faria, R. X.; Souza, A. L. A.; Resende, J. A. L. C.; Borges Farias, A.; Correia Romeiro, N.; de Luna Martins, D. Synthesis and evaluation of the anticancer and trypanocidal activities of boronic tyrphostins. ChemMedChem 2018, 13, 1395-1404.

4. Li, T.; Zhang, W.; Chen, W.; Miras, H. N.; Song, Y.-F. Layered double hydroxide anchored ionic liquids as amphiphilic heterogeneous catalysts for the Knoevenagel condensation reaction. Dalton Trans. 2018, 47, 3059-3067.

5. Clinical and Laboratory Standards Institute. Methods for dilution antimicrobial susceptibility tests for bacteria that grow aerobically; approved standard-ninth edition. CLSI Document M07-A9, 2012, Vol 32, Wayne, PA.

6. Bozdogan, B.; Ednie, L.; Credito, K.; Kosowska, K.; Appelbaum, C. P. Derivatives of a vancomycinresistant Staphylococcus aureus strain isolated at Hershey Medical Center. Antimicrob. Agents Chemother. 2004, 48, 4762-4765.

7. Hiramatsu, K.; Hanaki, H.; Ino, T.; Yabuta, K.; Oguri, T.; Tenover, F. C. Methicillin-resistant Staphylococcus aureus clinical strain with reduced vancomycin susceptibility. J. Antimicrob. Chemother. 1997, 4, 135-136.

8. Cassat, J. E.; Dunman, P. M.; McAleese, F.; Murphy, E.; Projan, S. J.; Smeltzer, M. S. Comparative genomics of Staphylococcus aureus musculoskeletal isolates. J. Bacteriol. 2005, 187, 576-592.

9. McDougal, L. K.; Steward, C. D.; Killgore, G. E.; Chaitram, J. M.; McAllister, S. K.; Tenover, F. C. Pulsed-field gel electrophoresis typing of oxacillin-resistant Staphylococcus aureus isolates from the United States: Establishing a national database. J. Clin. Microbiol. 2003, 41, 5113-5120.

10. Tsiodras, S.; Gold, H. S.; Sakoulas, G.; Eliopoulos, G. M.; Wennersten, C.; Venkataraman, L.; Moellering, R. C.; Ferraro, M. J. Linezolid resistance in a clinical isolate of Staphylococcus aureus. Lancet, 2001, 358, 207-208.

11. Baba, T.; Takeuchi, F.; Kuroda, M.; Yuzawa, H.; Aoki, K.; Oguchi, A.; Nagai, Y.; Iwama, N.; Asano, K.; Naimi, T.; Kuroda, H.; Cui, L.; Yamamoto, K.; Hiramatsu, K. Genome and virulence determinants of high virulence community-acquired MRSA. Lancet, 2002, 359, 1819-1827.

12. Arêde, P.; Ministro, J.; Oliveira, C. D. Redefining the role of the $\beta$-lactamase locus in methicillin-resistant Staphylococcus aureus: $\beta$-lactamase regulators disrupt the MecI-mediated strong repression on mecA and optimize the phenotypic expression of resistance in strains with constitutive mecA expression. Antimicrob. Agents Chemother. 2013, 57, 3037-3045.

13. Johnson, A. P.; Aucken, H. M.; Cavendish, S.; Ganner, M.; Wale, M. C.; Warner, M.; Livermore, D. M.; Cookson, B. D. Dominance of EMRSA-15 and -16 among MRSA causing nosocomial bacteraemia in the UK: analysis of isolates from the European Antimicrobial Resistance Surveillance System (EARSS). $J$. Antimicrob. Chemother. 2001, 48, 143-144.

14. Holden, M. T.; Feil, E. J.; Lindsay, J. A.; Peacock, S. J.; Day, N. P.; Enright, M. C.; Foster, T. J.; Moore, C. E.; Hurst, L.; Atkin, R.; Barron, A.; Bason, N.; Bentley, S. D.; Chillingworth, C.; Chillingworth, T.; Churcher, C.; Clark, L.; Corton, C.; Cronin, A.; Doggett, J.; Dowd, L.; Feltwell, T.; Hance, Z.; Harris, B.; Hauser, H.; Holroyd, S.; Jagels, K.; James, K. D.; Lennard, N.; Line, A.; Mayes, R.; Moule, S.; Mungall, 
K.; Ormond, D.; Quail, M. A.; Rabbinowitsch, E.; Rutherford, K.; Sanders, M.; Sharp, S.; Simmonds, M.; Stevens, K.; Whitehead, S.; Barrell, B. G.; Spratt, B. G.; Parkhill, J. Complete genomes of two clinical Staphylococcus aureus strains: evidence for the rapid evolution of virulence and drug resistance. Proc. Nat. Acad. Sci. U.S.A. 2004, 101, 9786-9791.

15. Bonapace, C. R.; Bosso, J. A.; Friedrich, L. V.; White, R. L. Comparison of methods of interpretation of checkerboard synergy testing. Diagn. Microbiol. Infect. Dis. 2002, 44, 363-366.

16. Odds, F. C. Synergy, antagonism and what the chequerboard puts between them. J. Antimicrob. Chemother. 2003, 52, 1.

17. Orhan, G.; Bayram, A.; Zer, Y.; Balci I. Synergy tests by E test and checkerboard methods of antimicrobial combinations against Brucella melitensis. J. Clin. Microbiol. 2005, 43, 140-143.

18. Llarrull, L. I.; Fisher, J. F.; Mobashery, S. Molecular basis and phenotype of methicillin resistance in Staphylococcus aureus and insights into new $\beta$-lactams that meet the challenge. Antimicrob. Agents Chemother. 2009, 53, 4051-4063.

19. Schaenzer, A. J.; Wlodarchak, N.; Drewry, D. H.; Zuercher, W. J.; Rose, W. E.; Ferrer, C. A.; Sauer, J. D.; Striker, R. GW779439X and its pyrazolopyridazine derivatives inhibit the serine/threonine kinase Stk1 and act as antibiotic adjuvants against $\beta$-lactam-resistant Staphylococcus aureus. ACS Infect. Dis. 2018, 4, 1508-1518.

20. Soulat, D.; Jault, J. M.; Duclos, B.; Geourjon, C.; Cozzone, A. J.; Grangeasse, C. Staphylococcus aureus operates protein-tyrosine phosphorylation through a specific mechanism. J. Biol. Chem. 2006, 281, $14048-14056$.

21. Dangel, A.; Ackermann, N.; Abdel-Hadi, O.; Maier, R.; Önder, K.; Francois, P.; Müller, C. W.; PanéFarré, J.; Engelmann, S.; Schrenzel, J.; Heesemann, J.; Lindermayr, C. A de novo-designed antimicrobial peptide with activity against multiresistant Staphylococcus aureus acting on RsbW kinase. FASEB J. 2013, $27,4476-4488$.

22. Boudreau, A. M.; Fishovitz, J.; Llarrull, I. L.; Xiao, Q.; Mobashery, S. Phosphorylation of BlaR1 in manifestation of antibiotic resistance in methicillin-resistant Staphylococcus aureus and its abrogation by small molecules. ACS Infect. Dis. 2015, 1, 454-459.

23. Hou, X.; Yuan, W.-C.; Jiang, Y.; Qi, H.-Y.; Wu, Z.-J. [M+H]- ion in isodiospyrin detected. J. Mass Spectrom. 2015, 50, 592-595. 